\title{
Industrial Materials for the Future R\&D Strategies: A Case Study of Boiler Materials for the Pulp and Paper Industry
}

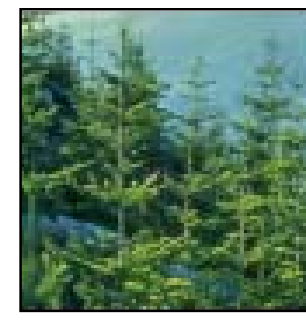

Photographs courtesy of Weyerhaeuser Company
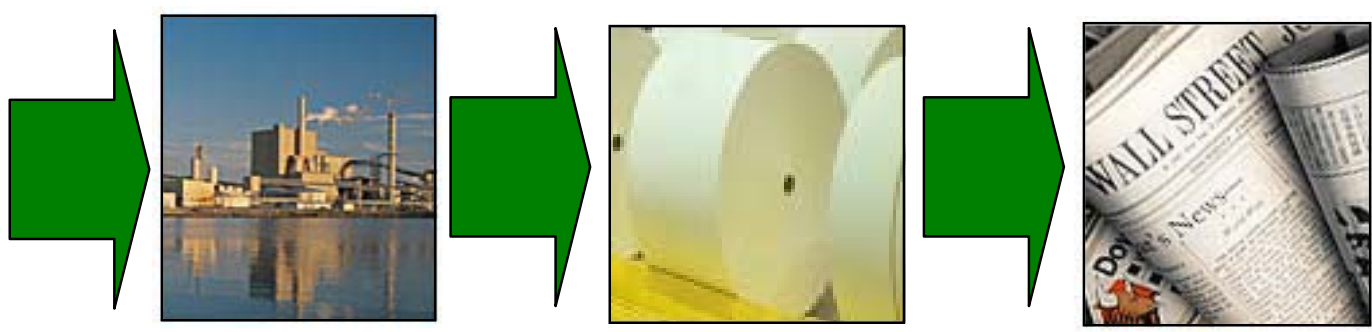

prepared by

David R. Howell

Richard Silberglitt

RAND

Arlington, Virginia

and

Douglas Norland

National Renewable Energy Laboratory

Washington, D.C.

prepared for

Industrial Materials for the Future Program

Industrial Technologies Program

U.S. Department of Energy

October 2002

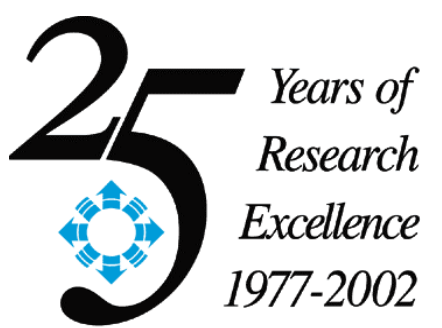

National Renewable Energy Laboratory

\section{NREL}

901 D Street, S.W., Suite 930

Washington, DC 20024-2157

(202) 646-5050

Operated for the U.S. Department of Energy by

Midwest Research Institute • Battelle • Bechtel
RAND

1200 South Hayes Street

Arlington, VA 22202-5050

(703) 413-1100

Main Offices: (310) 393-0411

1700 Main Street P.O. Box 2138

Santa Monica, CA 90407-2138 


\section{NOTICE}

This report was prepared as an account of work sponsored by an agency of the United States government. Neither the United States government nor any agency thereof, nor any of their employees, makes any warranty, express or implied, or assumes any legal liability or responsibility for the accuracy, completeness, or usefulness of any information, apparatus, product, or process disclosed, or represents that its use would not infringe privately owned rights. Reference herein to any specific commercial product, process, or service by trade name, trademark, manufacturer, or otherwise does not necessarily constitute or imply its endorsement, recommendation, or favoring by the United States government or any agency thereof. The views and opinions of authors expressed herein do not necessarily state or reflect those of the United States government or any agency thereof.

Available electronically at http://www.osti.gov/bridge

Available for a processing fee to U.S. Department of Energy

and its contractors, in paper, from:

U.S. Department of Energy

Office of Scientific and Technical Information

P.O. Box 62

Oak Ridge, TN 37831-0062

phone: 865.576.8401

fax: 865.576.5728

email: reports@adonis.osti.gov

Available for sale to the public, in paper, from:

U.S. Department of Commerce

National Technical Information Service

5285 Port Royal Road

Springfield, VA 22161

phone: 800.553 .6847

fax: 703.605.6900

email: orders@ntis.fedworld.gov

online ordering: http://www.ntis.gov/ordering.htm

Printed on paper containing at least $50 \%$ wastepaper, including $20 \%$ postconsumer waste 


\section{Table of Contents}

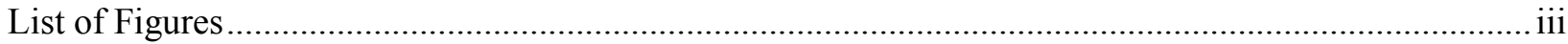

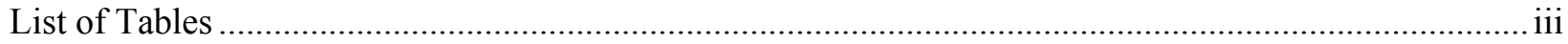

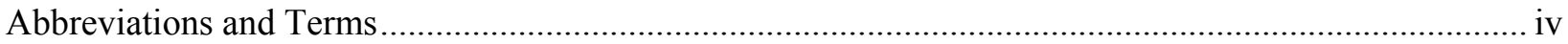

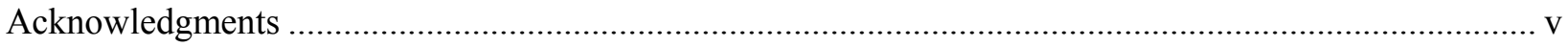

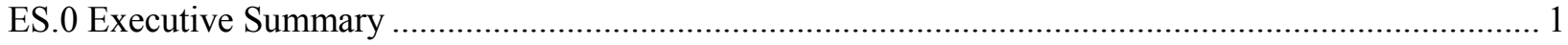

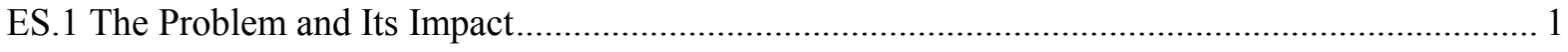

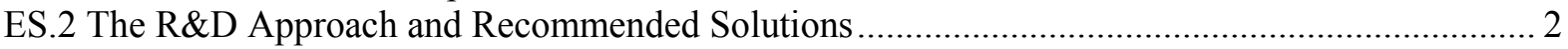

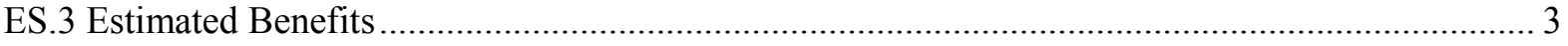

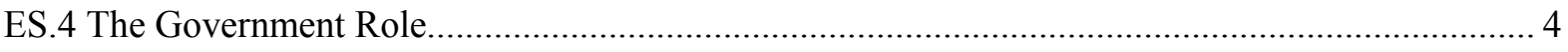

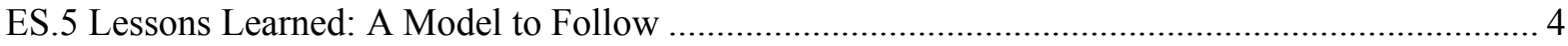

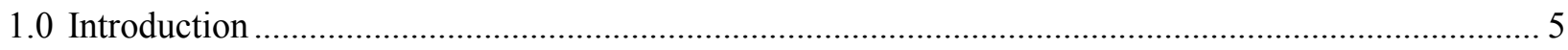

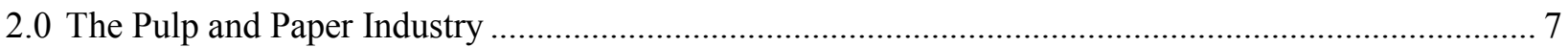

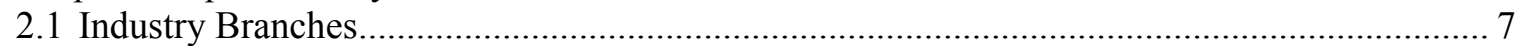

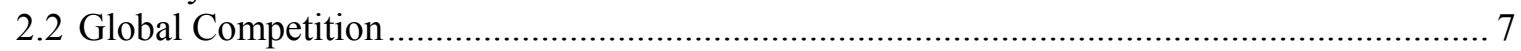

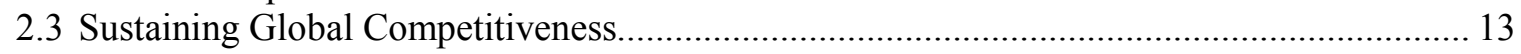

3.0 Description of the Problem: The Kraft Chemical Pulping Process ................................................... 14

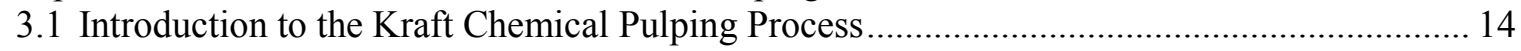

3.2 Wood Yard Operations: Timber Preparation ............................................................... 14

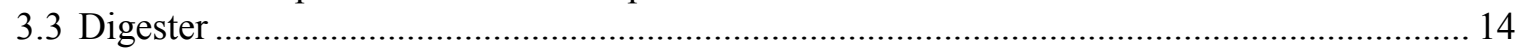

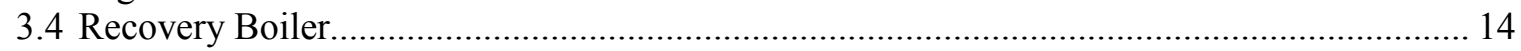

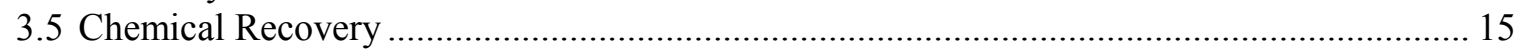

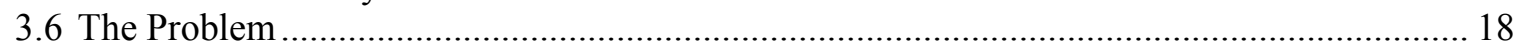

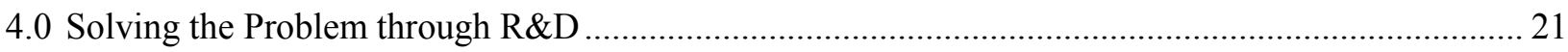

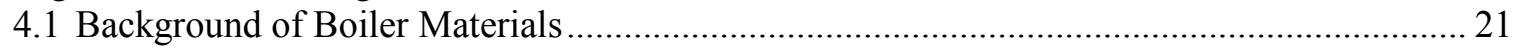

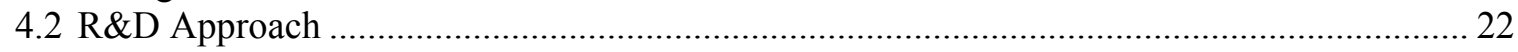

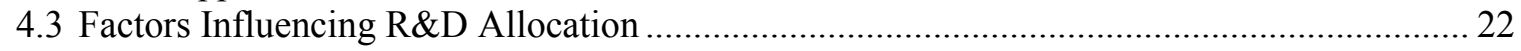

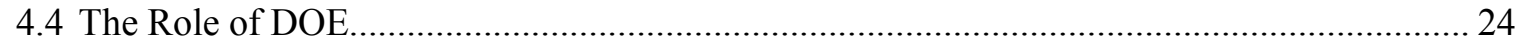

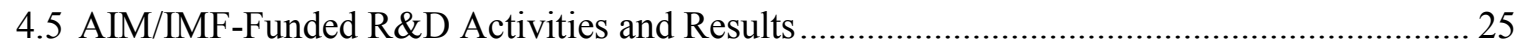

4.5.1 Overview of R\&D Activities ................................................................. 25

4.5.2 Task 1: Examination of Microscopic Characteristics of Cracked Tubes.............. 26

4.5.3 Task 2: Measurement of the Forces (Stresses) on the Surface of the Tube......... 26

4.5.4 Task 3: Modeling of the Forces (Stresses) on the Surface of the Tube .............. 27

4.5.5 Task 4: Determination of the Service Environment ......................................... 29

4.5.6 Tasks 5 and 6: Identification of Cracking Mechanism and Identification of More Ideal Processes and Materials ........................................ 30

5.0 Economic, Energy, and Environmental Impacts of the R\&D Program......................................... 32

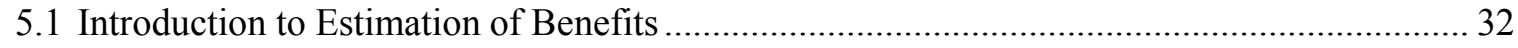

5.2 Industry Boiler Maintenance and Replacement Experience .............................................. 33

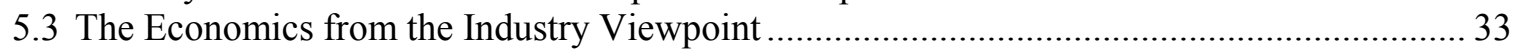

5.3.1 The Economics of Better Maintenance Practice.................................................. 34

5.3.2 The Economics of New Materials Upon Normal Replacement........................... 34 


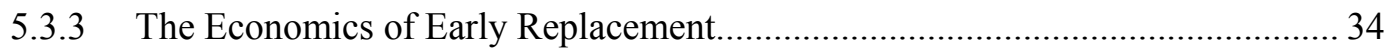

5.4 The Benefits of the IMF Kraft Recovery Boiler Materials Research Program ....................... 35

5.5 Unit Efficiency and Cost Impacts of the IMF Kraft Recovery Boiler R\&D Program ............ 39

5.6 Environmental Benefits of the IMF Kraft Recovery Boiler R\&D Program............................ 39

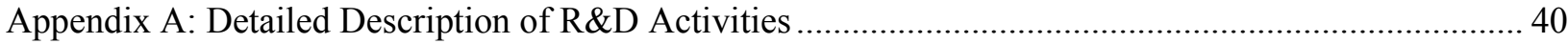

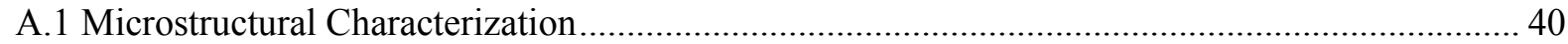

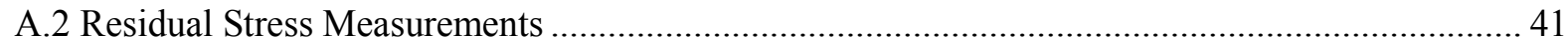

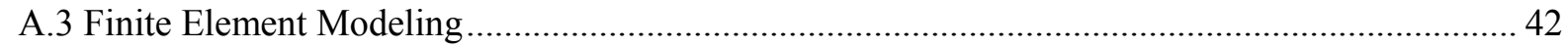

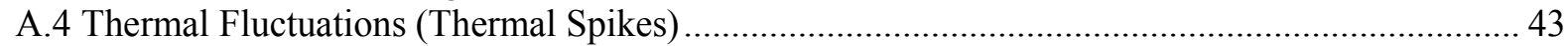

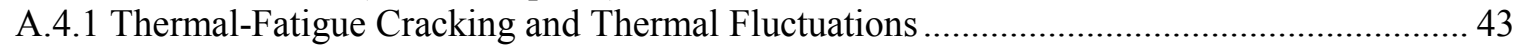

A.4.2 Outer-Layer Stress State and Thermal Fluctuations ......................................................... 44

A.5 Characterization of Service Environment - Stress-Corrosion Cracking ..................................... 44

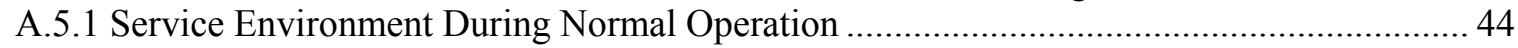

A.5.2 Service Environment During Start-up, Dry-out, Shutdown, and Water-wash.................... 45

A.6 Summary and Solutions to Composite Floor Tube Cracking ..................................................... 45

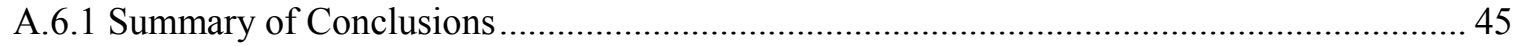

A.6.2 Path I: Improving Recovery Boiler Operating Procedures ................................................ 48

A.6.3 Path II: Improving Recovery Boiler Floor-Tube Materials .............................................. 48 


\section{List of Figures}

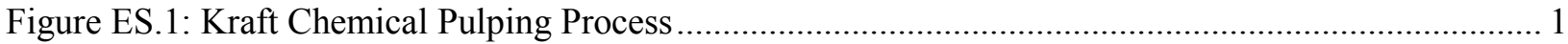

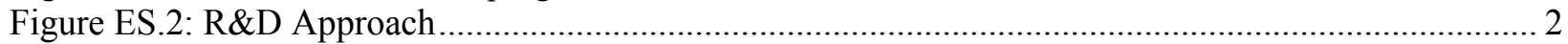

Figure ES.3: IMF Kraft Recovery Boiler R\&D Program: Cumulative Benefits ...................................... 3

Figure 1: 1999 Global Leaders in Paper and Paperboard Production...................................................... 8

Figure 2: U.S. Export Market in Paper and Allied Products in 1998 ................................................... 9

Figure 3a: 1983 Distribution of Paper and Paperboard Production .......................................................... 9

Figure 3b: 1999 Distribution of Paper and Paperboard Production....................................................... 9

Figure 4: Global Market for Paper and Paperboard Production ....................................................... 10

Figure 5: Top Energy-Intensive U.S. Industries. Manufacturing energy use (2001)............................... 11

Figure 6: Energy Self-Sufficiency: Pulp, Paper, and Paperboard .......................................................... 11

Figure 7: Fossil Fuel and Purchased Energy Consumption: Pulp, Paper, and Paperboard........................ 12

Figure 8: 1994 Energy Expenditures for the Pulp and Paper Industry (\$ million) .................................. 12

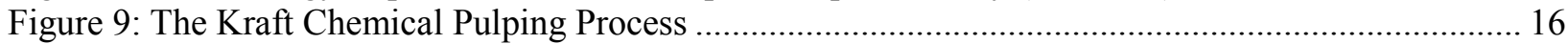

Figure 10: Babcock and Wilcox Recovery Furnace (circa 1968) ................................................... 17

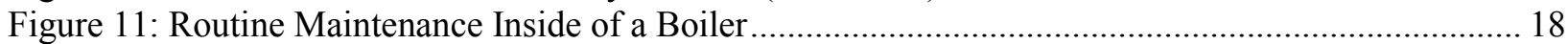

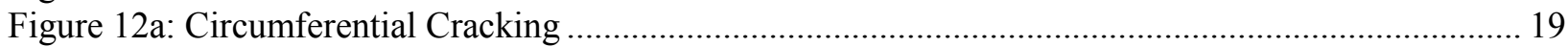

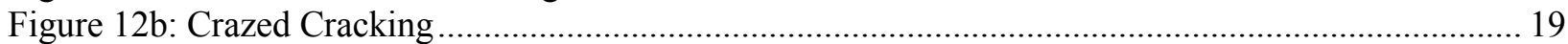

Figure 13: Timeline for Composite Tube Failures and DOE R\&D Program ....................................... 20

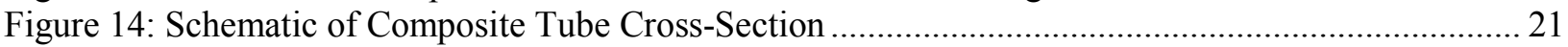

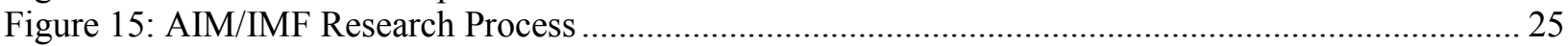

Figure 16: Schematic of Stress-Corrosion Cracking on Composite Floor Tubes in Recovery Boilers ...... 28

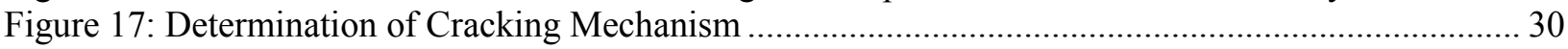

Figure 18a: Suite of Materials Properties for 304L Stainless Steel .................................................. 31

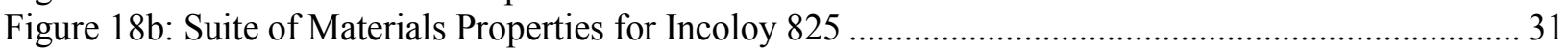

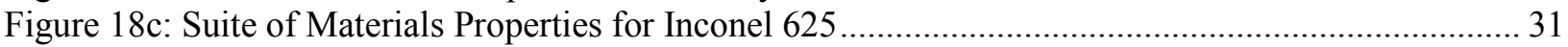

Figure 19: Number of Kraft Boilers Entering Service in the United States........................................... 32

Figure 20: Annual Energy Savings of IMF Kraft Recovery Boiler R\&D Program................................. 37

Figure 21: Cumulative Energy Savings of IMF Kraft Recovery Boiler R\&D Program............................ 37

Figure 22: Annual Economic Benefits of the IMF Kraft Recovery Boiler R\&D Program ....................... 38

Figure 23: Cumulative Economic Benefits of the IMF Kraft Recovery Boiler R\&D Program ................. 38

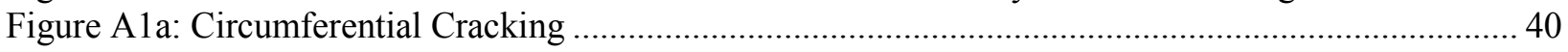

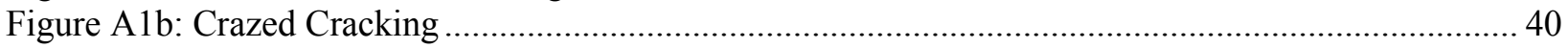

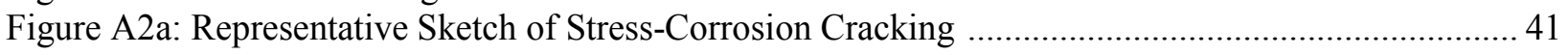

Figure A2b: Microscopic Photograph of Floor Tube Crack ............................................................ 41

Figure A3: Temperature of Composite Tube Surface during Normal Operation ...................................... 46

Figure A4: Temperature of Composite Tube Surface during Operation with a Thermal Fluctuation........ 47

Figure A5: Yield Stress versus Thermal Expansion Coefficient for Selected Materials .......................... 50

\section{List of Tables}

Table 1: Goods Manufactured by the Forest Products Industry ….................................................... 7

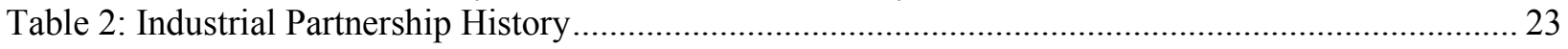

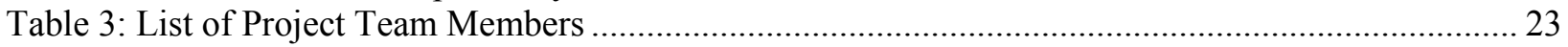

Table 4: Distribution of Kraft Recovery Boiler Shutdowns with Existing Technology ............................ 33

Table 5: Cost of Shutdowns and Boiler Tubes: Existing Versus New Materials ..................................... 33

Table 6: Cumulative Air-Pollutant Impacts of the IMF Kraft Recovery Boiler R\&D Program ............... 39

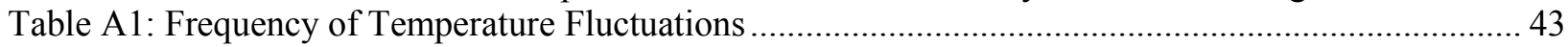

Table A2: Stress State and Corrosive Materials Present during Normal Operation ................................ 46

Table A3: Stress State and Corrosive Materials Present during Operation with a Thermal Fluctuation ... 48

Table A4: Comparison of Materials Properties ................................................................................ 49

Table A5: Material Composition Comparison Chart............................................................................. 49 


\section{Abbreviations and Terms}

$\begin{array}{ll}\text { AIM } & \text { Advanced Industrial Materials Program } \\ \text { BLRBAC } & \text { Black Liquor Recovery Boiler Advisory Committee } \\ \text { CRADA } & \text { Cooperative Research and Development Agreement } \\ \text { DOE } & \text { U.S. Department of Energy } \\ \text { E.U. } & \text { European Union } \\ \text { IMF } & \text { Industrial Materials for the Future Program } \\ \text { IPST } & \text { Institute of Paper Science and Technology } \\ \text { NAFTA } & \text { North American Free Trade Agreement } \\ \text { NREL } & \text { National Renewable Energy Laboratory } \\ \text { OIT } & \text { Office of Industrial Technologies } \\ \text { ORNL } & \text { Oak Ridge National Laboratory } \\ \text { Paprican } & \text { Pulp and Paper Research Institute of Canada } \\ \text { R\&D } & \text { research and development }\end{array}$




\section{Acknowledgments}

The authors wish to express their thanks to Charles Sorrell and Mike Soboroff of the Department of Energy for many intriguing discussions on this subject. We are grateful to the reviewers of this report, Rajkumar Raman of RAND and David Parrish of Factory Mutual Research Corporation, whose insightful comments and suggestions greatly improved the final product. James Keiser, Gorti Sarma, and Pete Angelini of Oak Ridge National Laboratory contributed valuable insights on the technical aspects of boiler tube analysis and impacts of the changed maintenance procedures and boiler tube materials on the pulp and paper industry. Peter Gorog of Weyerhaeuser and John Kulig and Keith Rivers of Babcock \& Wilcox provided essential data and information concerning the industrial aspects of this study. 


\section{ES.0 Executive Summary}

\section{ES.1 The Problem and Its Impact}

Figure ES.1: Kraft Chemical Pulping Process

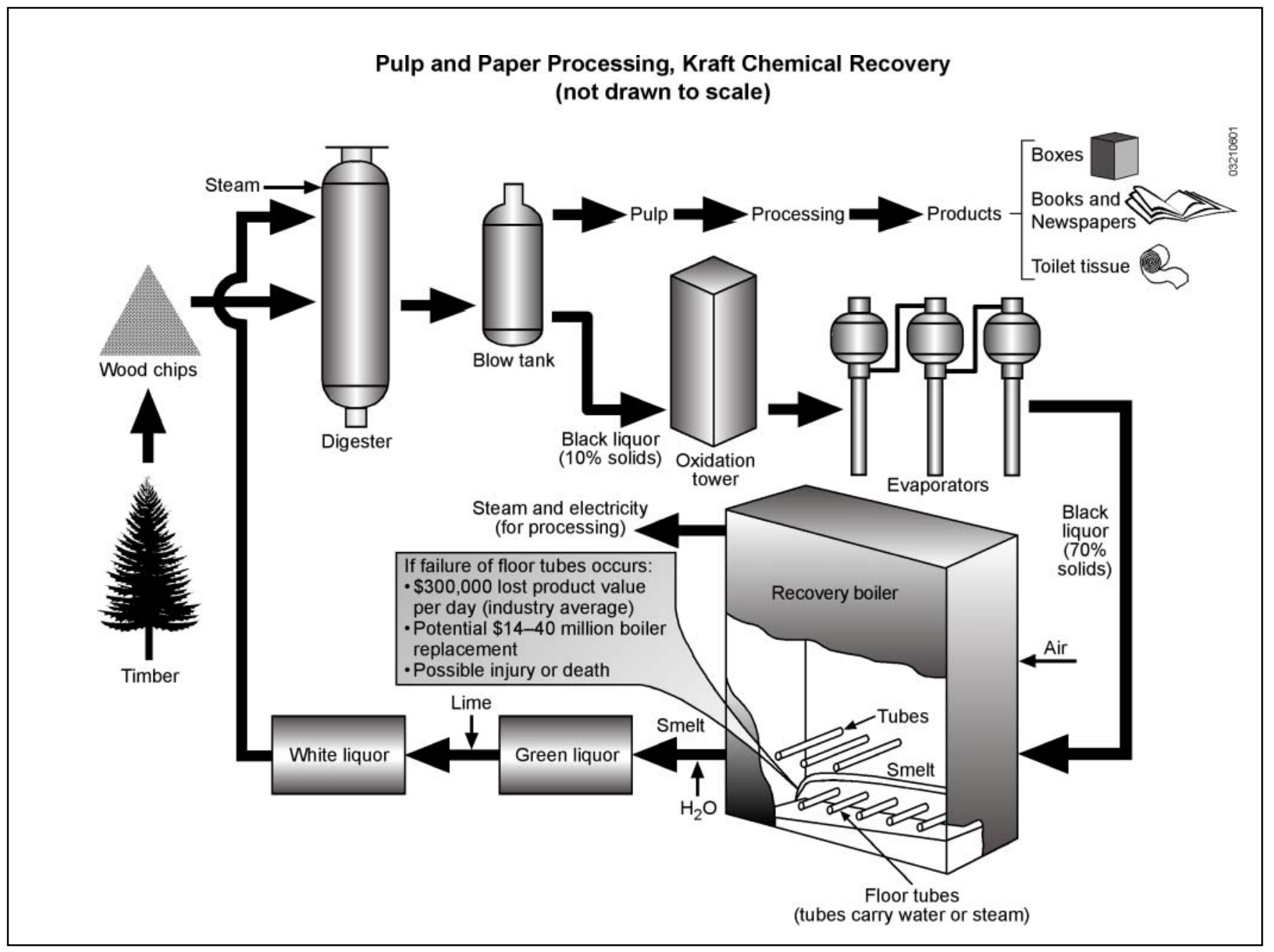

This report describes a case study performed by RAND and NREL of government-industry research and development (R\&D) aimed at solving materials problems encountered by the forest products industry. The principal problem addressed by the R\&D was the failure of tubes that carry water and steam inside boilers used to recover chemicals during papermaking. These recovery boilers are an essential component of the papermaking process because, in addition to providing recycled chemicals to the wood digester, they also provide a significant portion of the process steam and electricity required for plant operation. The industry estimates that, on average, for each day a recovery boiler is shut down, a company loses $\$ 300,000$.

The recovery boiler tubes operate in a highly corrosive, high-temperature environment that can cause cracking. If cracks in the tubes are deep enough to allow steam or water to escape and come into contact 
with molten salts, a large explosion can occur. The damage caused by such explosions typically requires days to weeks to repair. In severe cases, the damage can take months to repair, and plant personnel have been seriously injured or killed. Preventing cracks in recovery boiler tubes is essential to ensure plant safety and to prevent equipment losses as high as $\$ 40$ million, over and above the value of lost production.

\section{ES.2 The R\&D Approach and Recommended Solutions}

Figure ES.2: R\&D Approach

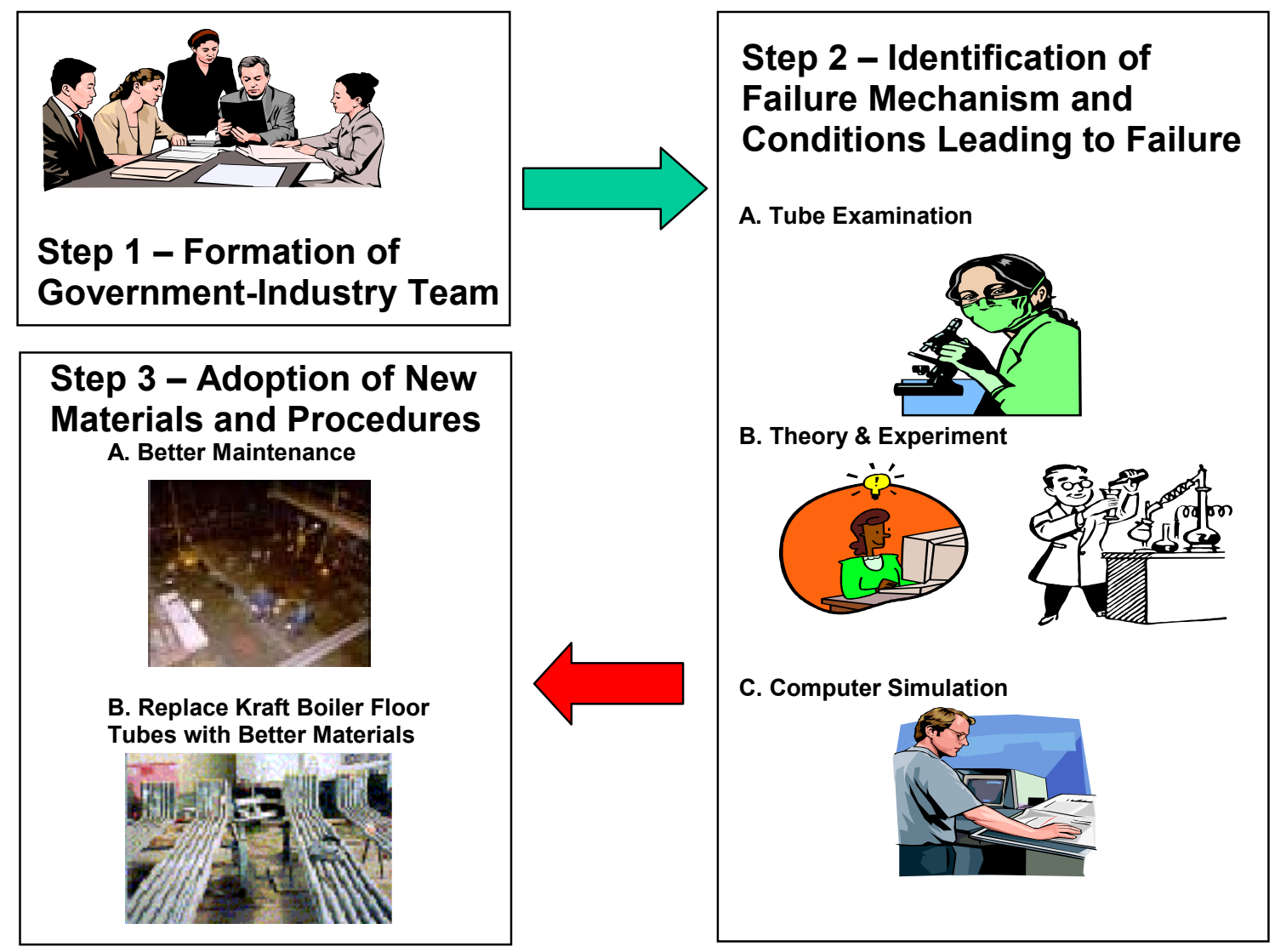

The government-industry R\&D that is the subject of this report began in 1995, sponsored by the Advanced Industrial Materials (AIM) Program (the predecessor to the Industrial Materials for the Future (IMF) Program) of the Department of Energy (DOE) Office of Industrial Technologies (OIT). By that time, the industry had determined that the replacement of carbon steel tubes with composite tubes, which were protected by an outer layer of stainless steel, had not solved the problem of tube cracking. A consortium that included 16 paper companies, four recovery boiler manufacturers, two tube fabricators, Oak Ridge National Laboratory, and U.S. and Canadian paper institutes performed the R\&D. The researchers examined tubes before and after failures and combined experimental measurements with theoretical calculations and computer simulations to identify the mechanism of cracking.

The government-industry team recommended two possible solutions to the problem. The first was a modification of maintenance procedures, in particular the water-wash and dry-out cycle, to reduce the occurrence of conditions that might promote a particular type of cracking (stress corrosion) on the surface of boiler floor tubes. The recommended changes in procedures were designed to reduce the 
likelihood that the prerequisites of the suggested cracking mechanism would be met. The second possible solution was to change the material that makes up the outer layer of the composite tube from stainless steel to a stronger and more crack-resistant metal alloy. While this solution will greatly increase the tubes' resistance to the cracking mechanism, cracks still could potentially occur therefore, the aforementioned changes to procedures are still recommended. While neither option makes the floor tubes impervious to cracking, both of the proposed solutions represent vast improvements of current methods and norms in the industry.

\section{ES.3 Estimated Benefits}

Figure ES 3: IMF Kraft Recovery Boiler R\&D Program: Cumulative Impacts

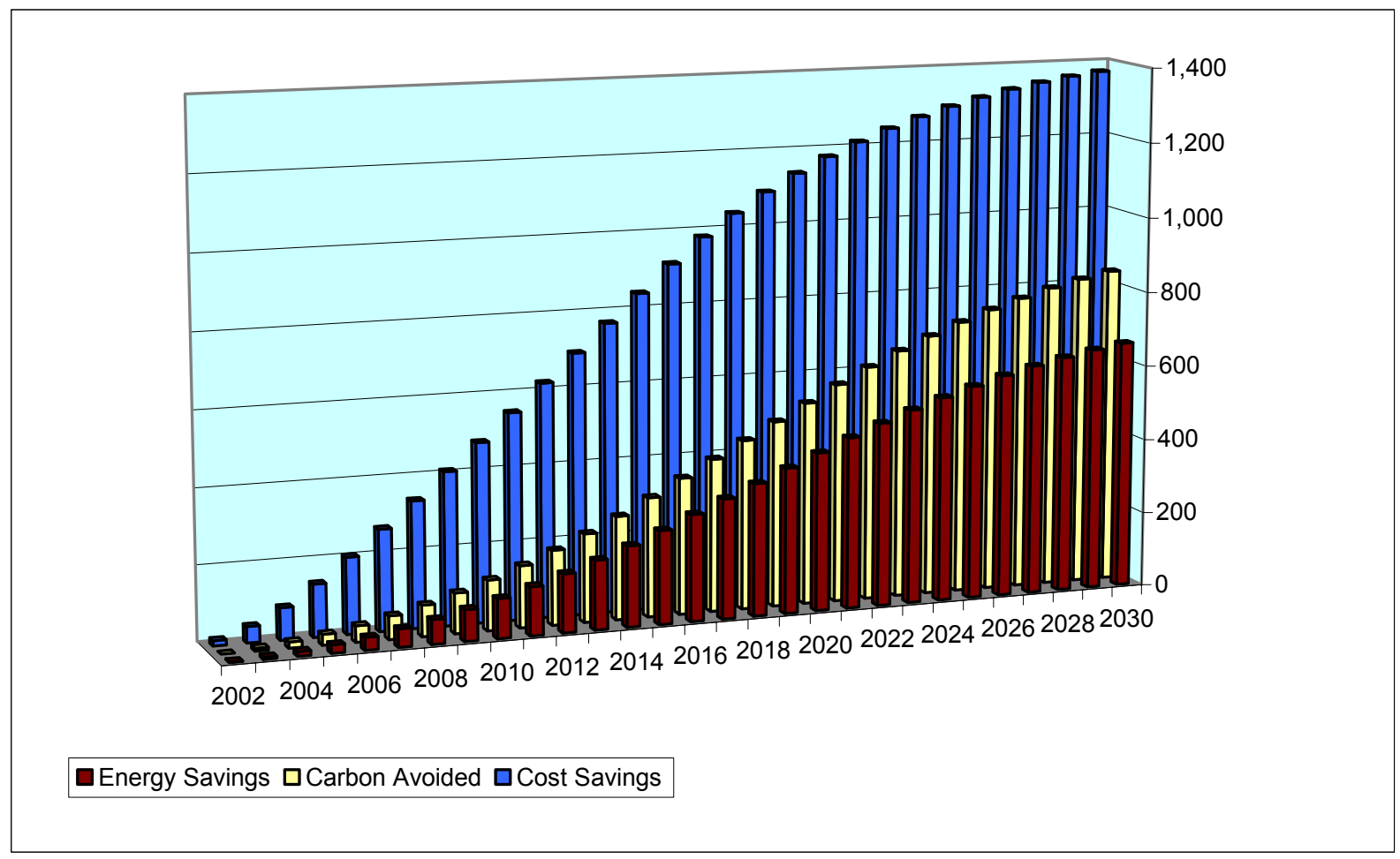

Cost savings $=$ Millions of $1995 \$$

Energy impacts $=$ Hundreds of billion Btu

Carbon reductions $=1,000$ tons of carbon equivalent

This analysis suggests that a strategy that combines improved maintenance procedures to avoid cracking with somewhat accelerated tube replacement will provide cumulative industry savings of 66 trillion Btu - with a net present value in energy and productivity savings of \$1,373 million (in 1995 dollars) by 2030. In addition, the energy savings by 2030 will translate into cumulative reductions of 8,700 tons of nitrogen oxides, 17,200 tons of sulfur dioxide, and 843,000 tons of carbon equivalent greenhouse-gas emissions. These estimates assume that one-half of the industry adopts the new technology by 2030 - reducing days shut down for maintenance by an average of two days - and that one-half of these plants save an additional average 1.5 percent of their energy use. 


\section{ES.4 The Government Role}

The systematic analysis of tube failures - and the integrated theoretical and experimental research program that led to the identification of the failure mechanism and the proposed solutions - was well beyond the capability of any single company or even an industry-only consortium. The AIM program played a pivotal role in providing funding that allowed the expertise and facilities of Oak Ridge National Laboratory (ORNL) and the paper institutes to be applied to the problem. AIM and ORNL also provided the coordination and liaison support to create and maintain the research team, which included personnel from the paper companies and the industry's equipment suppliers (tube fabricators and boiler manufacturers). Without such a broadly constituted team, the proposed R\&D solutions would have been difficult or impossible to implement. In fact, after having solved the recovery boiler floor tube problem, this team is now addressing other challenges such as materials failures near boiler primary air ports.

\section{ES.5 Lessons Learned: A Model to Follow}

This case study illuminated a number of critical factors in successfully solving industrial process problems through $R \& D$ that should guide future efforts:

1. It is essential to understand the details of the industrial process in order to identify the source and nature of the problem. This requires close cooperation between the plant managers and the research team, including access to industrial facilities and on-site inspection of the problem (in this case, the failed tubes).

2. The research team needs to apply its methods and facilities directly to the service environment of the industrial process. In this case, they examined failed tubes and modeled tube performance with temperatures, stresses, and the presence of corrosive materials measured in the recovery boiler.

3. In the case of a government-industry consortium such as this one, there needs to be an industry champion and a research-team leader. The industry champion, who makes the convincing argument to the industrial participants that granting access to facilities and sharing data is in the collective interest, takes positive action to ensure plant manager/research team cooperation. The research-team leader focuses the research effort on activities that can provide solutions under the service environment and keeps the industrial members of the team informed and involved in providing input that can influence research direction.

4. The research team must involve all supporting industries that have a stake in implementing the solutions found through $\mathrm{R} \& \mathrm{D}$ (in this case, the tube fabricators and the recovery boiler manufacturers). 


\subsection{Introduction}

This report describes a case study performed by RAND and NREL of government-industry research and development (R\&D) aimed at solving materials problems encountered by the pulp and paper industry. Paper plants recycle chemicals used to process wood into the pulp used to make paper. The heart of the chemical-pulping process is the recovery boiler that provides these recycled chemicals and produces a significant fraction of the process steam and electricity needed by the plant. Recovery boilers are such critical plant components that the industry estimates that, on average, for each day a recovery boiler is shut down, the plant loses $\$ 300,000$.

The principal problem addressed by the R\&D was the cracking of metal tubes, principally in the floor of the recovery boiler, which carry water to cool the inside of the boiler. The heat removed from the boiler turns the water to steam, which is then used for drying processes within the plant or to drive a steam turbine to produce electricity. If cracks in the tubes are deep enough to allow steam or water to escape and come into contact with molten chemicals, a large explosion can occur. The damage caused by such explosions typically requires days to weeks to repair. In severe cases, the damage can take months to repair, and plant personnel have been seriously injured or killed. Preventing cracks in recovery boiler tubes is essential to ensure plant safety and to prevent equipment losses as high as $\$ 40$ million, in addition to the production losses noted previously.

The R\&D described in this report was performed by a government-industry team between 1995 and 2000 and was sponsored by the Advanced Industrial Materials (AIM) Program - the predecessor to the Industrial Materials for the Future (IMF) Program - of the Department of Energy (DOE) Office of Industrial Technologies (OIT). It focused on cracking of composite tubes with an inner layer of carbon steel and an outer layer of more corrosion-resistant stainless steel. By examining tubes before and after failures - and through experimental measurements, theoretical calculations, and computer simulations of tube performance - the team determined that the problem was caused by stress-corrosion cracking. They also concluded that the conditions leading to the cracking did not exist during normal plant operation, but rather occurred only when the boiler was shut down for maintenance and the tubes were washed with water and then dried-out during boiler start-up. Allowing moisture to be in contact with the floor tubes above a certain temperature allows salts present in the boiler to dissolve, forming a liquid corrosive substance. Finally, they noted that occasional thermal fluctuations during operation could contribute to the failures by altering the stress state at the outer surface of the boiler tubes.

The government-industry team recommended two possible approaches to solving the problem. The first was a modification of maintenance procedures, in particular the water-wash and dry-out cycle, which will prevent the routine occurrence of the conditions that lead to stress-corrosion cracking. However, this change in procedure will not prevent the occurrence of the necessary (tensile) stress state at the tube surface; so that if it is not followed diligently, the cracking problem will reoccur. The second possible approach was to change the material that makes up the outer layer of the composite tube from stainless steel to a stronger and more corrosion-resistant metal alloy. This change will prevent most tube cracking even if current maintenance procedures are retained, and will greatly reduce the probability of cracking that depends on thermal fluctuations during normal plant operation to alter the stress state of the outer surface of the tubes. While neither option makes the floor tubes impervious to cracking, both of the proposed solutions represent vast improvements of current methods and norms in the industry.

These two recommended approaches have different costs and benefits and are not mutually exclusive. For example, the industry could adopt the improved maintenance procedures and use the new materials whenever boiler tubes are slated for replacement. We performed a financial analysis based on industrial experience with recovery boiler tube maintenance requirements and replacement rates. This analysis 
suggests that a strategy combining improved maintenance procedures to avoid cracking with accelerated tube replacement (e.g., at a rate of 5.0 percent instead of the historical 1.5 percent) would provide cumulative industry-wide savings of 66 trillion Btu - with a net present value in energy and productivity savings of $\$ 1,356$ million (1995 dollars with a 5 percent discount rate) during a 30 -year time period. In addition, the energy savings would translate into cumulative reductions of 8,700 tons of nitrogen oxides, 17,200 tons of sulfur dioxide, and 843,000 tons of carbon equivalent greenhouse-gas emissions by 2030 .

The balance of this report is organized as follows: Chapter 2 provides a brief overview of the forestproducts industry and its papermaking component, explaining that cost containment is a critical factor in maintaining U.S. market share. This fact drives the R\&D to improve energy efficiency and productivity by reducing recovery boiler tube maintenance requirements. Chapter 3 then describes the R\&D problem; and Chapter 4 summarizes the approach, as well as the data and analysis that led to the solution. A more detailed description of the technical aspects of the work is presented in the appendix. Finally, Chapter 5 presents the financial analysis and the estimated benefits of pursuing the recommended solutions based on the $\mathrm{R} \& \mathrm{D}$ results. 


\subsection{The Pulp and Paper Industry}

\subsection{Industry Branches}

The U.S. forest products industry is separated into two groups: (1) lumber and wood products, and (2) paper and allied products. These two categories are often combined because both depend on wood for raw materials. Paper and allied products is commonly referred to as the pulp and paper industry. Table 1 shows examples of some of the products manufactured by the two branches of the forest-products industry. ${ }^{1}$

Table 1: Goods Manufactured by the Forest Products Industry

\begin{tabular}{|c|c|}
\hline \multicolumn{2}{|c|}{ Forest Products Industry } \\
\hline Lumber and Wood Products & Pulp and Paper Products \\
\hline Plywood & Stationery \\
\hline Wood cabinets & Food containers \\
\hline Wood boxes & Packaging and boxes \\
\hline Wood buildings & Sanitary products \\
\hline
\end{tabular}

The pulp and paper industry includes both the processing of lumber into pulp (the raw material used to manufacture paper) and various types of papermaking. This case study examines the research and development activities in the pulping process of the pulp and paper industry. The product of each type of papermaking is paper and paperboard (paper that is $0.30 \mathrm{~mm}\left(0.012 \mathrm{in}\right.$.) or greater in thickness). ${ }^{2}$ Thus, paper and paperboard production data indicate relative competitiveness in the global market. Figure 1 shows the top 15 countries in paper and paperboard production in 1999.

The United States leads the pulp and paper industry in paper and paperboard production. However, the United States also leads the world in consumption of paper and paperboard products, consuming more than 90 percent of its production; publishing more than 2 billion books, 350 million magazines, and 24 billion newspapers annually in the United States. ${ }^{3}$

\subsection{Global Competition}

In the 1990s, domestic sales leveled off, pushing the industry to pursue the export market more aggressively. "Exports have played an increasingly important role in the industry, accounting for nearly 8 percent of U.S. paper goods shipments in 1991, compared with 6.6 percent in 1989." Simultaneously, trade increased with Canada and Mexico because of lower tariffs due to the North American Free Trade Agreement (NAFTA). Figure 2 shows the dominance of NAFTA on the U.S. export market. $^{5}$

There are several factors that affect the U.S. position in the market:

1) Emerging players in the market

2) High domestic-labor costs

\footnotetext{
1 "Forest Products Industry Analysis Brief," U.S. Energy Information Administration. Available at http://www.eia.doe.gov/emeu/mecs/iab/forest_products/.

${ }^{2}$ Smook, G.A., Handbook for Pulp \& Paper Technologists, Angus Wilde Publications, Inc., P.O. Box 1036, Bellingham, WA 98227-1036, (1992), ISBN 0-9694628-1-6.

3 “Forest Products Industry Profile," U.S. Department of Energy, Office of Industrial Technologies. Available at http://www.oit.doe.gov/forest/pdfs/forest.pdf or through clearinghouse at 1-800-862-2086.

${ }^{4}$ Stanley, Gary, "U.S. Global Trading Outlook: Paper Products," Office of Metals, Materials, and Chemicals, (March 1995), 202-482-0375. Available at http://www.tradeport.org/ts/ntdb/usgto/paper.html.

${ }^{5}$ U.S. Industry \& Trade Outlook 2000, McGraw-Hill, (2000), ISBN 0-07-135245-7. Data from the U.S.

Department of Commerce, Bureau of the Census.
} 
3) High cost of environmental compliance

4) High capital intensity of production

Figure 1: 1999 Global Leaders in Paper and Paperboard Production ${ }^{6}$

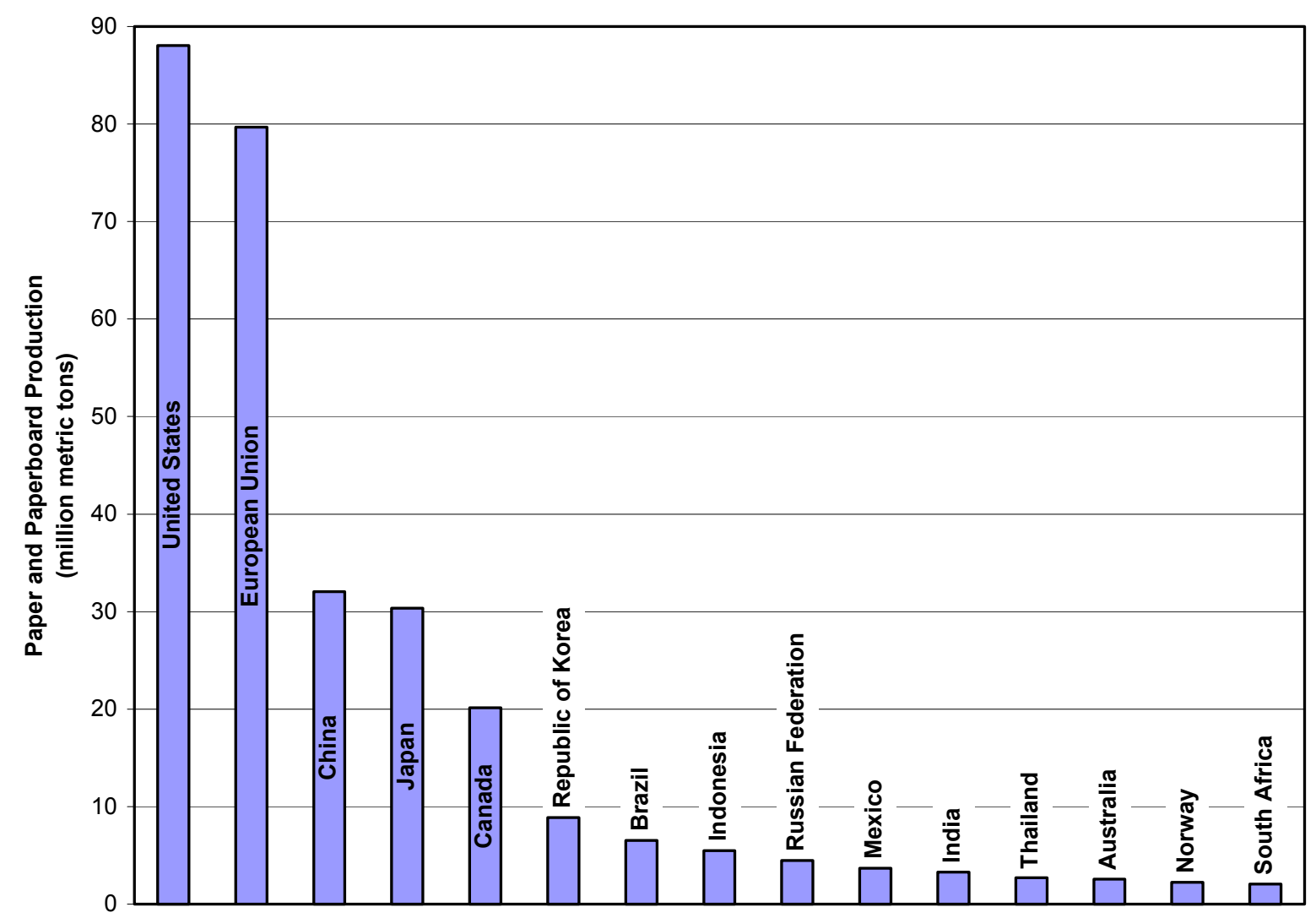

1) Emerging players in the market: In the past 10 years, several developing countries have had an impact on the market. These emerging economies have been able to attain comparable production technologies with lower costs of environmental compliance and lower labor costs. In particular, Brazil and developing countries in Asia (such as Indonesia and the Republic of Korea) have had a significant effect on the distribution of production. Figure 3a shows an industry snapshot of the production of paper and paperboard in 1983, while Figure $3 \mathrm{~b}$ shows a production snapshot in $1999 .^{7}$ Note that the large increase in production in the European Union (E.U.) is a direct result of Spain and Portugal joining the E.U. in 1986; and Austria, Finland, and Sweden joining in 1995. The substantial increase in production in Asia caused decreases in the market shares of the United States, Europe (E.U. and non-E.U.), and Canada. The impact of this trend on the global market from 1983 to 1999 is shown in Figure 4. Notice that Mexico, South America, and others remain fairly static during this time interval. Canada experiences a minor decrease in global production share over time. Europe (E.U. and non-E.U. states) and the United States experience substantial

\footnotetext{
${ }^{6}$ Data source: Statistical Yearbook $-45^{\text {th }}$ Issue, (2001), United Nations, Reproduction Section, New York, NY 10017, ISBN 92-1-061189-6. Available from http://www.un.org/Pubs.

${ }^{7}$ Ibid.
} 
decreases in global production share; while Asia is consistently rising until the Asian financial crisis in the late-1990s. ${ }^{8,9}$

Figure 2: U.S. Export Market in Paper and Allied Products in $1998^{10}$

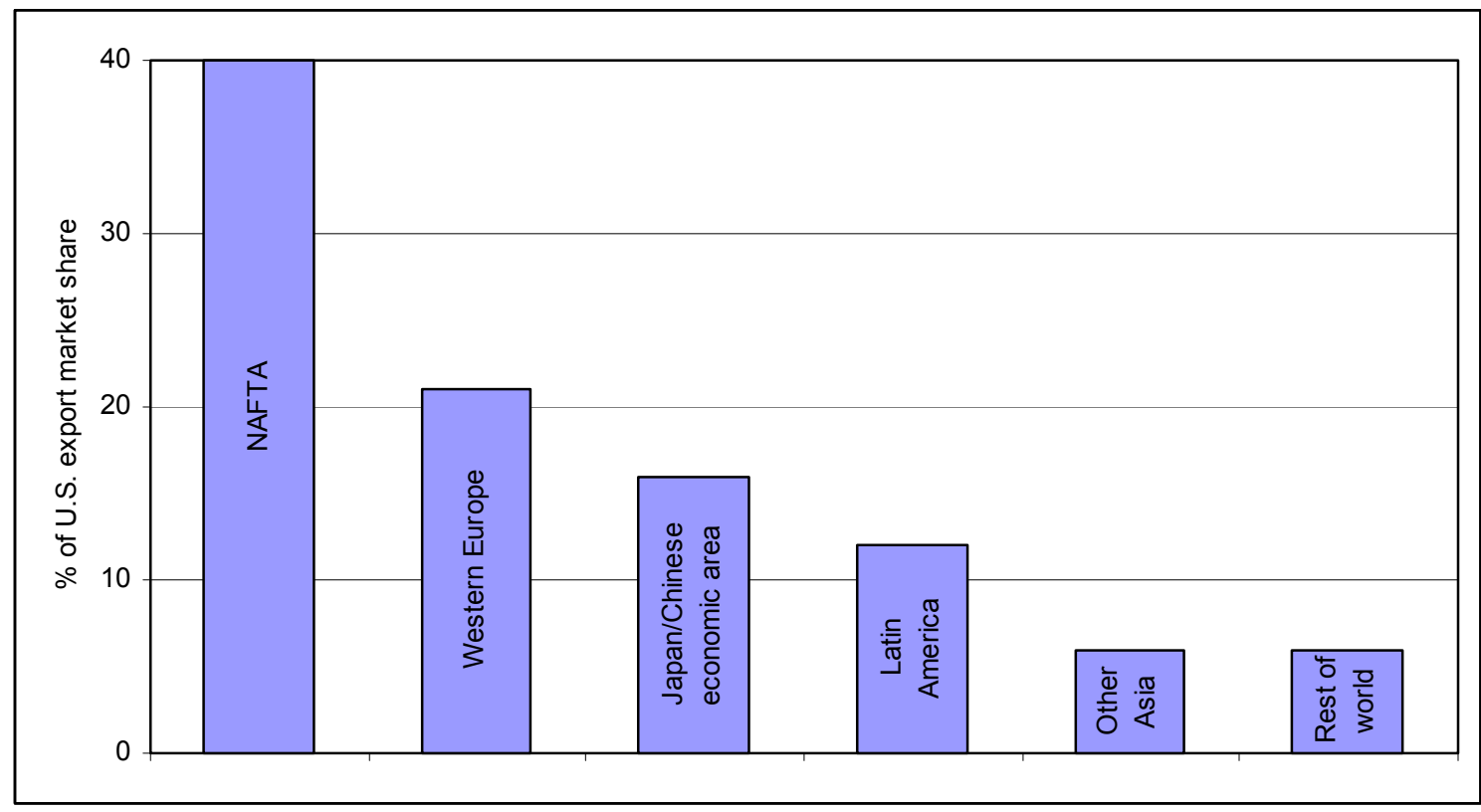

Figure 3a: 1983 Distribution of Paper and Paperboard Production

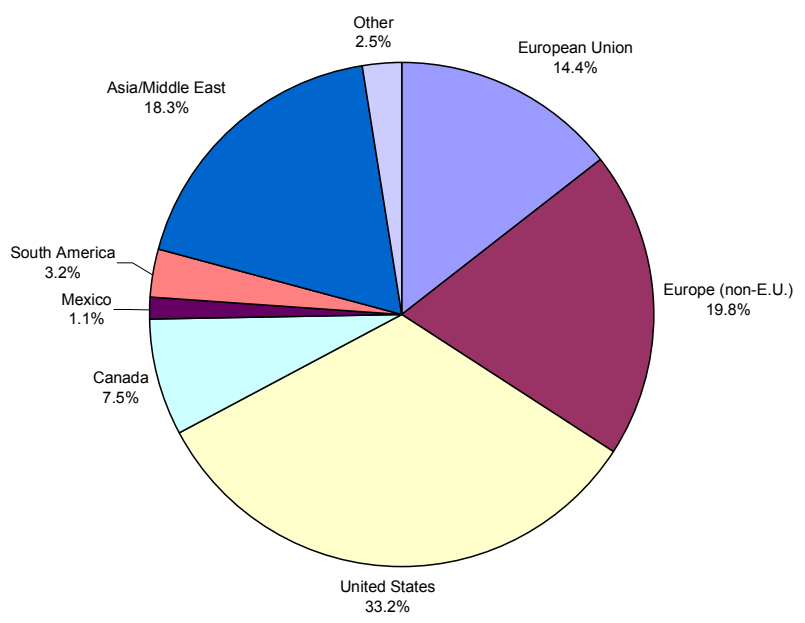

Total production $=177$ million tons
Figure 3b: 1999 Distribution of Paper and Paperboard Production

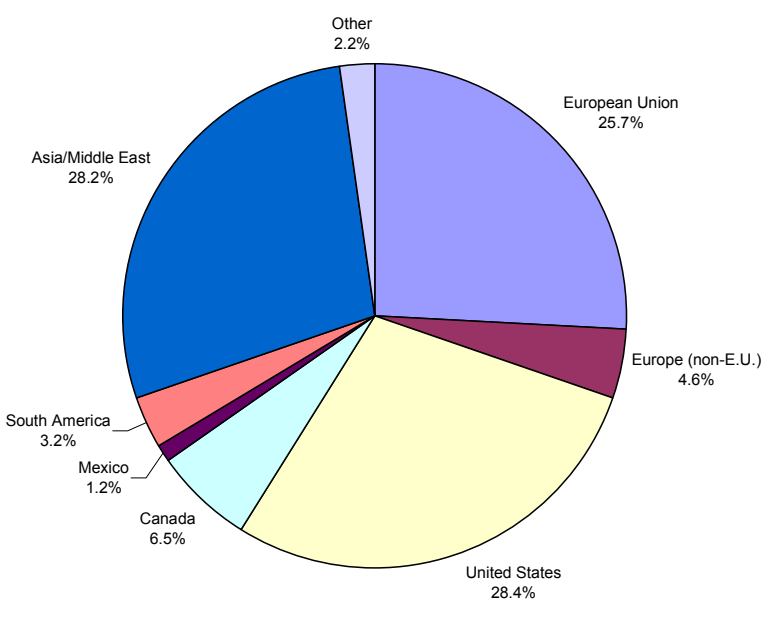

Total production $=\mathbf{3 0 9}$ million tons

\footnotetext{
${ }^{8}$ Ibid.

${ }^{9}$ Data source: Statistical Yearbook $-40^{\text {th }}$ Issue, (1995), United Nations, Reproduction Section, New York, NY 10017, ISBN 92-1-061163-2.

${ }^{10}$ Ibid.
} 
Figure 4: Global Market for Paper and Paperboard Production ${ }^{11}$

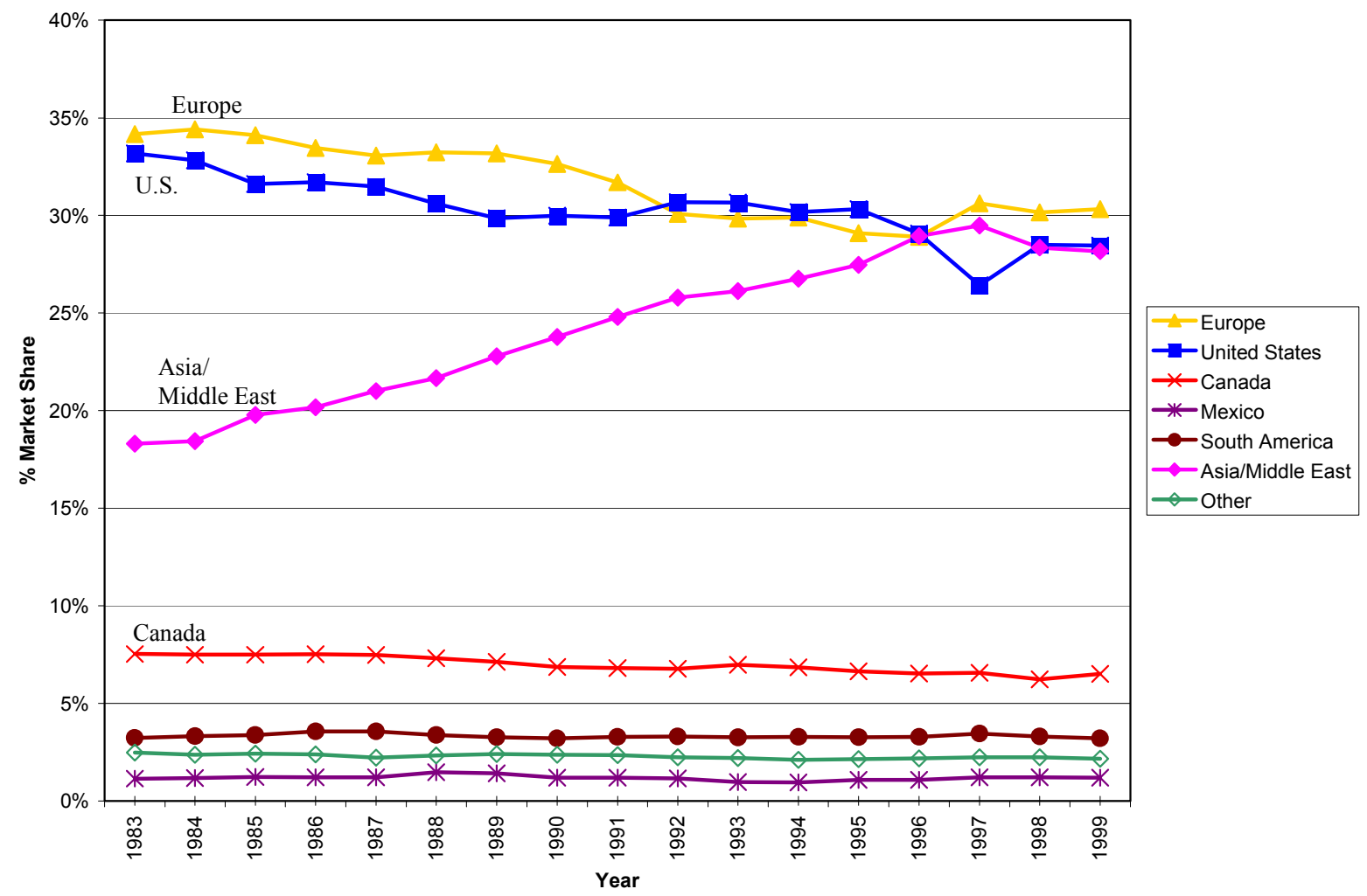

2) High domestic-labor costs: The average hourly wage for workers in the pulp and paper industry was $\$ 15.31$ in $1997 .{ }^{12}$ The average for the entire forest products industry was $\$ 13.65$ for the same year. ${ }^{13}$ Low-wage labor availability in emerging markets makes it more difficult for the United States and other developed markets (such as Canada and Europe) to compete.

3) High cost of environmental compliance: Another factor contributing to the diminishing shares of global production of key countries such as the United States, Canada, and E.U. nations is the high cost of meeting environmental regulations. "Over the 1998-2000 period, expenditures for environmental and energy (non-output-related) projects are forecast to account for nearly 23.5 percent of total capital outlays over that 3-year period." ${ }^{14}$ In 1994, the forest products industry expenditures for pollution abatement totaled $\$ 771.3$ million in capital expenditures and $\$ 2.2$ billion in operating expenditures. ${ }^{15}$

4) High capital intensity of production: The kraft chemical pulping process is the most common process used in the United States, accounting for more than 75 percent of U.S. pulp production. ${ }^{16}$ The kraft process requires large energy expenditures. The industry recognizes this and relies on a chemical recovery process that generates electricity to make the process economically feasible; however, it still requires large amounts of purchased fuel and energy. As shown in Figure 5, the forest products industry (due almost entirely to the pulp and paper industry) is ranked third among the largest consumers of energy for heat and power in the manufacturing sector. ${ }^{17}$ It follows

\footnotetext{
11 Ibid.

${ }^{12}$ U.S. Industry \& Trade Outlook 2000, op cit.

13 "Forest Products Industry Profile," U.S. Department of Energy, Office of Industrial Technologies, op cit.

${ }^{14}$ U.S. Industry \& Trade Outlook 2000, op cit.

15 "Forest Products Industry Analysis Brief," U.S. Energy Information Administration, op cit.

${ }^{16}$ Smook, G.A., op cit.

17 “Annual Energy Outlook 2001,” Energy Information Administration, (December 2000), DOE/EIA-0383 (2001).
} 
petroleum refining and chemicals industries at first and second. The pulp and paper industry has recognized improving the self-generation of energy and recovery of chemicals as critical elements to lowering fuel and energy expenditures. Figure 6 shows that energy self-sufficiency for selected years increases over time. Figure 7 shows that fossil fuel and purchased energy consumption for selected years decreases over time. Figure 8 shows that almost half of the energy expenditures for the industry in 1994 were for electricity.

Figure 5: Top Energy-Intensive U.S. Industries: Manufacturing Energy Use (2001)

(Total U.S. industrial energy use $=\mathbf{3 4 . 1}$ quadrillion Btu)

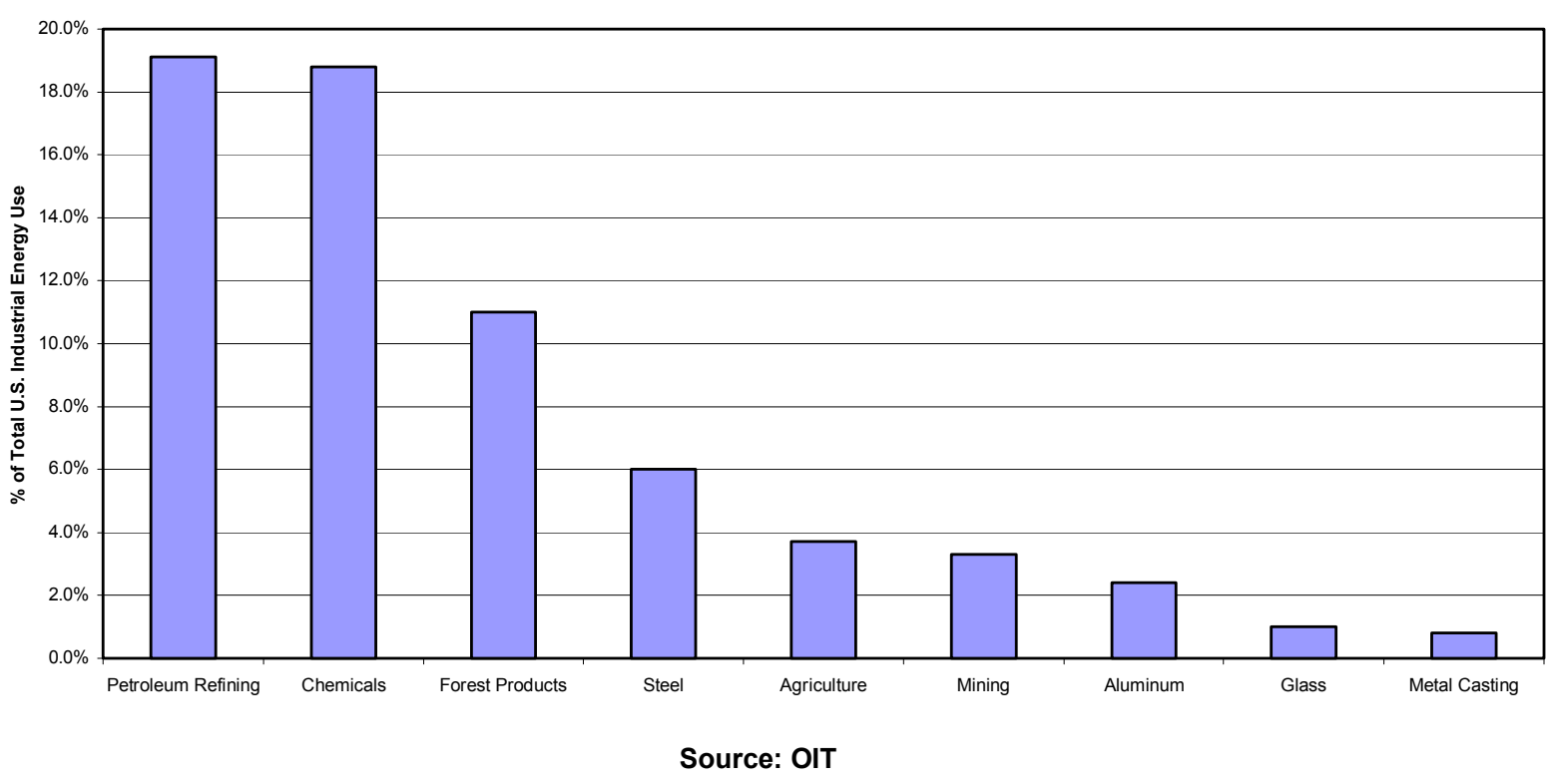

Figure 6: Energy Self-Sufficiency: Pulp, Paper, and Paperboard ${ }^{18}$

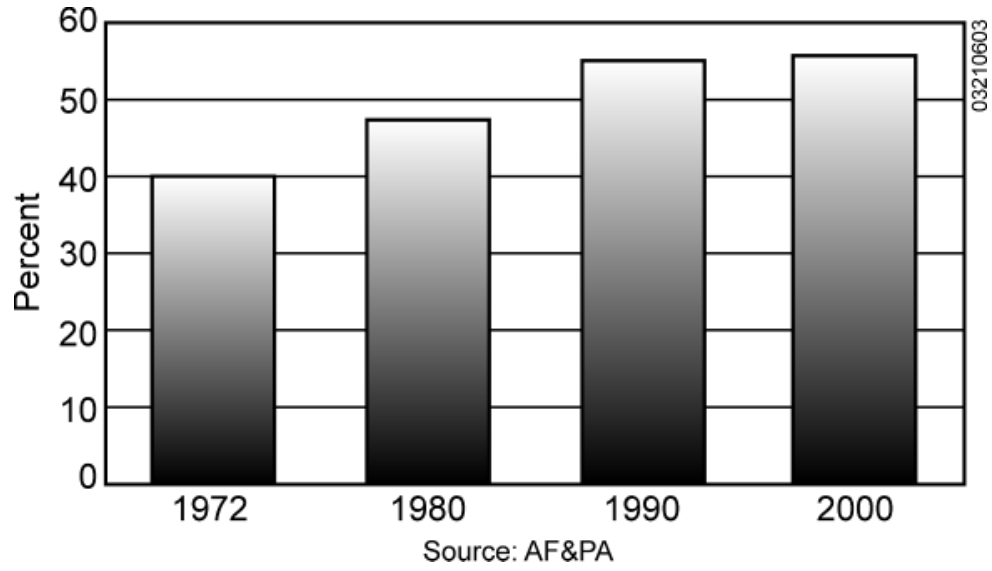

\footnotetext{
${ }^{18}$ Figure from "Energy Use by the Paper Industry" reprinted with permission of the American Forest and Paper Association, Inc., 1111 Nineteenth Street NW, Washington, D.C. 20036. Available at http://www.afandpa.org/iinfo/environment/Energy use.html.
} 
Figure 7: Fossil Fuel and Purchased Energy Consumption: Pulp, Paper, and Paperboard ${ }^{19}$

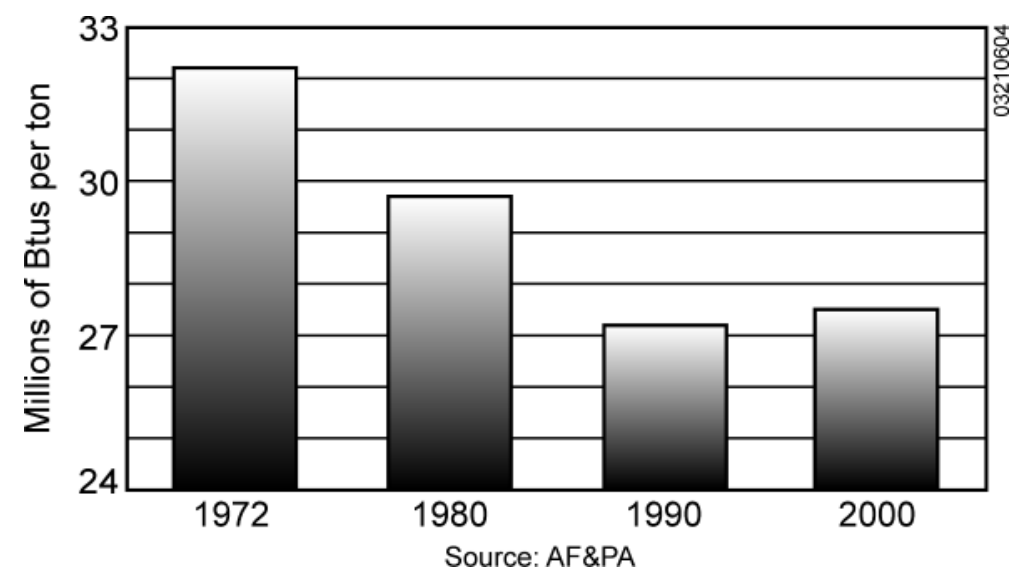

Figure 8: 1994 Energy Expenditures for the Pulp and Paper Industry (\$ million) ${ }^{20}$

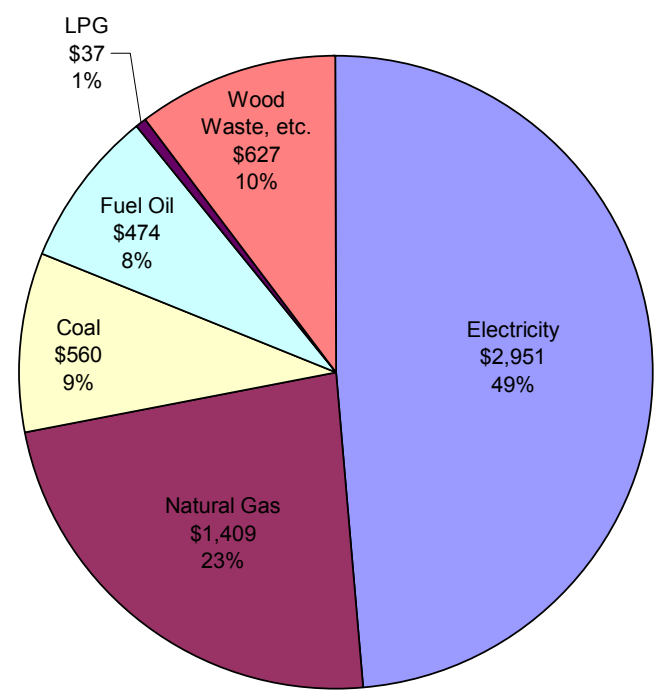

\footnotetext{
${ }^{19}$ Ibid.

${ }^{20}$ Source: U.S. Energy Information Administration, 1000 Independence Avenue SW, Washington, D.C. 20585, (202) 586-8800. Available at http://www.eia.doe.gov/emeu/mecs/mecs94/consumption/mecs5.html.
} 


\subsection{Sustaining Global Competitiveness}

Each of the four factors discussed above affects the ability of the United States to maintain its position in the global market for pulp and paper. Addressing these factors is key to sustaining U.S. global competitiveness.

Because the products are commodities, price is the key factor in maintaining competitiveness. It is unlikely that the U.S. pulp and paper industry will be able to reduce wages to compete with lower-wage overseas labor. However, the final two factors provide avenues for cost reductions by U.S. industry. The challenges presented to the industry by the high cost of environmental compliance and capital intensity of production can be met by finding new technologies that lower emissions through improving efficiency. This strategy uses research and development to create technologies that reduce the controllable costs (economic and environmental) in the pulp and paper industry.

The U.S. Department of Energy (DOE) funds projects that seek to lower energy use, costs of production, and environmental impacts. Any steps that can be taken to lower the costs and environmental impacts of producing pulp and paper products will bolster U.S. competition in the global market. This case study examines the activities of the DOE's Advanced Industrial Materials (AIM) Program - the predecessor to the Industrial Materials for the Future (IMF) Program - in sponsoring materials research and development aimed at achieving lower costs through improved energy efficiency and productivity. 


\subsection{Description of the Problem: The Kraft Chemical Pulping Process}

\subsection{Introduction to the Kraft Pulping Process}

The goal of all pulping processes is to separate the cellulose and hemicelluloses from lignin. Cellulose is the fibrous substance that is used to make pulp and paper. Lignin acts as an adhesive to hold wood fibers together. ${ }^{21}$ The removal of the lignin results in a pulp that is well suited for the production of paper.

The kraft chemical pulping process is the predominant process used in the United States. It was invented by C.F. Dahl and uses sulfides and hydroxides to chemically degrade lignin, while leaving the cellulose fibers largely intact. The kraft process was patented by Dahl in 1884 and was first used commercially in Sweden in 1885. This process gained popularity because of the increased strength of the pulp compared to alternate pulping methods. The process was dubbed "kraft pulping" since kraft means strength in both German and Swedish. In the 1930s, G.H. Tomlinson revolutionized the kraft process by creating a recovery furnace that could burn spent sulfate liquors and recover heat and chemicals. $^{22}$

Figure 9 outlines the kraft chemical pulping process, which is discussed in detail below.

\subsection{Wood Yard Operations: Timber Preparation}

The kraft pulping process begins with cutting timber in the wood yard to reduce it to a manageable size (10-30 mm long and 3-6 mm thick) for the pulping process. ${ }^{23} \mathrm{Next}$, the logs are put into a cylindrical container that rotates them. The friction from the logs rotating against each other and the sidewalls of the cylinder removes the bark from the logs. The bark escapes through slots in the cylinder and is burned for energy recovery in other plant processes. It is necessary to remove the outer bark, which is a contaminant in pulp and paper, because it does not contain any fibrous materials. Then, the logs are further reduced by chipping the logs with a large rotating disk (or drum) that has knives on the face of the disk (or wall of the drum). The knives slice the logs into wood chips that escape through slots in the disk (or wall of the drum). The chips are then passed through a screen to filter out large knots and oversized chips. ${ }^{24}$

\subsection{Digester}

The wood chips that have been reduced to a manageable size are sent to the digester. The digester steams and cooks the wood chips in a solution of sodium hydroxide and sodium sulfide, known as white liquor, under high pressure and temperature. The wood chips are then broken into individual fibers by release and impact through a blow valve into the blow tank. These fibers are called the pulp and can be used for papermaking. The leftover substance composed of chemical materials and wood impurities (consisting of mostly lignin) is called black liquor. ${ }^{25}$

\subsection{Recovery Boiler}

The black liquor passes through a series of evaporators to increase the percentage of solids in the liquor; if combustion takes place with below 58 percent solids, explosions can occur. Black liquor below 58

\footnotetext{
${ }^{21}$ EPA Fact Sheet: "The Pulp and Paper Industry, the Pulping Process, and Pollutant Releases to the Environment." United States Environmental Protection Agency, (November 1997), EPA-821-F-97-011. Available at http://www.epa.gov/waterscience/pulppaper/jd/fs2.pdf.

${ }^{22}$ Smook, G.A., op cit.

${ }^{23}$ Ibid.

24 "Materials Needs and Opportunities in the Pulp and Paper Industry," Advanced Industrial Materials (AIM) Program, (August 1995), Oak Ridge National Laboratory ORNL/TM-12865.

${ }^{25}$ Ibid.
} 
percent solids is often called weak liquor and above 58 percent solids is called strong liquor. The percentage of solids is measured by a series of optical refractometers to assure that only strong black liquor is allowed to continue to the recovery boiler.

Concentrated black liquor is sent to and combusted in the recovery boiler to recover feedstock. Water flows through the recovery boiler tubes to keep the metal temperature at approximately $330^{\circ} \mathrm{C}\left(626^{\circ} \mathrm{F}\right)$ and turns to steam that is used for drying processes and for electricity generation by steam turbines. Steam and electricity produced by the recovery boiler account for approximately 40 percent of the energy supply for the entire paper mill. ${ }^{26}$

When the black liquor is burned, a substance composed of sodium carbonate and sodium sulfide called smelt - forms at the bottom of the boiler. The salts that make up the smelt have a high melting point and thus form a solid at the surface of the water-cooled boiler tubes. Above the layer of solid smelt is a layer of molten smelt that reaches depths of several inches and temperatures of $925^{\circ} \mathrm{C}-$ $980^{\circ} \mathrm{C}\left(1700^{\circ} \mathrm{F}-1800^{\circ} \mathrm{F}\right){ }^{27} \mathrm{~A}$ critical task in the recovery boiler is to assure that the water flowing through the boiler tubes does not leak and subsequently come into contact with the molten smelt. If this happens, an explosion can occur in the boiler because of the instantaneous vaporization of the water. The effects of smelt-water explosions are described below. ${ }^{28,}{ }^{29}$ A schematic of the recovery boiler is shown in Figure 10.

\subsection{Chemical Recovery}

When the smelt in the recovery boiler reaches a sufficient depth, it flows out of the boiler through smelt spouts and is sent to the chemical recovery process. The smelt is separated into small clusters by a series of shatter jets, which spray steam onto the smelt at a high speed. Because the smelt is broken into small packets, this process causes very small explosions when operating properly. The shatter jet process facilitates dissolving smelt in water. ${ }^{30}$ The smelt-water solution is called green liquor. The green liquor is treated with hydrated lime, which turns the sodium carbonate into sodium hydroxide. Notice that this process converts the chemical composition of the green liquor into that of white liquor. The white liquor resulting from the chemical recovery process is then fed back into the digester to continue through the pulping process again. ${ }^{31}$

\footnotetext{
${ }^{26}$ The Industrial Sector (p 4.25), http://www.ornl.gov/ORNL/Energy_Eff/PDF/CON444/ch4.pdf

${ }^{27}$ Parrish, D. "Black Liquor Recovery Boilers - An Introduction, Inspector's Insight," National Board Bulletin, (Winter 1998). Available at http://www.nationalboard.org/Publications/Bulletin/WI98.pdf.

${ }^{28}$ Ibid.

${ }^{29}$ Keiser, J.R. et al. "Causes and Solutions for Cracking of Coextruded and Weld Overlay Floor Tubes in Black Liquor Recovery Boilers,” (1998), project update prepared for the U.S. Department of Energy, Oak Ridge National Laboratory ORNL/CP-97848.

${ }^{30}$ Smook, G.A., op cit.

31 "Materials Needs and Opportunities in the Pulp and Paper Industry," op cit.
} 


\section{Figure 9: The Kraft Chemical Pulping Process}

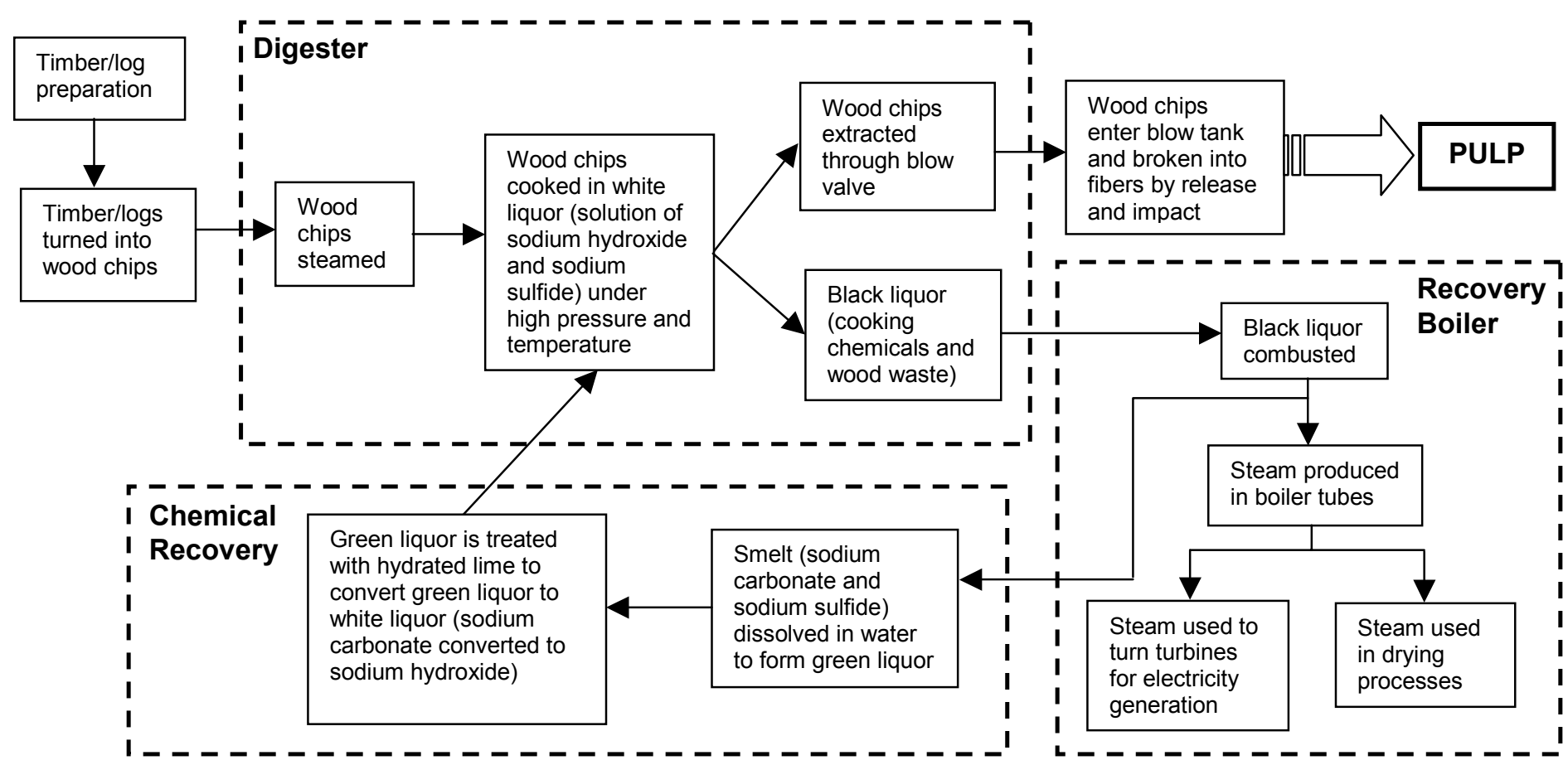


Figure 10: Babcock and Wilcox recovery furnace (circa 1968) ${ }^{32}$

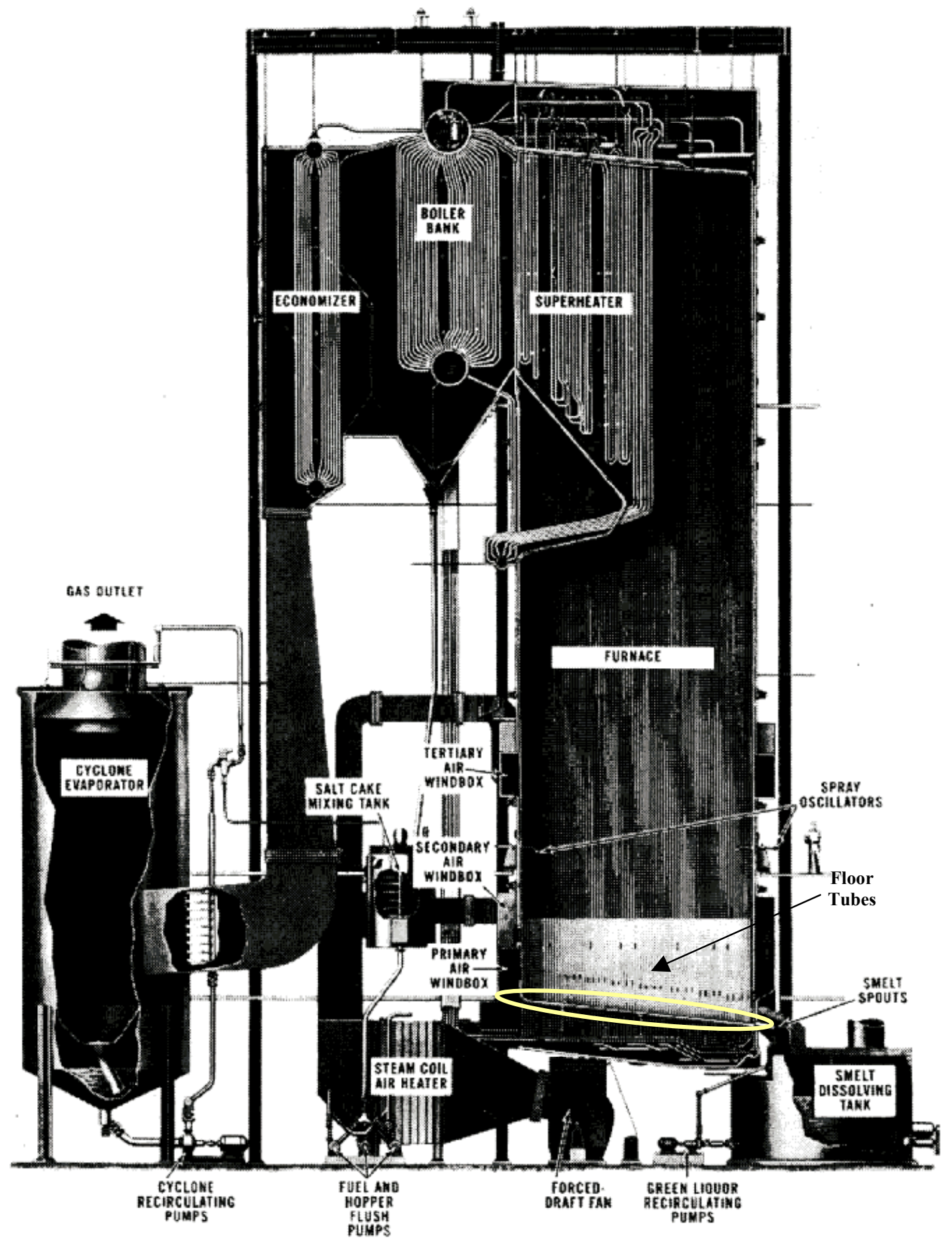

${ }^{32}$ Figure taken from Smook, G.A. op cit. 


\subsection{The Problem}

The recovery boiler is the heart of the kraft pulping process. It makes the kraft process economically feasible through the generation of steam and electricity and the recovery of chemicals. Approximately 50 percent of the paper mills in the United States use only one kraft recovery boiler. Materials used in the recovery boiler operate under high temperatures in a highly corrosive environment. Routine shutdowns of the boiler are necessary to clean and maintain boiler components and check for signs that might indicate potential failure of the components during future operation. A photograph of a crew performing routine maintenance inside a boiler is shown in Figure 11. When the recovery boiler is shut down, the entire plant greatly reduces or ceases production. ${ }^{33}$ This results in enormous costs due to losses in production (an average of approximately $\$ 300,000$ per plant per shutdown day). ${ }^{34}$ Consequences for plants with more than one recovery boiler will be diminished since production will not completely stop. However, these plants will still suffer a reduced production capacity.

\section{Figure 11: Routine Maintenance Inside of a Boiler ${ }^{35}$}

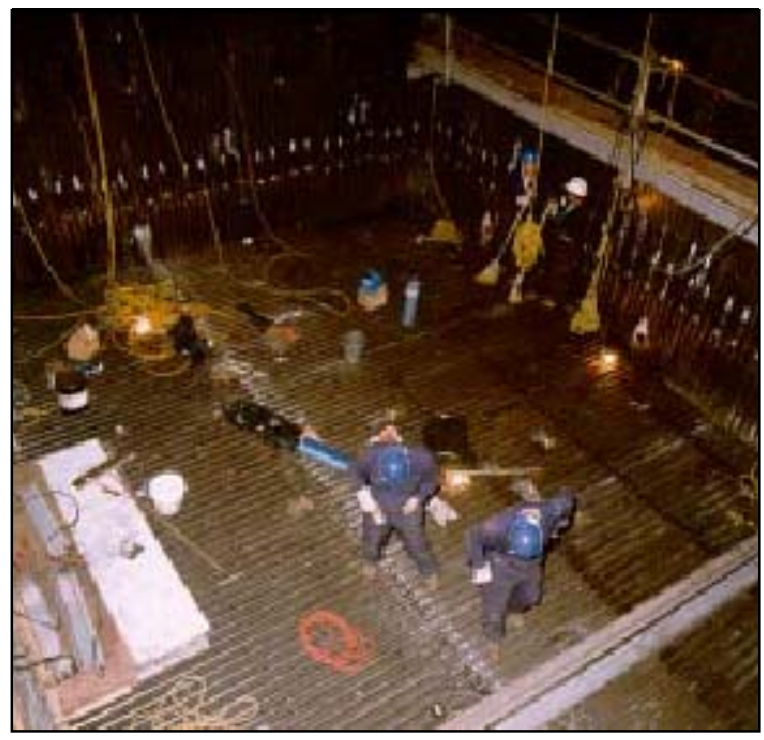

The core challenge in the kraft chemical pulping process is identifying and using materials in the recovery boiler that are resistant to the highly corrosive service environment, thus reducing the frequency of scheduled and unscheduled shutdowns.

If a boiler tube cracks, it can cause an unplanned shutdown and additional damage to the boiler. Photographs of two types of cracking commonly found in recovery boiler floor tubes are shown in Figure 12 (this figure is described in more detail in Appendix A). ${ }^{36}$ When cracks in the boiler tubes extend deep enough to allow water and steam to leak into the molten smelt environment of the recovery boiler, a large explosion can occur. In a 1998 review of recovery boiler accidents, David Parrish (P.E. of the Factory Mutual Research Corporation) noted that the instantaneous vaporization of one pound of

\footnotetext{
${ }^{33}$ Ibid.

${ }^{34}$ This estimate derives from a consensus of industry experts (P. Angelini, Oak Ridge National Laboratory, private communication).

${ }^{35}$ Barna, J.L., K.B. Rivers. "Improving Recovery Boiler Furnace Reliability with Advanced Materials and Application Methods," (January 1999), BR-1668. Illustration, courtesy of the Babcock and Wilcox Company, Barberton, Ohio, available at http://www.babcock.com/pgg/tt/pdf/BR-1668.pdf.

${ }^{36}$ Figure taken from Barna, J.L., op cit.
} 
water in the recovery boiler could cause an explosion equivalent to a half pound of TNT. Parrish stated that the Black Liquor Recovery Boiler Advisory Committee (BLRBAC) "has been notified of over 150 [black liquor recovery boiler] explosions in North America. In most incidents, [recovery boiler] damage required days to weeks to repair. In the worst incidents, damage is extensive, taking months to repair, and injury and death of operating personnel has resulted." ${ }^{37} \mathrm{He}$ further noted that, in addition to the production loss from downtime, ordering, and installing a replacement boiler costs $\$ 18$ million to $\$ 40$ million. This emphasizes the gravity of boiler-tube cracking, which causes these explosions by releasing water into contact with molten smelt. It was crucial that U.S. pulp and paper mills address this issue to ensure the safety of plant personnel, reduce energy consumption and emission of greenhouse gases, and enhance U.S. competitiveness in the global market.

Figure 12a: Circumferential Cracking

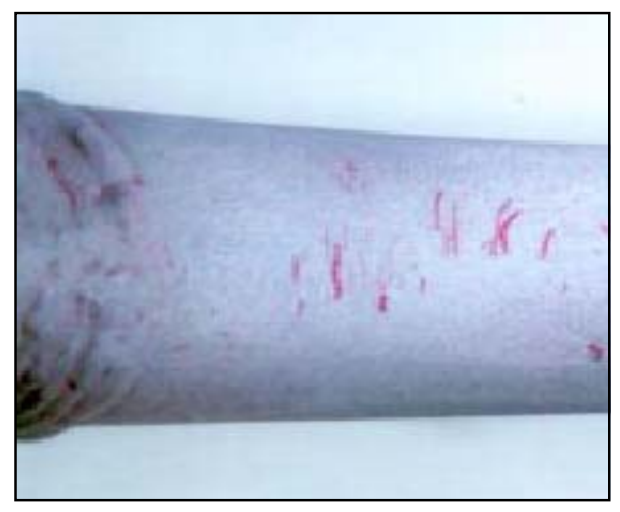

Figure 12b: Crazed Cracking

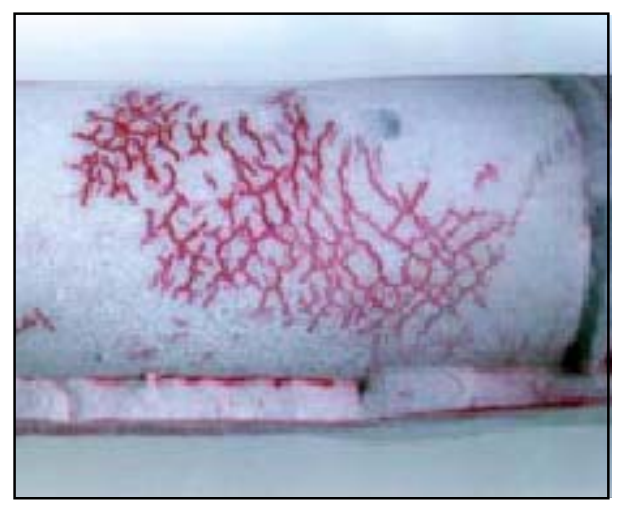

The pulp and paper industry identified cracking boiler tubes (made of carbon steel) as the leading cause of boiler shutdowns in the 1960s. Beginning in 1972, composite tubes, consisting of an inner layer of carbon steel and an outer layer of stainless steel, were installed in kraft recovery boilers. However, within several years, these composite tubes began to crack; and by 1992, the tube-cracking problem had returned worldwide. The U.S. Department of Energy (DOE) Advanced Industrial Materials (AIM) program began an $R \& D$ project in 1995, in collaboration with the forest products industry, with the goals of determining the cause of cracking in kraft recovery boiler floor tubes and identifying the necessary materials properties that would eliminate boiler-tube cracking. ${ }^{38}$ The floor tubes were targeted because they were identified by industry as the most severe problem. Two factors determine the likely severity of a boiler-tube leak: (1) the amount of water coming in contact with the smelt and (2) proximity to the smelt bed. As the amount of water and/or the proximity of the leak to the smelt bed increases, the likelihood of a severe smelt-water explosion increases. While floor-tube leaks are typically smaller, they are much closer to the smelt bed. Almost 23 percent of tube leaks recorded by BLRBAC that caused a smelt-water explosion, which caused damage to the recovery boiler, were caused by leaks in floor tubes. ${ }^{39}$ This case study describes the background, activities, and results of this R\&D program, which continues under the Industrial Materials for the Future (IMF) program of the DOE Office of Industrial Technologies (OIT). Figure 13, on the following page, is a timeline summarizing significant events and program funding, leading to the development of new procedures and materials.

\footnotetext{
${ }^{37}$ Parrish, D. "Black Liquor Recovery Boilers - An Introduction, Inspector's Insight," op cit.

${ }^{38}$ Department of Energy, "Advanced Industrial Materials (AIM) Program: Compilation of Project Summaries and Significant Accomplishments FY1999," (May 2000), Oak Ridge National Laboratory, ORNL/TM-2000/90.

Available from the National Technical Information Service, Springfield, VA, http://www.ntis.gov/ordering.htm.

${ }^{39}$ Grace, T.M., "1994 Kraft Recovery Short Course,” Chapter 6.7: Smelt-Water Explosions, Course Notes, TAPPI

PRESS, Technology Park/Atlanta, P.O. Box 105113, Atlanta, GA 30348-5113, (1994), TP 010656/94 XE.
} 


\section{Figure 13: Timeline for Composite Tube Failures and DOE R\&D Program ${ }^{40}$}

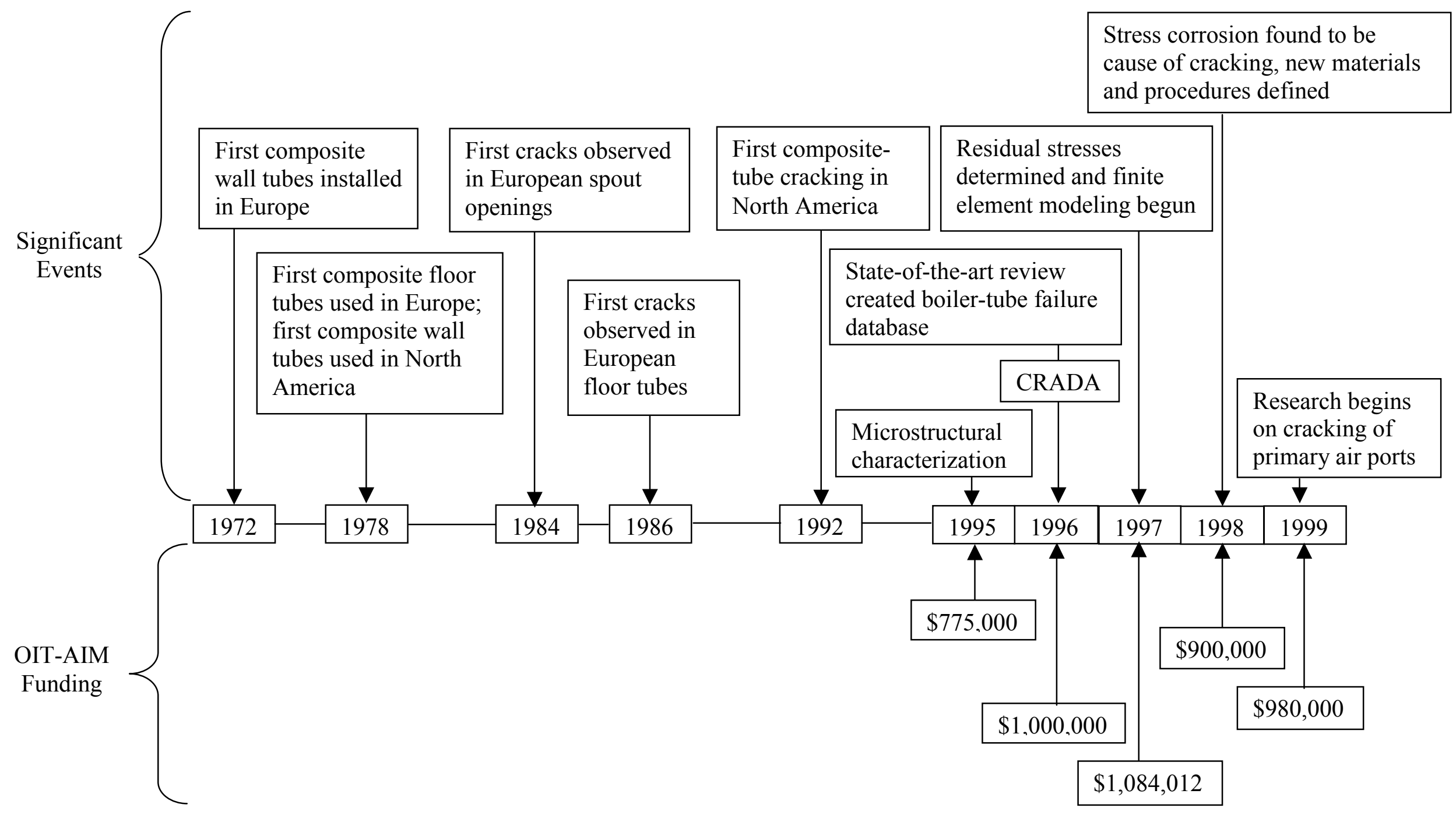

\footnotetext{
${ }^{40}$ A Cooperative Research and Development Agreement (CRADA) is a partnership between research entities and industries to facilitate data collection, development of new materials and processes, and testing performance of commercial prototypes.
} 


\subsection{Solving the Problem through R\&D}

\subsection{Background of Boiler Materials}

Before the introduction of composite boiler tubes in the 1970s, carbon steel (SA-210 Gd A1) tubes with studs on the outer surface were used in the kraft recovery boiler. Carbon steel tubes were chosen for their low price, ease of welding, and capability to withstand very high pressures. The carbon steel tubes typically had $2 \mathrm{~cm}$-long studs on their outer surfaces to promote the solidification of smelt on the floor of the boiler. Solid smelt insulates the tubes from the high temperatures inside the boiler. However, at high temperatures, the carbon steel exhibits an especially high sulfidation rate, which sometimes led to failure of the tubes. ${ }^{41}$

The forest products industry began using coextruded composite tubes to address the high sulfidation rates of the carbon steel. The composite tubes are created by combining two billets of the desired innerand outer-surface materials, then coextruding the combined billet through a die at a high temperature this creates a tube with one material on the outer surface and a different material on the inner surface. This allowed the industry to have a tube with one suite of materials properties on the outer surface of the tube and a separate suite of materials properties on the inner surface of the tube. This was a landmark development because the inner and outer surfaces of the tubes were being exposed to different environments.

Type 304L stainless steel was chosen for the outer surface of the composite tubes because of its resistance to sulfidation at high temperatures. Tubes are typically fabricated with a total wall thickness of about $0.635 \mathrm{~cm}(0.25 \mathrm{in}$.), inner tube wall thickness of about $0.457 \mathrm{~cm}(0.18 \mathrm{in}$.), outer tube wall thickness of about $0.178 \mathrm{~cm}$ (0.07 in.), and external diameter of 6.35 to $7.62 \mathrm{~cm}$ (2.5 to $3.0 \mathrm{in}$.). Figure 14 is a schematic of a $6.35 \mathrm{~cm}$ ( 2.5 in.) composite tube cross-section.

\section{Figure 14: Schematic of Composite Tube Cross-Section ${ }^{42}$}

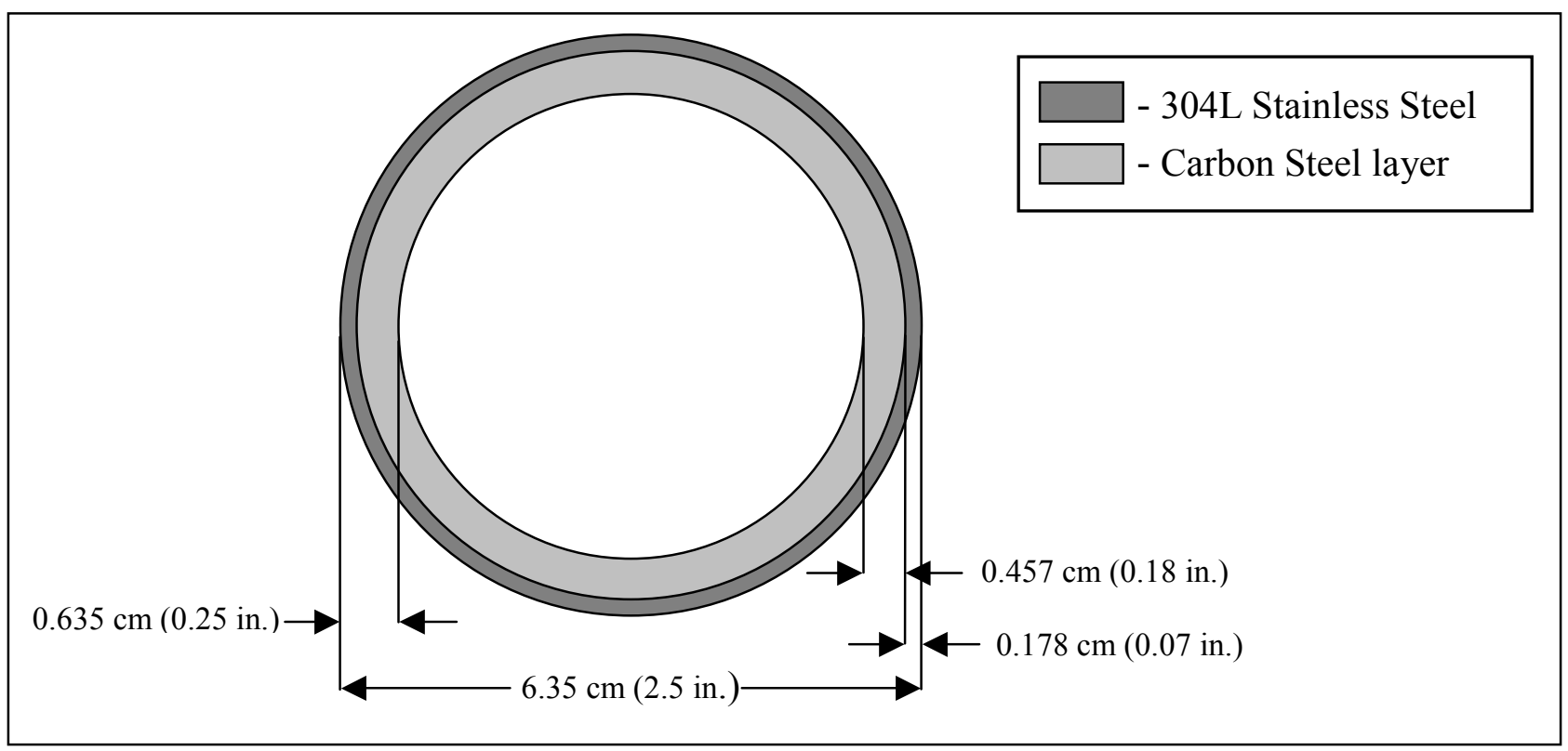

41 "Materials Needs and Opportunities in the Pulp and Paper Industry," op cit.

${ }^{42}$ Figure 14 is a scale drawing of a $6.35 \mathrm{~cm}$ (2.5 in.) composite tube cross-section. 
As noted in Figure 13, the first composite tubes were installed in the walls of a recovery boiler in 1972 in Scandinavia. In 1978, composite tubes were used as recovery boiler floor tubes in Scandinavia. The first composite wall tubes used in North America, were installed in 1978. Composite floor tubes were commonplace in paper mills by the mid-1980s. ${ }^{43}$

The expectation of the industry was that the coextruded composite tubes would provide a very lowmaintenance recovery boiler because of their increased corrosion resistance, as compared to carbon steel. However, the outer layer of 304L stainless steel did not prove to be impervious to the service environment. Following almost a decade of tube-cracking problems in Europe, the first case of composite floor-tube cracking was reported in North America in 1992. ${ }^{44}$ While the serious nature of the problem was recognized, there were insufficient data to determine the failure mechanism. Beginning in 1995, the OIT AIM Program began to fund R\&D to address the potentially devastating consequences associated with composite tube failure.

\subsection{R\&D Approach}

A team of researchers from Oak Ridge National Laboratory, the Pulp and Paper Research Institute of Canada, the Institute of Paper Science and Technology, and partners from the pulp and paper industry, coordinated a project to determine the mechanism responsible for the composite tube cracking. Though many cracking mechanisms - such as thermal fatigue, mechanical fatigue and stress-corrosion cracking - are well understood, research to define the service environment in which the tubes were operating was needed to determine which mechanism or mechanisms were responsible for the cracking of the composite floor tubes.

Industrial cooperation, to facilitate data collection on the operating conditions, was an essential element that enabled the successful performance of this research. Access to the boilers for on-site inspection and testing was critical to define the service environment and to obtain data on the tube characteristics before and after failures. After acquiring this information, the research team was then able to use offsite facilities to conduct further tests on the tubes, together with modeling and simulation of tube behavior under the service environment, to identify failure mechanisms and define a desired suite of materials properties to avoid failures.

\subsection{Factors Influencing R\&D Allocation}

The R\&D funding was driven by the mission of the AIM Program (now that of IMF) to research, design, develop, engineer, and test new and improved materials, as well as more profitable uses of existing materials. Defining the desired suite of materials properties is a requirement to accomplish this mission. And achieving the key research objective of identifying the failure mechanism of the composite tubes requires defining the kraft recovery boiler environment.

This project required considerable funding to perform the R\&D. A single company would not have been able to absorb the necessary costs to complete the research because of the highly cost-sensitive nature of global competition in the pulp and paper industry. Pulp and paper companies also lack the necessary materials expertise and facilities to perform the R\&D as described in the following section. This created an ideal scenario for the AIM Program to fund a national laboratory-led project to provide the pulp and paper industry with the key components that were absent in the industry.

\footnotetext{
${ }^{43}$ Keiser, J.R. et al. "Overview of the DOE Studies of Recovery Boiler Floor Tube Cracking," (1998), project update prepared for the U.S. Department of Energy, Oak Ridge National Laboratory ORNL/CP-97302.

${ }^{44}$ Keiser, J.R. et al. "Why do Kraft Recovery Boiler Composite Floor Tubes Crack?," TAPPI Journal, 84:8, (August 2001), p. 48. Technical Association of the Pulp and Paper Industry, 15 Technology Parkway South, Norcross, GA 30092
} 
AIM began funding research on boiler materials with a budget of $\$ 775,000$ in mid-1995 to achieve their objectives. ${ }^{45}$ This required both expertise and facilities that were available at Oak Ridge National Laboratory (ORNL), the Pulp and Paper Research Institute of Canada (Paprican), and the Institute of Paper Science and Technology (IPST). As noted above, the participation of the industry was critical to obtaining the required data on tube failures. From the beginning, industrial partners were dedicated to cooperating with research teams to examine the problem. The AIM recovery boiler materials project started with 10 paper companies, five recovery boiler manufacturers, and one composite tube fabricator as industrial partners. The program continues today with 16 paper companies, four recovery boiler manufacturers $^{46}$, and two composite tube fabricators; and, having achieved their objectives with respect to the problem of the floor tubes, the program now focuses on improved materials for boiler air ports. Table 2 shows the collaboration with industrial partners over time. The pulp and paper companies, boiler manufacturers, tube fabricators, and research organizations involved in this project are listed in Table 3.

Table 2: Industrial Partnership History

\begin{tabular}{|c|c|c|c|}
\hline FY & $\begin{array}{c}\text { Paper } \\
\text { Companies }\end{array}$ & $\begin{array}{c}\text { Recovery Boiler } \\
\text { Manufacturers }\end{array}$ & $\begin{array}{c}\text { Tube } \\
\text { Fabricators }\end{array}$ \\
\hline 1995 & 10 & 5 & 1 \\
\hline 1996 & 14 & 4 & 2 \\
\hline 1997 & 17 & 4 & 2 \\
\hline 1998 & 17 & 4 & 2 \\
\hline 1999 & 16 & 4 & 2 \\
\hline
\end{tabular}

Table 3: List of Project Team Members

\begin{tabular}{|c|c|}
\hline Paper Companies & $\begin{array}{c}\text { Recovery Boiler Manufacturers } \\
\text { and Tube Fabricators }\end{array}$ \\
\hline Boise Cascade Corp. & ABB Combustion Engineering \\
\hline Champion International Corp. & Ahlstrom Recovery Inc. \\
\hline Diashowa Marubeni Int. & Babcock \& Wilcox Co. \\
\hline Georgia-Pacific Corp. & Kvaerner Pulping Inc. \\
\hline P.H. Glatfelter Co. & Sandvik Steel AB \\
\hline International Paper & Welding Services Inc. \\
\hline Irving Pulp and Paper Ltd. & Research Organizations \\
\hline Louisiana Pacific & Oak Ridge National Laboratory \\
\hline MacMillan Bloedel Packaging Inc. & Institute of Paper Science and Technology \\
\hline Mead Corp. & Pulp and Paper Research Institute of Canada \\
\hline Parsons \& Whittemore Inc. & \\
\cline { 1 - 1 } Potlatch Corp. & \\
\cline { 1 - 1 } Riverwood International Corp. & \\
\cline { 1 - 1 } Smurfit-Stone Container Corp & \\
\cline { 1 - 1 } Union Camp Corp. & \\
\cline { 1 - 1 } Westvāco Corp. &
\end{tabular}

45 “EMaCC Annual Technical Progress Report FY 1995,” DOE/EE-0113, U.S. Department of Energy, Washington, D.C., (December 1996).

${ }^{46}$ The purchase of Tampella by Kvaerner Pulping, Inc., accounts for the decrease in recovery boiler manufacturer participants. 


\subsection{The Role of DOE}

Without the active participation of the AIM Program, it is extremely unlikely that the failure mechanism would have been elucidated sufficiently to achieve any substantial fraction of the potential benefits of R\&D. Identification of the failure mechanism required a level of expertise and facilities, and sustained funding during several years, that were beyond the capabilities of any single company. For example, the on-site inspections of failed tubes were performed during maintenance shutdowns when the industry staff already was busy with the maintenance work. Because each day of shutdown costs the company an average of $\$ 300,000$, the tube inspection had to be performed by national laboratory staff without causing any delay in the maintenance work. With AIM funding, failed tubes were then removed and tested at national laboratory facilities, and an extensive program of materials testing and simulation of materials performance was carried out at ORNL. Neither the paper companies nor the boiler manufacturers had the necessary facilities, expertise, or resources to perform this work.

Providing the industry with the funding and the expertise to perform the necessary R\&D is insufficient by itself. Initially, paper companies were unwilling to provide access to their production facilities, fearing such access might end up giving their competitors useful knowledge of their operating practices and production details. J. Peter Gorog, Weyerhaeuser Company, emerged as the industrial champion, breaking the industrial inertia by convincing the companies to allow access for the national laboratory personnel to collect and share data on tube failures. This led to the establishment of the necessary links to enable a robust industrial network that participated in the national laboratory/industry team. An industrial champion is a critical component to the success of a project such as this.

In addition to funding the research to identify the failure mechanism and define improved procedures and/or new materials, the AIM Program played another key role. AIM established, sustained, and managed a national laboratory/industry team that included all of the relevant paper companies and boiler manufacturers, plus tube fabricators and paper research institutes from the United States and Canada. A key component in the success of this team was the presence of a laboratory/industry team leader - James R. Keiser, ORNL, was the R\&D team leader. The R\&D team leader and the industrial champion worked together on this project to create and continue dynamic relationships. The R\&D team leader set the precedent of being able to work quickly and efficiently with companies to assure that R\&D activities would not interfere with plant operations while gathering and analyzing the requisite information to achieve the objectives of the project.

The interactions between the laboratories and the industrial partners were vital to the success of the project. These exchanges fostered the growth of knowledge about the service environment in which the tubes operate. It was only through a better knowledge of the service environment that alternate materials or processes could be defined. After new materials or processes were identified, applications engineering was required. Applications engineering is a complex process of improving new materials to meet the specific needs of the industry; retrofitting existing equipment with new materials, and demonstrating that the new materials have a more suitable suite of properties than those currently in use. This requires a substantial commitment from both researchers and industrial partners. Notice that this is an iterative process; if a project is successful, industrial partners will continue to share information with researchers concerning new challenges that plants are facing. These new challenges can become new projects for researchers. Thus, once a successful network is created, it can lead to a continuing relationship between industry and laboratories. Figure 15 illustrates this process. The success of the materials for recovery boiler floor tubes led the industry/laboratory research team to continue their collaboration to explore the cracking of primary air ports in recovery boilers.

The national resource created by the industry/laboratory collaboration has continued to address challenges faced by the pulp and paper industry. It was through this collaboration that the industry achieved a consensus, allowing access to their facilities, which provided the necessary data to solve the 
problem. In addition, without the presence of the tube fabricators on the team, there would have been no vehicle for providing new composite tubes with improved properties. The AIM Program's role in coordination and liaison between these disparate industries - and in providing the expertise and facilities of the national laboratory - was a critical factor in achieving the success and benefits.

\section{Figure 15: AIM/IMF Research Process}

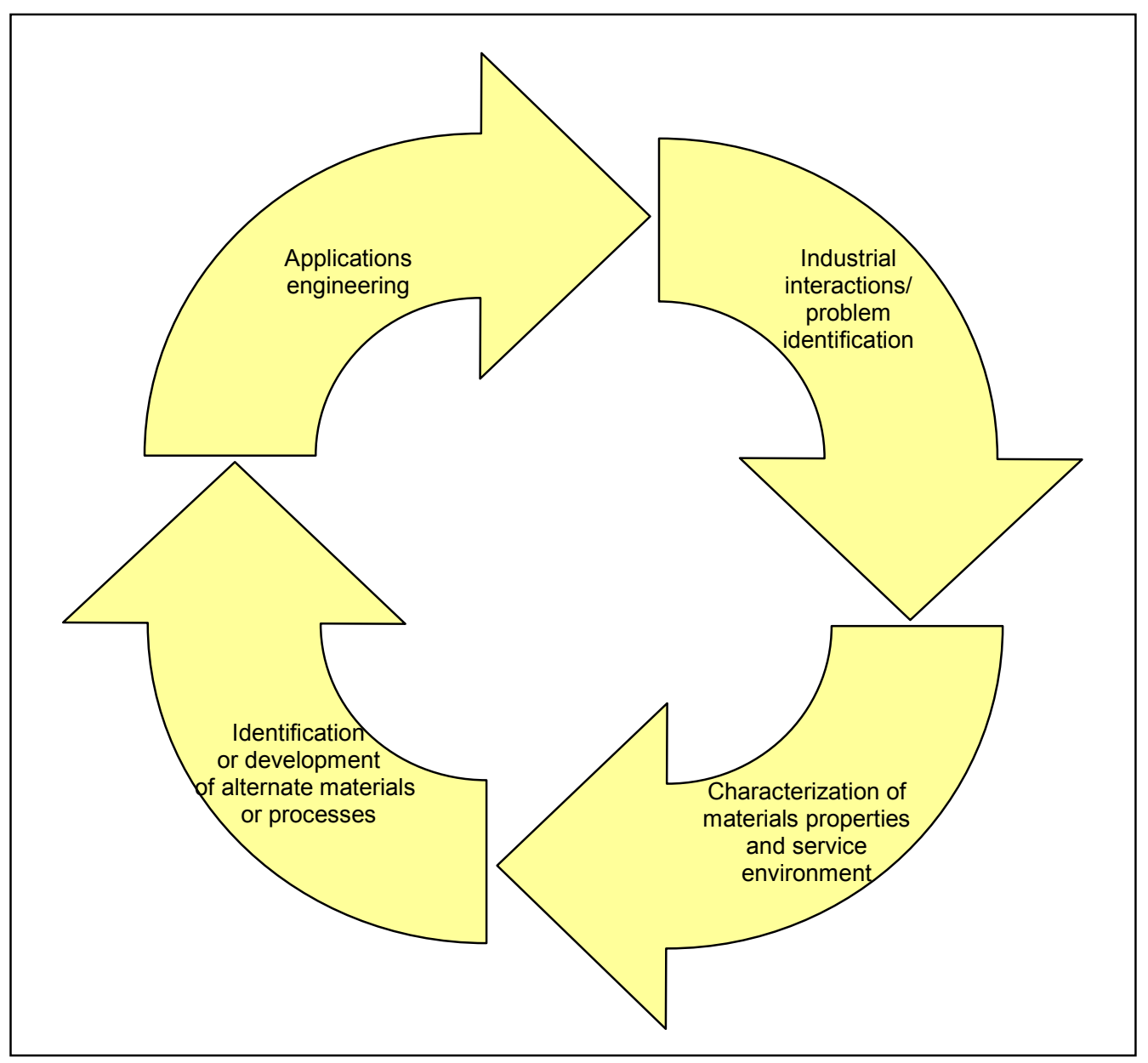

\subsection{AIM/IMF-Funded R\&D Activities and Results}

\subsubsection{Overview of R\&D Activities}

Six tasks were performed to identify the composite tube failure mechanism and identify the desired suite of materials properties to reduce or eliminate failures: ${ }^{47}$

1) Examine the microscopic characteristics of cracked tubes

2) Measure the forces (stresses) on the surface of the tube

3) Model the forces (stresses) on the surface of the tube

4) Define the characteristics of the service environment (e.g. temperature, chemicals present, etc.)

5) Identify the cause of the cracking

6) Identify more ideal processes, materials, or materials properties

\footnotetext{
${ }^{47}$ Keiser, J.R. et al. "Causes and Solutions for Cracking of Coextruded and Weld Overlay Floor Tubes in Black Liquor Recovery Boilers,” (1998), op cit.
} 
Industrial partners facilitated completion of Tasks 1 and 2 by providing researchers with a large number of samples of cracked composite tubes with varying intervals of exposure and Task 4 by providing access to processing plants. The interaction between researchers and industry was pivotal in this case; because, prior to this project, very few cracked composite tubes were examined. Instead, the cracked tubes were either allowed to operate after cracking had occurred or were repaired without being removed from the boiler floor. The result was a substantial data gap that the researchers had to fill. ${ }^{48}$

The general results of these tasks are discussed here; for a detailed treatment of the findings, see Appendix A.

\subsubsection{Task 1: Examination of Microscopic Characteristics of Cracked Tubes}

Microscopic photographs (up to $25,000 \mathrm{X}$ ) of cracks in 304L stainless steel composite tubes were used to define some general characteristics of the cracking. These general characteristics suggested that the cracking might be caused by stress corrosion.

Stress-corrosion cracking can occur if the following two conditions are met within the appropriate temperature range: (1) a force (stress) is pulling the molecular structure of the material apart and (2) a liquid corrosive substance is present. The stress described in the first condition is called a tensile stress. The presence of a tensile stress alone will not be severe enough to cause a crack. For a crack to occur, a liquid corrosive substance must be present while the material is experiencing a tensile stress in the critical temperature range.

An analogous situation to boiler floor tube cracking is stretching out a rubber band between your hands. The rubber band may not break despite the force (from your hands) pulling it apart. However, while the rubber band is in this state, it may be more vulnerable to breaking by other means. Take the case where we stretch a rubber band and cut a small piece of the rubber away (but not all the way through). This may or may not cause the rubber band to break, but we intuitively know that the rubber band is more likely to break than if we had cut the same small piece of the rubber away when it was not stretched out. In fact, in the latter case, when the rubber band is in a relaxed state, cutting away a piece of the rubber will not break the rubber band unless the cut covers the entire width of the rubber band. Applying this analogy to boiler tubes: The stretching of the rubber band is analogous to the stress present at the surface of the tubes, and the cutting away a piece of the rubber is analogous to the presence of a corrosive material. Notice that in both cases, two conditions must be met simultaneously for a failure to result.

As we will see below, the system becomes even more complex when we consider the effect that the strength of the rubber band or the material making up the outer layer of the tube has on the failure mechanism.

\subsubsection{Task 2: Measurement of the Forces (Stresses) on the Surface of the Tube}

The forces (stresses) were measured at the surface of the tube before and after service in the recovery boiler. Before entering service, none of the materials tested had the necessary tensile stresses present on the surface of the tubes for stress-corrosion cracking to occur. After exposure to the service environment, tubes manufactured with a 304L stainless-steel outer layer exhibit the necessary stresses on the surface for stress-corrosion cracking to occur after exposure to the service environment. Tubes manufactured with Incoloy 825 and Inconel 625 (two alternate materials for the outer layer of the composite tubes) did not have the necessary stress state on the surface of the tubes for stress-corrosion cracking to occur. Therefore, tubes manufactured with 304L stainless steel were more likely to experience stress-corrosion cracking after tube surfaces have been exposed to typical boiler operations (i.e. in the absence of a thermal spike, the effects of which will be discussed in the following two sections).

48 “FY 1995 - AIM Annual Progress Report,” (April 1996), Oak Ridge National Laboratory, ORNL/TM-13225. 
4.5.4 Task 3: Modeling of the Forces (Stresses) on the Surface of the Tube

Mathematical modeling (referred to as finite element modeling) was used to predict the stresses on the tubes during service, attempting to discover when the stresses on the surface of the tubes manufactured with 304L stainless steel might become tensile. The results suggested that when the boiler is cooling during a shutdown for maintenance, the stresses on the surface of the 304L stainless steel composite tubes become tensile. This happens for a combination of two elements: (1) the carbon steel layer and the 304L stainless steel layer of the tube expand and contract at different rates when heated or cooled respectively; (2) the strength of the 304L stainless steel is relatively low when compared to the stresses present at the surface of the tube. These two elements are discussed in further detail below.

1) When the boiler is heated to operating temperatures, the two materials constantly adhere to each other; however, the outer layer will try to expand at a higher rate than the inner layer. The outer layer's faster expansion is hindered by the slower expansion of the carbon steel. This creates an effective force (stress) tending to confine the outer material in a smaller volume. This is the opposite of a tensile stress; this type of stress is called compressive (because of its inward direction).

2) The second element is that the strength (or yield strength) of the $304 \mathrm{~L}$ stainless steel is not large enough to withstand the stresses formed because of the different expansion rates between the outer layer and the inner layer of the tube. When these stresses go beyond a particular threshold (the yield strength), the material shifts to relieve the forces (stresses) acting on it. This is known as plastic deformation. When plastic deformation occurs, there are only small inward forces acting on the surface of the tube. However, after plastic deformation has occurred, when the boiler is cooled for shutdown, the outer layer will try to contract more quickly than the inner layer. Now the slower contraction of the inner layer of carbon steel is hindering the faster contraction of the outer layer of $304 \mathrm{~L}$ stainless steel.

The upper portion of Figure 16 shows a representative sketch of the thermal expansion of the inner and outer layers. The lower portion of Figure 16 is a profile of a localized area of the tube during the different stages of operation, showing the inner- and outer-layer expansion and contraction, as well as the associated stresses on the tube surface. This figure displays only one of the possible directions in which material expansion and the associated stresses can occur, i.e. axial. Note that the distorted surfaces of the composite tube are exaggerated graphical representations, for ease of viewing, of the plastic deformation that has occurred; the actual surfaces would not be visibly deformed.

The difference in rates of thermal expansion and contraction between the outer and inner layers of $304 \mathrm{~L}$ composite tubes - and the relatively low yield strength of the 304L stainless steel - result in an effective outward (tensile) stress on the surface of the tube. This stress state promotes stress-corrosion cracking. 
Figure 16: Schematic of Stress-Corrosion Cracking on Composite Floor Tubes in Recovery Boilers

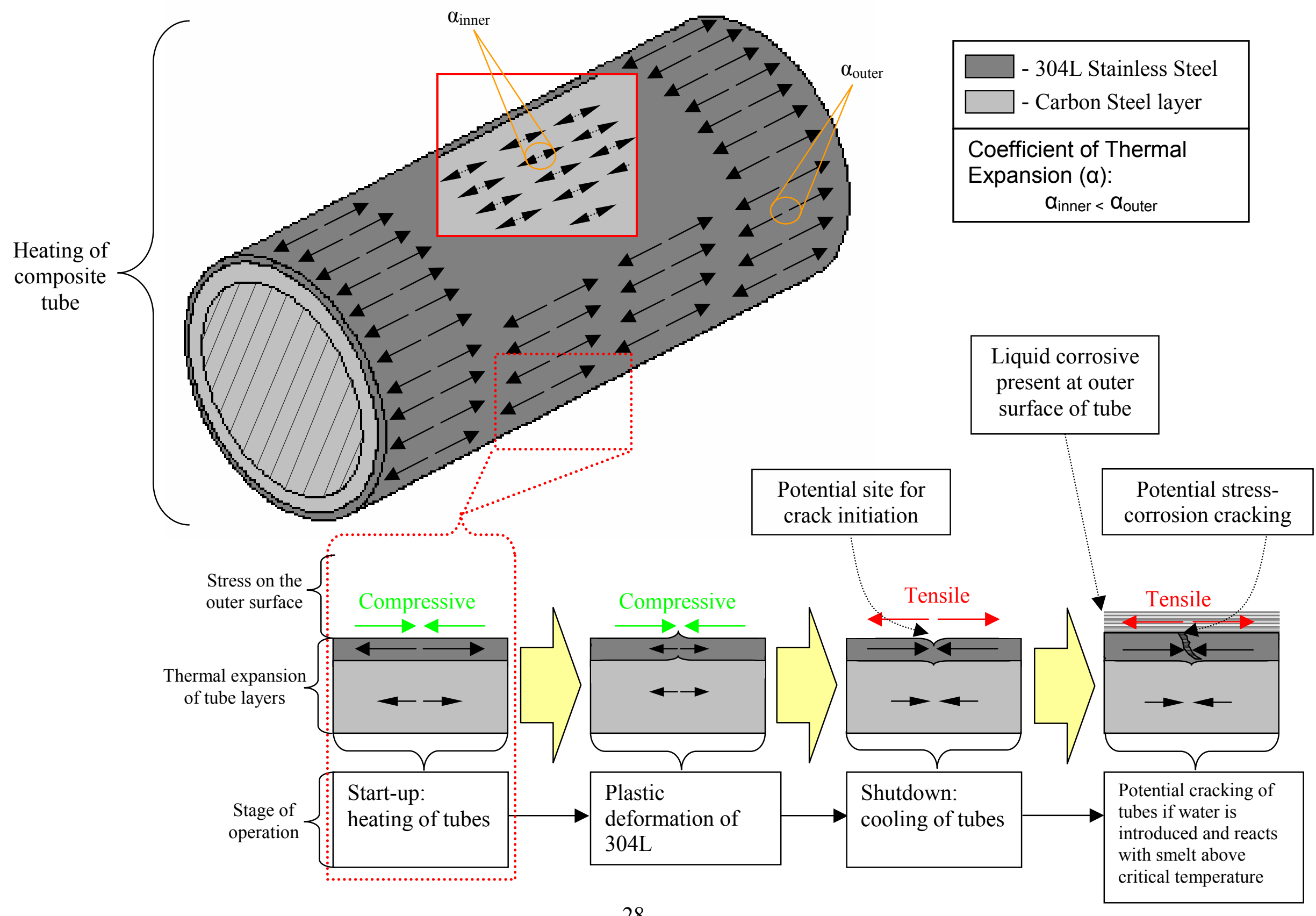


It is important to remember that, under normal operating conditions, tensile stresses are only formed on the 304L stainless steel and not on Incoloy 825 or Inconel 625 . Both the Incoloy 825 or Inconel 625 have a higher yield strength than the 304L stainless steel and a rate of thermal expansion closer to that of the inner layer of carbon steel. However, at least one condition is known to change the stresses present at the surface of the Incoloy 825 or Inconel 625 to tensile. This condition is the occurrence of a thermal fluctuation. A thermal fluctuation may be caused when a fracture occurs in the solid layer of smelt at the boiler floor. This can allow molten smelt to flow down nearer to the boiler floor tubes, creating a rapid increase and decrease in the temperature of the tube. If the temperature fluctuation is large enough, it can cause both Incoloy 825 and Inconel 625 to plastically deform by the same mechanism described above as in the case of the 304L stainless steel under normal operating conditions. If the thermal fluctuation is large enough to apply stresses that exceed the yield strength, the material will plastically deform. In addition, thermal fluctuations can make the tensile stresses already present in the 304L stainless steel even more severe, leading to a higher likelihood of cracking.

It is estimated that tubes manufactured with $304 \mathrm{~L}$ stainless steel will plastically deform with a thermal fluctuation of approximately $50^{\circ} \mathrm{C}$ or greater; Incoloy 825 will plastically deform with a thermal fluctuation of approximately $100^{\circ} \mathrm{C}$ or greater; and Inconel 625 will plastically deform with a thermal fluctuation of $150^{\circ} \mathrm{C}$ or greater. The Inconel 625 requires the largest thermal fluctuation to plastically deform because it has the highest yield strength and the closest match to the rate of expansion of the carbon steel layer. Likewise, the Incoloy 825 requires the second-largest thermal fluctuation to plastically deform, because it has the second-highest yield strength and the second-best match to the rate of expansion of the carbon steel layer. Higher temperature fluctuations occur less frequently (see Table A1 in Appendix A). While no material is immune to the problem of thermal fluctuations, materials with a closer match to the thermal expansion rate of carbon steel and higher yield strengths are more resistant. Thermal fluctuations can cause tensile stresses in all materials tested if they are of sufficient magnitude and the rate of expansion is not sufficiently close enough to that of the carbon steel layer. These stresses can promote stress-corrosion cracking in the localized area of the thermal fluctuation.

4.5.5 Task 4: Determination of the Service Environment

Before the AIM/IMF-funded boiler materials project, thermal fatigue was widely believed to cause composite tube cracking. Thermal-fatigue cracking occurs when a material is subjected to frequent changes in temperature. If these cyclic temperature fluctuations occur in sufficient frequency, it can weaken the molecular structure of the material enough to cause it to crack.

Comparison of thermal-fatigue behavior of 304L stainless steel against standard design curves for thermal fatigue suggested that there were not a sufficient number of thermal fluctuations to cause thermal-fatigue cracking. While examination of tubes that had been in service revealed exposure to thermal fluctuations, an insufficient number of fluctuations were experienced to promote thermalfatigue cracking. Thermal-fatigue cracking was determined not to be the cause of recovery boiler floor tube cracking.

These results suggested that stress corrosion was the likely cause of the cracking. Stress-corrosion cracking requires that a tensile stress on the outer-surface of the tube and a liquid corrosive substance be present simultaneously in the appropriate temperature range. To determine if the second component was present in the service environment, information about the characteristics of the service environment was needed. This revealed that the necessary components for stress-corrosion cracking were not present during normal operation of the recovery boiler since a liquid corrosive was not in contact with the floor tubes. However, the environment created when the boiler is washed with water and subsequently heated to remove any moisture present is ideal for stress-corrosion cracking. This suggested two potential 
paths to solve the problem: (1) change the process such that the environment that causes cracking does not exist in the critical temperature range or (2) use new materials that are not susceptible to cracking.

\subsubsection{Tasks 5 and 6: Identification of Cracking Mechanism and Identification of More Ideal Processes and Materials}

Figure 17 illustrates the logic behind the development of the conclusions concerning tube cracking.

Figure 17: Determination of Cracking Mechanism

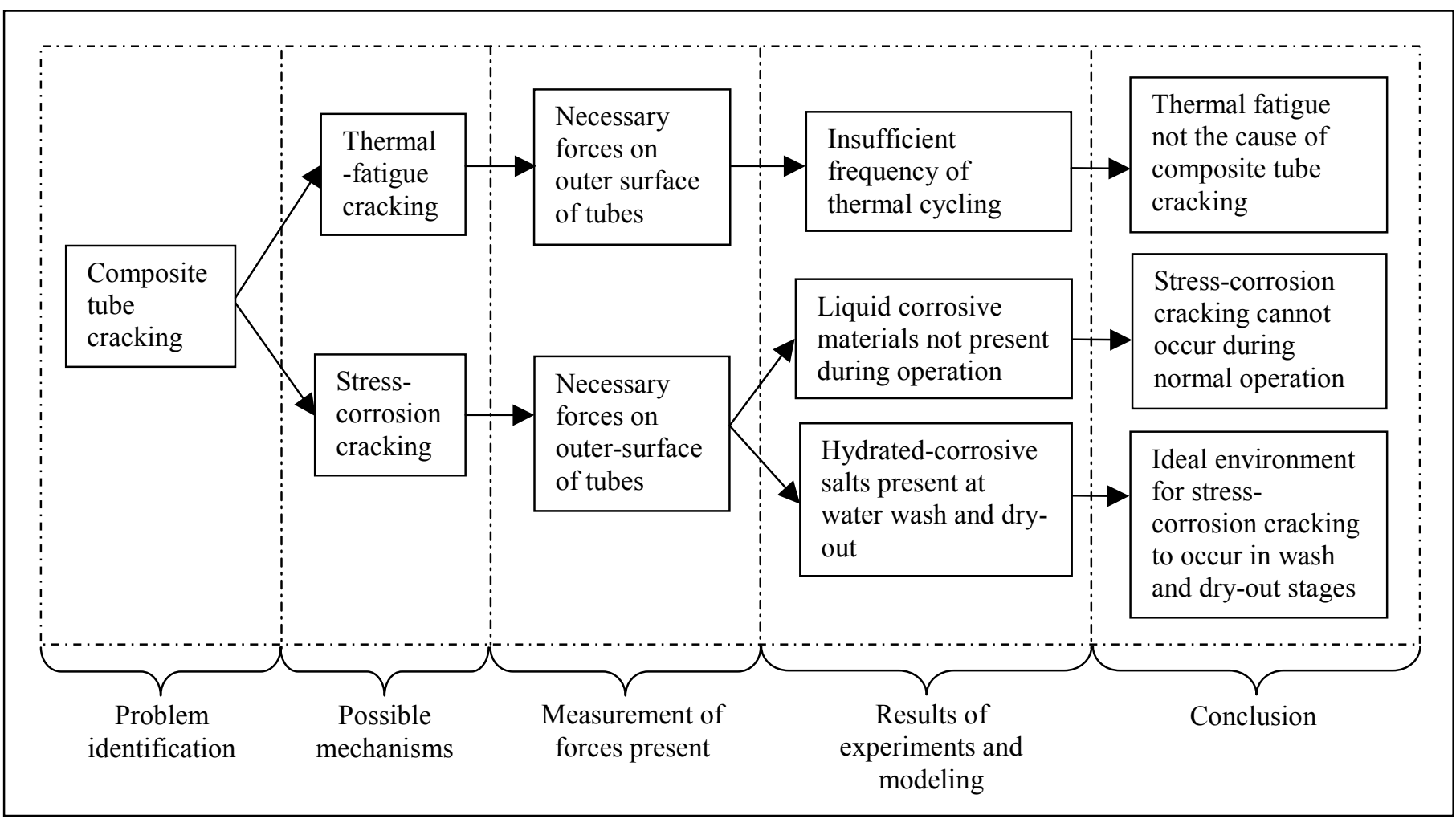

Returning to our earlier analogy of a stretched rubber band that has a small piece of rubber cut out of it, we notice that there are three physical characteristics (materials properties) that are inextricably linked together: (1) the amount that the rubber band is stretched, (2) the strength of the rubber band, and (3) the severity of the piece cut out of the rubber band. Similarly, the boiler floor tubes possess three physical characteristics that are linked together: (1) the differences in expansion and contraction rates between the inner and outer layers (coefficient of thermal expansion), (2) the yield strength, and (3) the resistance to corrosion. The first characteristic determines the magnitude of the force applied on the surface of the tube when the boiler is heated and cooled. The second characteristic determines how well the material will be able to resist the forces applied from the first characteristic (i.e. whether a tensile stress will result). The third characteristic determines how effectively a corrosive substance can attack the material. Notice that no single undesirable characteristic can cause stress-corrosion cracking. This set of intimately connected physical characteristics is referred to as a suite of materials properties. Figure $18 \mathrm{a}, \mathrm{b}$, and $\mathrm{c}$ show a schematic of the materials properties suites for the materials examined in this study.

The results of the AIM-funded R\&D suggest two potential methods to address the problem of recovery boiler floor tube cracking. The first potential solution is to change maintenance procedures so that 
moisture is not allowed to come into contact with the floor tubes above certain temperatures during water-wash and dry-out periods. The second potential solution is to change the materials used on the outer layer of the composite tubes. Using metals with a more ideal suite of materials properties greatly reduces the likelihood of floor-tube cracking. The following chapter analyzes how the industry might react to the results of this project based on the economic incentives of each potential solution.

Figure 18a: Suite of Materials Properties for 304L Stainless Steel

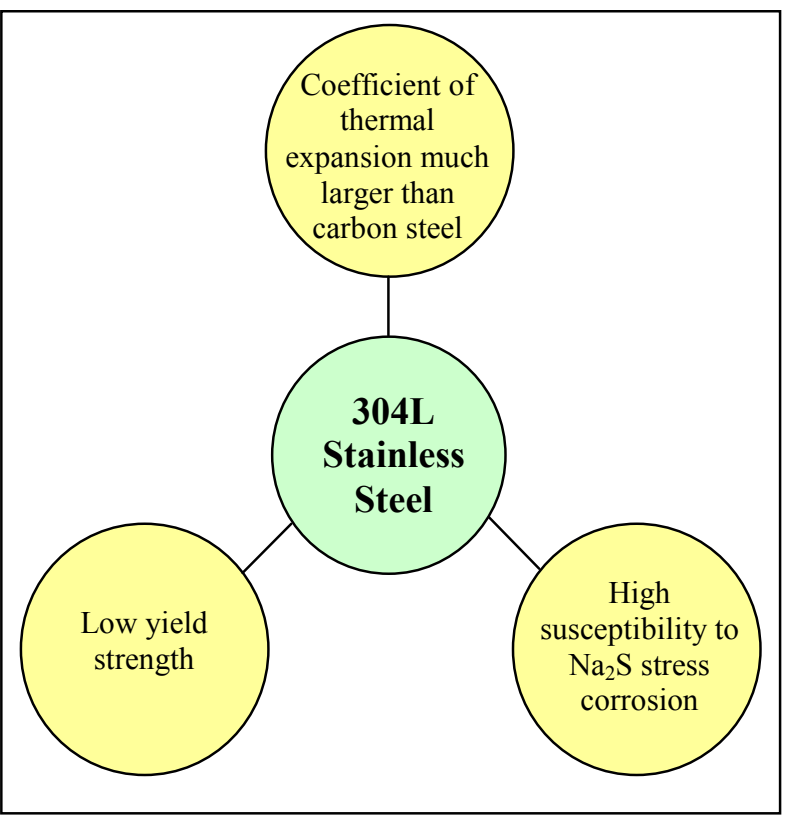

Figure 18c: Suite of Materials Properties for Inconel 625

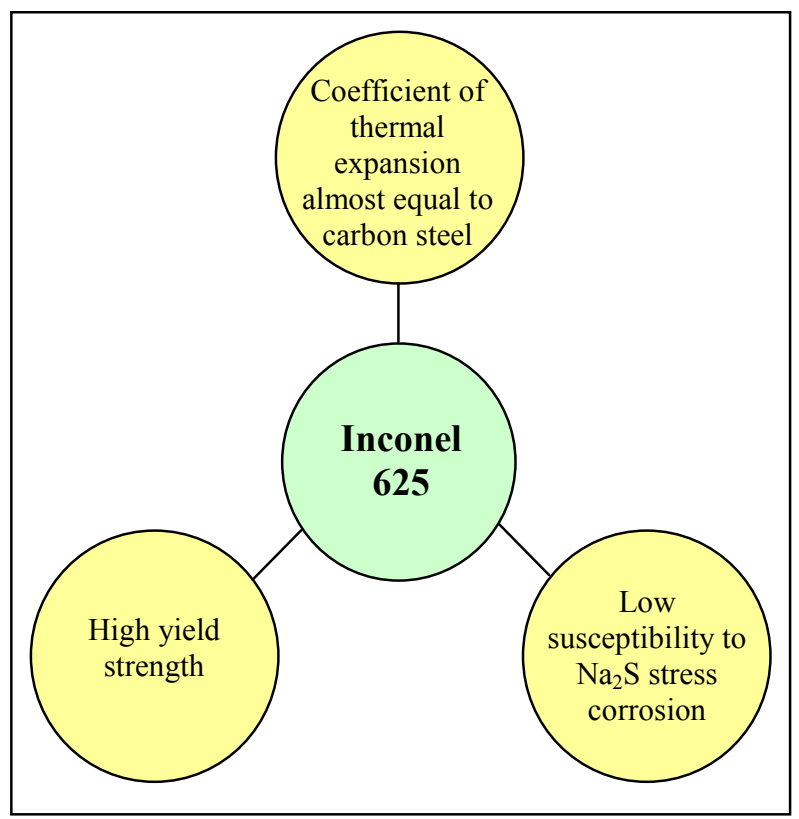

Figure 18b: Suite of Materials Properties for Incoloy 825

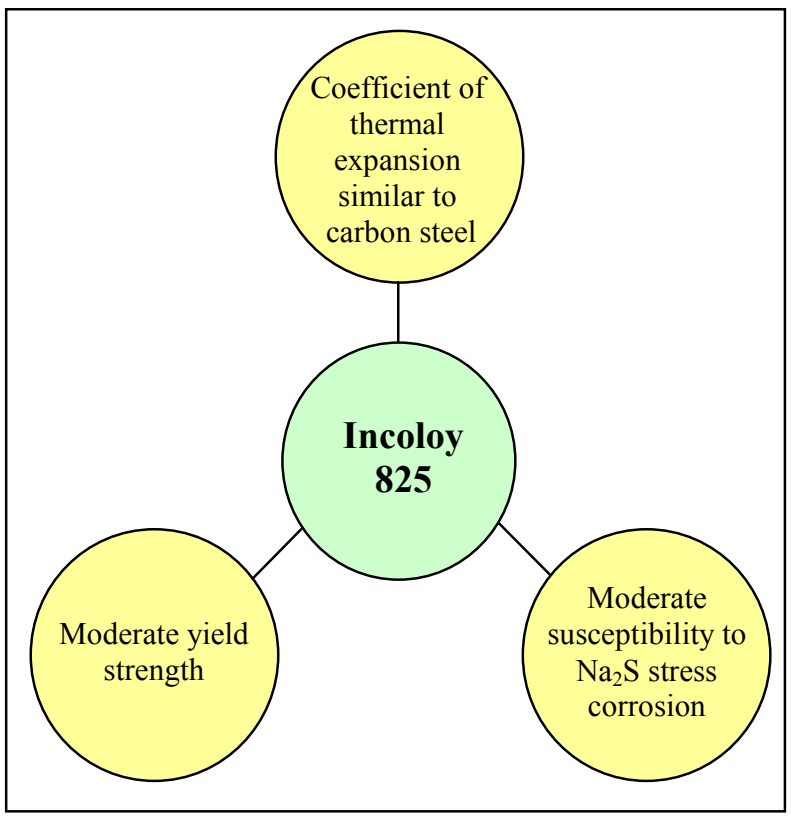




\subsection{Economic, Energy, and Environmental Impacts of the R\&D Program}

\subsection{Introduction to Estimation of Benefits}

Pulp and paper products represent one of the most capital-intensive industries. The average mill invests more than $\$ 120,000$ in materials and equipment per employee. This is more than double the average of other U.S. manufacturing industries. ${ }^{49}$ The recovery boiler is the most capital-intensive part of a pulp and paper plant. Figure 19 shows the number of recovery boilers entering service in the United States over time.

Figure 19: Number of Kraft Boilers Entering Service in the United States ${ }^{50}$

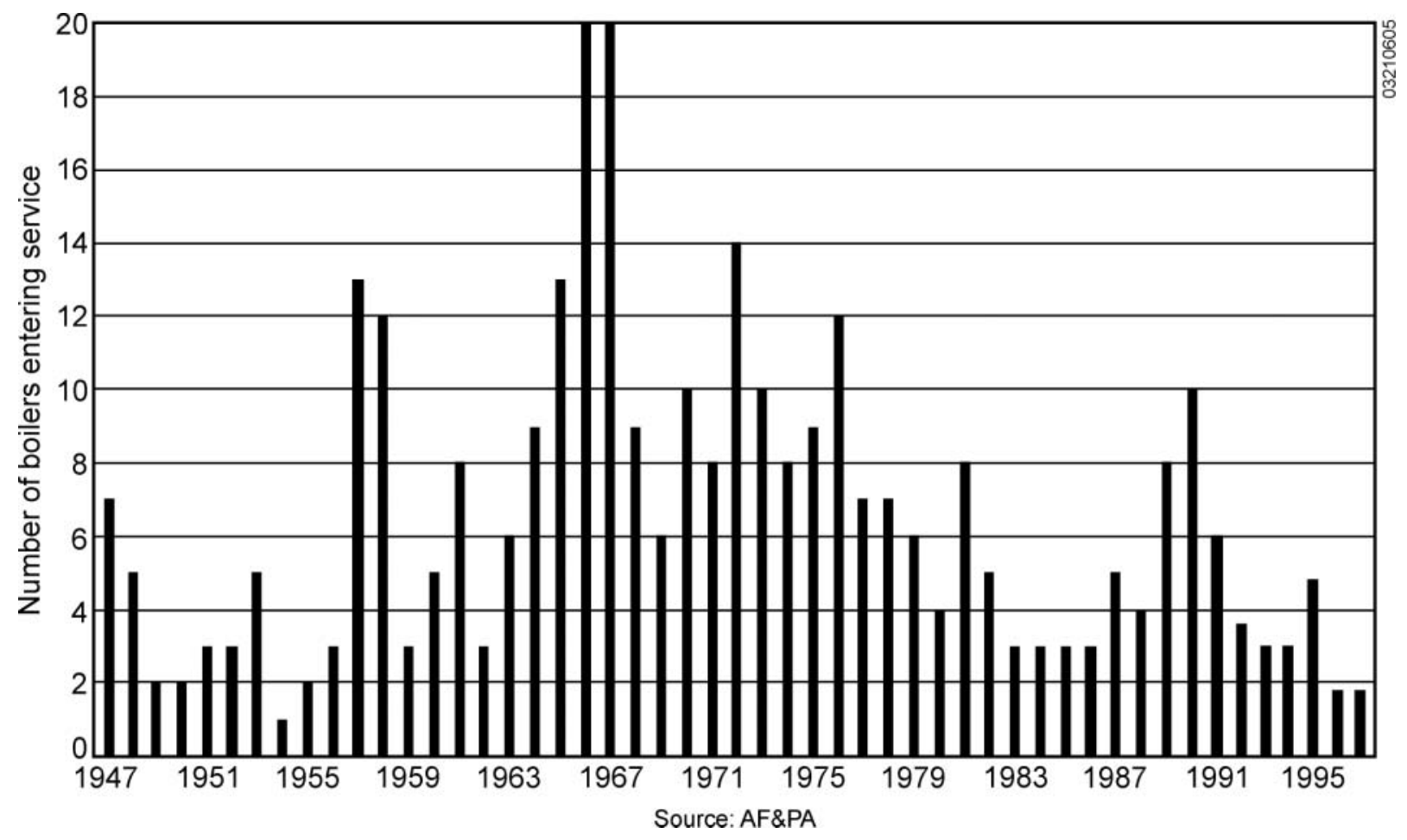

Kraft recovery boilers are responsible for generating about 40 percent of the energy used by a mill by burning lignin to produce steam for drying and electricity generation. ${ }^{51}$ Approximately 30 percent of the mills using the kraft chemical pulping process have only one recovery boiler. ${ }^{52}$ This means that when

\footnotetext{
49 “AGENDA 2020: A Technology Vision and Research Agenda for America's Forest, Wood and Paper Industry," AF\&PA (1994)

${ }^{50}$ Figure taken from The Industrial Sector ( $\left.\mathrm{p} 4.25\right)$, http://www.ornl.gov/ORNL/Energy_Eff/PDF/CON444/ch4.pdf

${ }^{51}$ Ibid.

${ }^{52}$ Estimated by NREL from data in Figure 19 combined with information from conversations with John Kulig, Design Engineer, and Keith Rivers, Manager, Service Business Development, Babcock \& Wilcox. During the $1950 \mathrm{~s}$ and $1960 \mathrm{~s}$, it was common practice in the industry to install double boilers so production could continue during maintenance of one of the boilers. Beginning in the 1970s, this practice was considered noneconomic and installation of single boilers became the norm.
} 
the recovery boiler is shut down, the entire mill production is shut down. ${ }^{53}$ This results in huge losses of production. Some estimates for cost due to lost production are as high as $\$ 1$ million per day. ${ }^{54}$

This section presents the results of analyses of the economic, energy, and environmental impacts resulting from the IMF kraft recovery boiler R\&D program.

\subsection{Industry Boiler Maintenance and Replacement Experience}

The industry provided the IMF program data on its kraft recovery boiler maintenance and replacements experience. Table 4 shows that experience. Eighty-four percent of the boilers are shut down once a year for maintenance for lengths varying from nine to 16 days. About seven percent of the boilers experience two shutdowns totaling 18 days and another seven percent experience three shutdowns totaling 27 days. About three plants a year experience shutdowns of 40 days to replace the boiler's tubes.

Table 4: Distribution of Kraft Recovery Boiler Shutdowns with Existing Technology

\begin{tabular}{|l|c|c|c|c|c|c|}
\hline Number of Shutdowns per Year & $\mathbf{1}$ & $\mathbf{1}$ & $\mathbf{1}$ & $\mathbf{2}$ & $\mathbf{3}$ & Replacement \\
\hline Number of boilers & 71 & 70 & 27 & 15 & 14 & 3 \\
\hline Percent of total boilers & 35.5 & 35.0 & 13.5 & 7.5 & 7.0 & 1.5 \\
\hline Number of days required per shutdown & 9 & 12 & 16 & 9 & 9 & 40 \\
\hline Number of shutdown days per boiler per year & 9 & 12 & 16 & 18 & 27 & 40 \\
\hline
\end{tabular}

The industry also provided the IMF program data on the cost of shutdowns and boiler tube replacement for both the existing materials and the new materials. Table 5 shows these data.

Table 5: Cost of Shutdowns and Boiler Tubes: Existing Versus New Materials

\begin{tabular}{|l|c|c|}
\hline Cost Category & Existing Materials & New Materials \\
\hline Shutdown Cost - Maintenance Only & $\$ 60,000$ & $\$ 30,000$ \\
\hline Shutdown Cost at Replacement & $\$ 200,000$ & $\$ 200,000$ \\
\hline Cost of Replacement & $\$ 700,000$ & $\$ 1,000,000$ \\
\hline Average Per Day Value of Lost Production & $\$ 300,000$ & $\$ 300,000$ \\
\hline
\end{tabular}

The use of the new materials reduces maintenance costs during shutdowns by 50 percent (from $\$ 60,000$ to $\$ 30,000)$. However, when boiler tubes are replaced with tubes made of the new materials, it will cost a mill $\$ 300,000$ more than replacing with tubes made of the existing materials. Approximately one-third of the plants operate with a single boiler. When the boiler is shut down, production stops - and it is estimated that $\$ 300,000$ in revenue is lost each day of the shutdown. For plants with more one than one boiler, production is similarly affected because most plants today are operating at or near full capacity. ${ }^{55}$

\subsection{The Economics from the Industry Viewpoint}

The analysis begins by separately examining from the individual plant's point of view (a) the impact of adopting better maintenance practices and (b) the impact of replacing boiler tubes with tubes made of the new materials. This provides insights on how the industry might respond in adopting the better maintenance practice and the new materials technology.

\footnotetext{
53 "Materials Needs and Opportunities in the Pulp and Paper Industry," Advanced Industrial Materials (AIM) Program, (August 1995), op cit.

${ }^{54}$ How ORNL Helps the Paper Industry: http://www.ornl.gov/ORNLReview/rev28-4/text/paper.htm

${ }^{55}$ Conversation with Keith Rivers, Babcock \& Wilcox.
} 


\subsubsection{The Economics of Better Maintenance Practice}

The research of the IMF kraft recovery boiler program demonstrated that significant reductions if not outright elimination - in stress-corrosion cracking of the boiler tubes will result from simply waiting for the boiler tubes to cool sufficiently before cleaning. Adopting this practice will reduce the average number of days a boiler is shut down, thereby reducing average shutdown costs and increasing production. The effect of the additional production increases energy use (and cost) slightly for plants with one boiler. Because there is minimal added cost of implementing the better maintenance practice, and the value of the cost savings and added production far outweigh the cost of the additional energy use, adoption of the better maintenance practice provides an immediate payback.

It was assumed that as a result of better maintenance, boilers on average will move into the next best maintenance category (e.g., in Table 4, a boiler that was likely to experience three shutdowns in a given year would instead experience two shutdowns). ${ }^{56}$ Given this assumption, the average benefit per plant for adopting better maintenance practice provides an immediate payback and a net present value (NPV) worth $\$ 6.5$ million. ${ }^{57}$ For the industry as a whole, it is conservatively assumed that adoption of the better maintenance practice will penetrate one-half of the industry within 10 years. ${ }^{58}$

\subsubsection{The Economics of New Materials Upon Normal Replacement}

The IMF kraft recovery boiler R\&D program estimated that replacing boiler tubes with tubes made of the new material would allow for a 1 percent increase in boiler design efficiency. In addition, the materials properties would allow for use of higher concentrations of black liquor, which could result in a maximum increase in boiler efficiency of 3 percent.

Even more important economically, pulp and paper mills will experience fewer days of shutdown (averaging seven shutdown days per year compared to an industry average of 13 days). The materials cost of a shutdown remains the same regardless of tube material; however, tubes made of the new materials cost $\$ 300,000$ more to purchase and install. Given these facts, it was estimated to be in the economic interest of all mills to install boiler tubes made of the new materials when they face a normal boiler-tube replacement decision. The greater efficiency of the boiler saves more energy than the added production uses more energy, resulting in a net energy (and cost) savings. For the plants, the NPV of the replacement with tubes made of the new material is estimated to range between \$18 million to \$21 million. On average, replacing boiler tubes with tubes made of the new materials pays back the added capital cost for the boiler, in either case, in one year. For the industry as a whole, it is assumed that adoption of tubes made with the new materials will penetrate one-half of the industry during the normal replacement cycle.

\subsubsection{The Economics of Early Replacement}

Because it is so profitable to invest in the new boiler-tube materials when a boiler-tube replacement is required, an analysis was conducted to determine if it made sense to replace the tubes before normal replacement. Doing so will accelerate the savings from lower energy and shutdown costs, but will also accelerate the capital investment, which is now counted as the full \$1 million in the analysis instead of

\footnotetext{
${ }^{56}$ This is a very conservative assumption, because it is thought that adoption of the better maintenance practice might move all boilers to at least the one-shutdown, 12-day category.

${ }^{57}$ All NPVs were calculated using 1995 dollars, a 20-year typical boiler-tube life, and a 5 percent discount rate.

${ }^{58}$ Throughout the analysis, assumptions follow the methodology used by the U.S. DOE in estimating R\&D program benefits under the Government Performance and Results Act (GPRA). For this program, it was assumed that for technical and other reasons, the maximum feasible adoption of the new technology would be 60 percent, and that 90 percent of this potential would ultimately be achieved (the net effect being about a 50 percent overall adoption).
} 
the difference between the cost of the new materials versus the cost of the existing materials $(\$ 300,000) .{ }^{59}$

An analysis was conducted for the typical boiler, assuming typical maintenance and replacement experience. Under these assumptions, the payback ranges from 3.3 to 4.7 years, and the NPV ranges from $\$ 7.8$ to $\$ 10.7$ million. The U.S. DOE assumes the adoption of discretionary improvements in process technologies having paybacks between three-five years will take 40 years. The implication of this assumption is explored below in the economic analysis performed for the IMF kraft recovery boiler $\mathrm{R} \& \mathrm{D}$ program.

\subsection{The Benefits of the IMF Kraft Recovery Boiler Materials Research Program}

To estimate the overall benefit of the IMF kraft recovery boiler R\&D program an assumption had to be made about what would have happened in the absence of the program. Without the program, the industry would have been faced with organizing itself to identify and contract out the R\&D, as well as undertake the full time and cost of information outreach. This would have cost the industry almost $\$ 4.7$ million just to duplicate the public investment in the IMF kraft recovery boiler program. It might well have been the case that the industry would not have been able to accomplish this, but we assume here that it could and that it would have delayed discovery and adoption of the IMF program results by 15 years.

The analysis of the IMF program's impact uses the following information and key assumptions:

- IMF funded the research during 1995-1999;

- IMF research results are disseminated during the years 2000-2001;

- Starting in 2002, one-half of the plants begin to adopt better maintenance practices, taking five years to do so;

- Starting in 2002, one-half of the plants begin replacing their boiler tubes with the materials. Replacement averages 5 percent per year (corresponding to 20 years for full penetration);

- Of the plants adopting the new technology, one-half only take advantage of the reduction in shutdown days; the other half take advantage of the potential to increase boiler efficiency, averaging a 0.75 percent gain in efficiency;

- Future cash streams are discounted at a 5 percent societal discount rate to 1995 (or 1995 dollars)

- In the absence of the program, the industry would have achieved the same research results and benefits - but 15 years later.

Given the above data and assumptions, the IMF kraft recovery boiler research program (all monetary amounts in 1995 dollars for the period 1995-2030):

- Saves a cumulative net 42 trillion Btu through 2020 and 66 trillion through 2030.

- Saves industry $\$ 67$ million in industry energy costs for an investment of $\$ 4.5$ million.

- Results in $\$ 6.6$ million in saved industry maintenance costs and increases production valued at $\$ 1.3$ billion.

- Saves a net total of $\$ 1,356$ million. $^{60}$

\footnotetext{
${ }^{59}$ Of course, there is a capital cost savings of an equal amount in the year replacement would otherwise have occurred.

${ }^{60}$ Values calculated show the $\$ 1,355.9$ million equals benefits of $\$ 67.2$ million in energy cost savings, $\$ 6.6$ million in shutdown cost savings, $\$ 1,299.7$ million in additional product value less $\$ 4.5$ million in DOE R\&D, and $\$ 13.1$ million in industry R\&D and investment in better tube materials.
} 
Figures 20 and 21 show the annual and cumulative energy savings, and Figures 22 and 23 the annual and cumulative economic benefits ${ }^{61}$ of the IMF kraft recovery boiler R\&D program through 2030. In Figure 21, the quick increase in energy savings is the result of the quick adoption of the better maintenance practice, reaching a cumulative 10.6 trillion Btu in 2010. Then as the slow but steady adoption of the new boiler tube materials technology takes hold, energy savings accumulate, reaching cumulative totals of 42.3 trillion Btu in 2020 and 66.2 trillion Btu by 2030. Figure 23 shows that the cumulative economic benefits of the IMF kraft recovery boiler R\&D program are negative from 1995 to 1999 as the IMF program funds the research. Cumulative benefits remain negative through 2002 as the results of the R\&D research are disseminated and industry begins investing in the better materials technology. Then, in 2003, the overall costs savings of the better maintenance practice and boiler tube replacement take hold and the cumulative benefits accelerate rapidly, cumulating to almost $\$ 1,373$ million by 2030. Again, these are the cumulative benefits in 1995 dollars, assuming the IMF program accelerates R\&D by 15 years.

${ }^{61}$ Economic benefits include added revenue from increased production, reductions in maintenance and repair, and net changes in energy costs (efficiency gains less added energy use from higher production). Increases in costs associated with materials were considered minimal and ignored. It was also assumed there were no labor savings (other than already accounted for in the reductions in O\&M costs). 
Figure 20: Annual Energy Savings of IMF Kraft Recovery Boiler R\&D Program

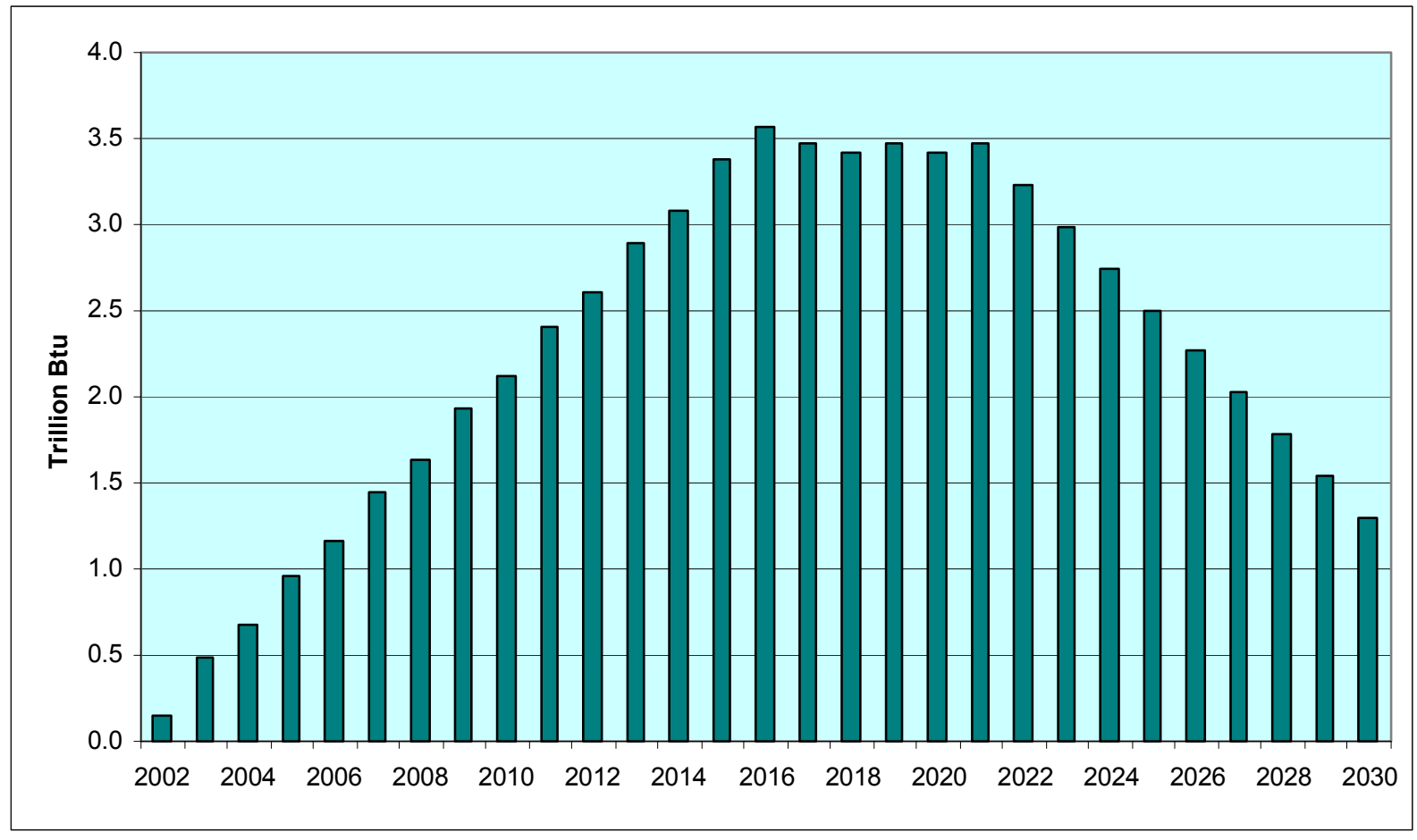

Figure 21: Cumulative Energy Savings of IMF Kraft Recovery Boiler R\&D Program

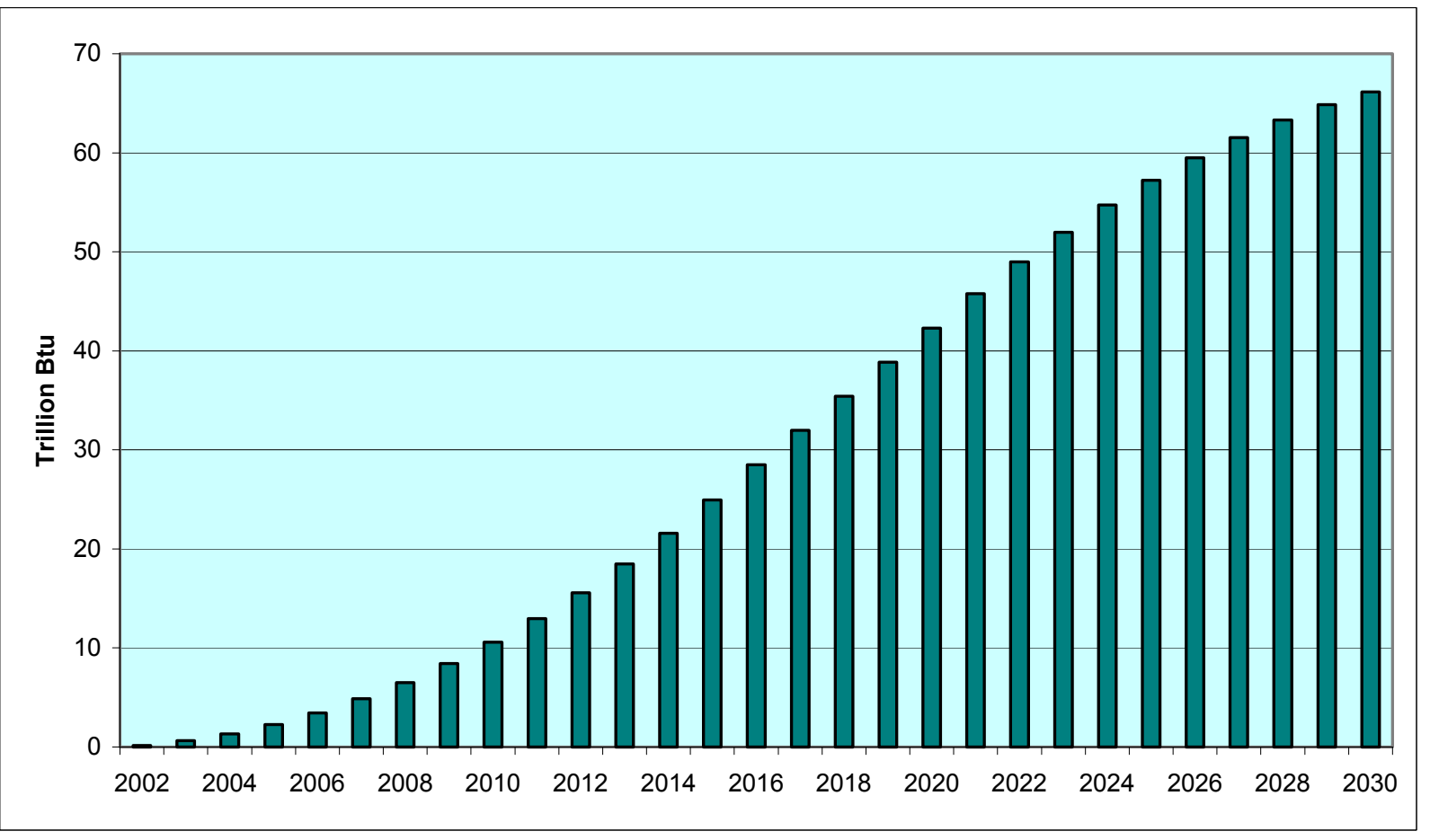


Figure 22: Annual Economic Benefits of the IMF Kraft Recovery Boiler R\&D Program

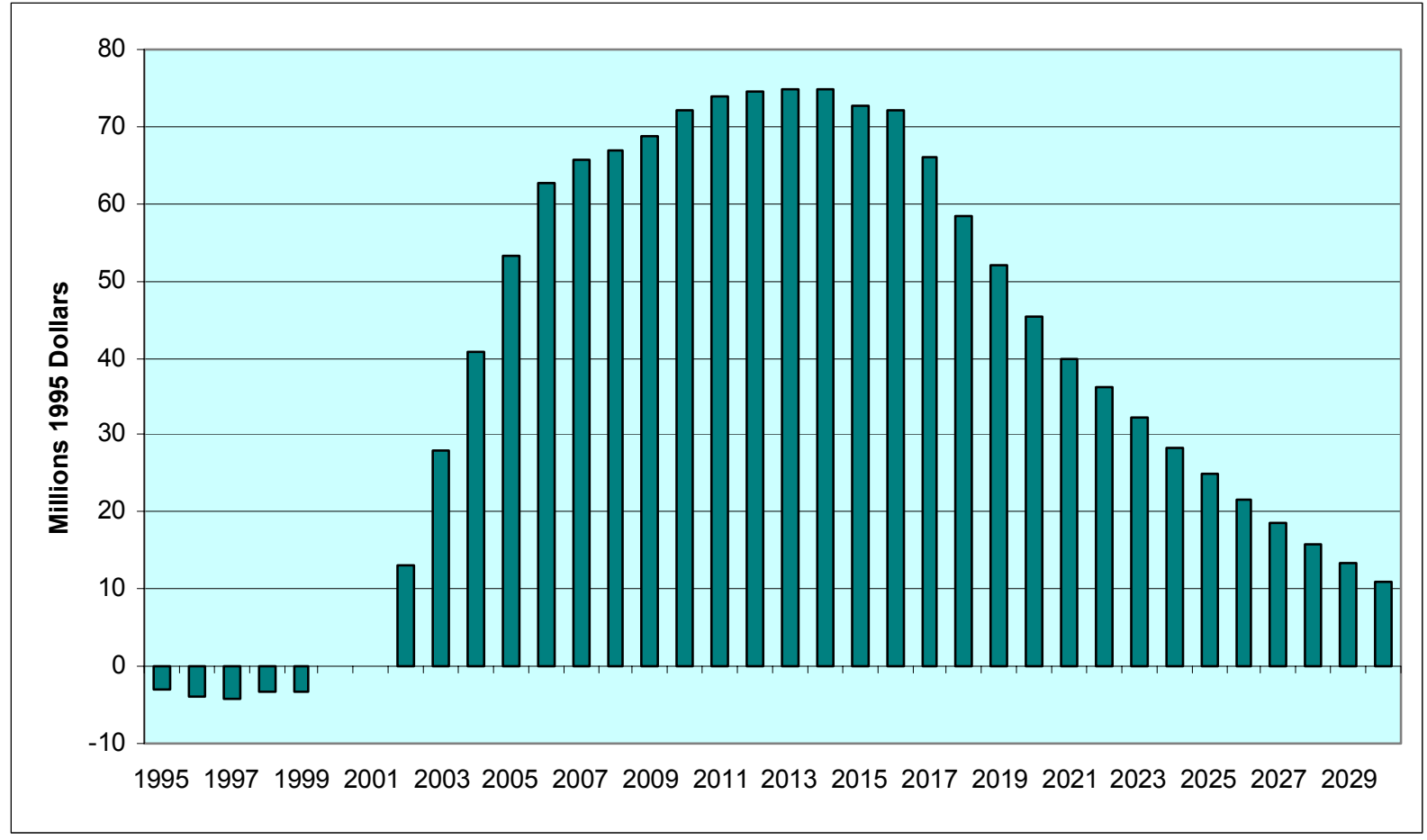

Figure 23: Cumulative Economic Benefits of the IMF Kraft Recovery Boiler R\&D Program

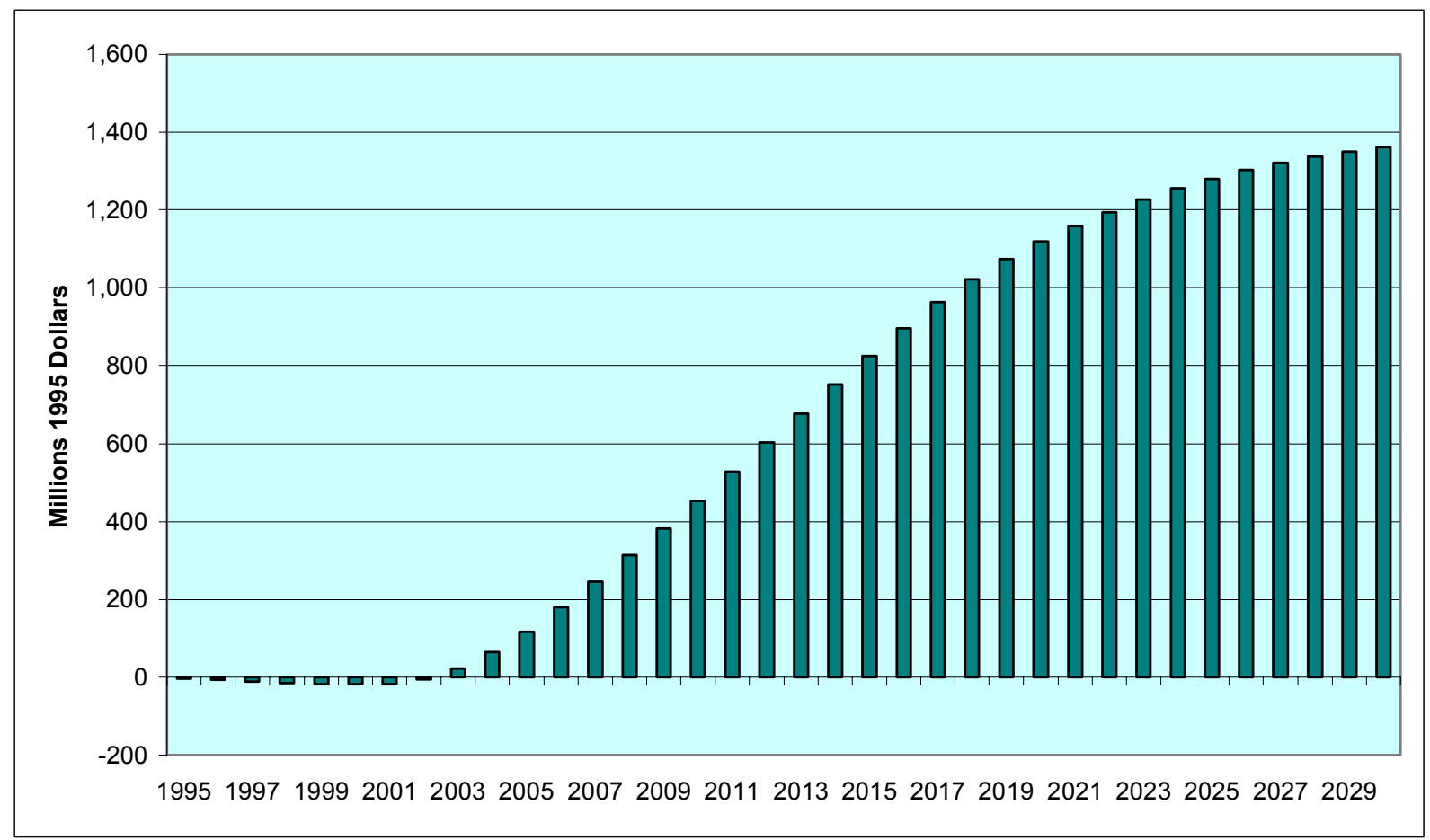




\subsection{Unit Efficiency and Cost Impacts of the IMF Kraft Recovery Boiler R\&D Program}

Better maintenance decreases days of shutdown. Replacing boiler tubes can increase overall recovery boiler efficiency by up to 3 percent as well as decrease the days and costs of shutdown. We estimate an average reduction in energy use per pound (for those plants taking advantage of the efficiency improvement opportunities) of $190 \mathrm{Btu}$, from 12,685 Btu to 12,495 Btu (a 1.5 percent improvement). For these plants, energy cost per ton also decreases by an average of $\$ 1.03$, from $\$ 68.47$ a ton to $\$ 67.44$ a ton.

\subsection{Environmental Benefits of the IMF Kraft Recovery Boiler R\&D Program}

The environmental benefits for the IMF kraft recovery boiler R\&D program are directly related to the net energy savings year-by-year. Table 6 shows the impacts on criteria air pollutants and greenhouse gases for selected years following the R\&D program. Again, these impacts assume the effect of the IMF program is to accelerate the recovery boiler materials research (and impacts) by 15 years. Similar to the energy impacts, emissions of air pollutants and greenhouse gases grow quickly until 2010 and then more gradually through 2030 (and beyond). By 2030, cumulative reductions of 8,700 tons of nitrogen oxides; 17,200 tons of sulfur dioxide; 1,400 tons of particulates (PM-10); and 843,000 tons (carbon equivalent) are obtained.

Table 6: Cumulative Air-Pollutant Impacts of the IMF Kraft Recovery Boiler R\&D Program

\begin{tabular}{|c|c|c|c|c|}
\hline Year & $\begin{array}{c}\text { Nitrogen Oxides } \\
(\mathbf{1 , 0 0 0} \text { Tons })\end{array}$ & $\begin{array}{c}\text { Sulfur Dioxide } \\
(\mathbf{1 , 0 0 0} \text { Tons })\end{array}$ & $\begin{array}{c}\text { Particulates } \\
\text { (PM-10) } \\
(\mathbf{1 , 0 0 0} \text { Tons) }\end{array}$ & $\begin{array}{c}\text { Carbon Dioxide } \\
\text { (1,000 Tons CE) }\end{array}$ \\
\hline 2010 & 1.4 & 2.7 & 0.2 & 135 \\
\hline 2020 & 5.5 & 11.0 & 0.9 & 539 \\
\hline 2030 & 8.7 & 17.2 & 1.4 & 843 \\
\hline
\end{tabular}




\section{Appendix A: Detailed Description of R\&D Activities}

Six tasks were performed to determine the cause of cracking in the composite boiler floor tubes and to define a suite of desired materials properties. As previously stated in Section 4.5, the six tasks were as follows:

1) Examine the microstructural characteristics of cracked tubes

2) Measure the material stress states

3) Model the material stress states

4) Define the characteristics of the service environment

5) Conduct laboratory studies to identify the cracking mechanism

6) Identify more ideal processes or materials properties

\section{A.1 Microstructural Characterization}

Microstructural characterization began in 1995, using photographic techniques to examine unexposed tubes made of different materials and comparing the results to those on cracked tubes. ${ }^{62}$ In 1996 and 1997, transmission electron microscopy was used to collect data on exposed tubes at very high magnifications (up to $25,000 \mathrm{X}$ ). ${ }^{63}$ Dye-penetrant methods were used to visualize the cracks.

Exposed tubes revealed two primary types of cracking. The first is circumferential cracking, in which cracks form near the outer surface and extend toward the interface between the inner and outer tubes as the crack becomes narrower. As the crack approaches the interface, it becomes parallel to the interface. The tubes exhibited a second type of cracking - crazed cracking - which shows no preferential direction of propagation, leading to wider cracks with the presence of substantial amounts of corrosive materials. Crazed cracks also become parallel to the interface as they approach the carbon steel layer. Which type of cracking will occur depends on the direction of the stress on the surface of the tube. Circumferential cracking was more common in the tubes examined in this study. ${ }^{64}$ Photographs of both types of cracking are shown in Figure A1 ${ }^{65}$ Figure A2a ${ }^{66}$ shows a representative sketch of stresscorrosion cracking and Figure $\mathrm{A} 2 \mathrm{~b}^{67}$ shows a microscopic photograph of a floor-tube crack.

Figure A1a: Circumferential Cracking

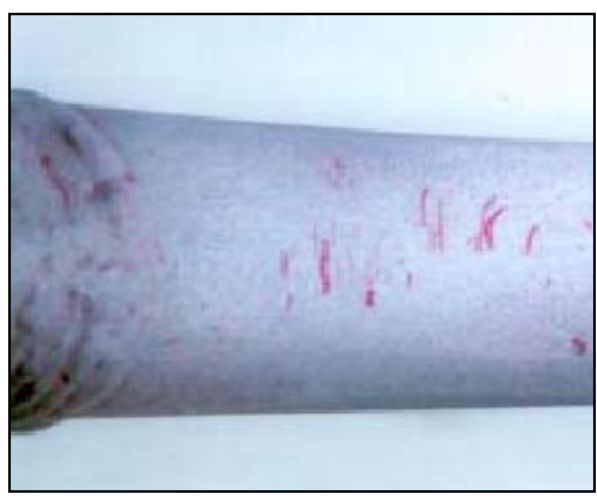

Figure A1b: Crazed Cracking

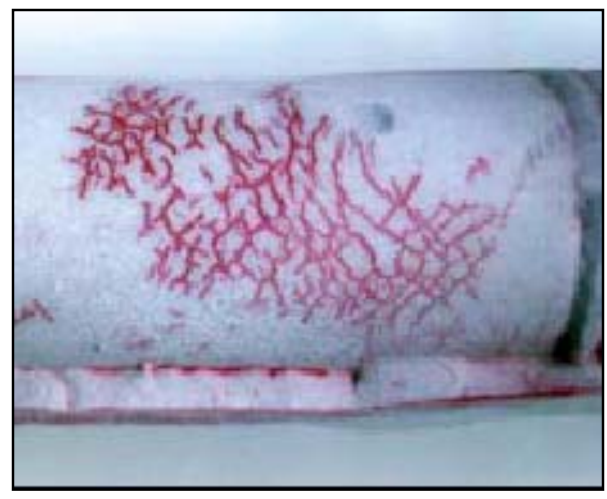

\footnotetext{
${ }^{62}$ Keiser, J.R. et al. "Causes and Solutions for Cracking of Coextruded and Weld Overlay Floor Tubes in Black Liquor Recovery Boilers,” (1998), op cit.

63 "FY 1996 - AIM Annual Progress Report," (April 1997), Oak Ridge National Laboratory, ORNL/TM-13399. Available from the National Technical Information Service, Springfield, VA, http://www.ntis.gov/ordering.htm.

${ }^{64}$ G. Sarma, Oak Ridge National Laboratory, private communication.

${ }^{65}$ Figure taken from Barna, J.L., op cit.

${ }^{66}$ Figure taken from Smook, G.A. op cit.

${ }^{67}$ Figure taken from Barna, J.L., op cit.
} 
Figure A2a: Representative Sketch of Stress-Corrosion Cracking

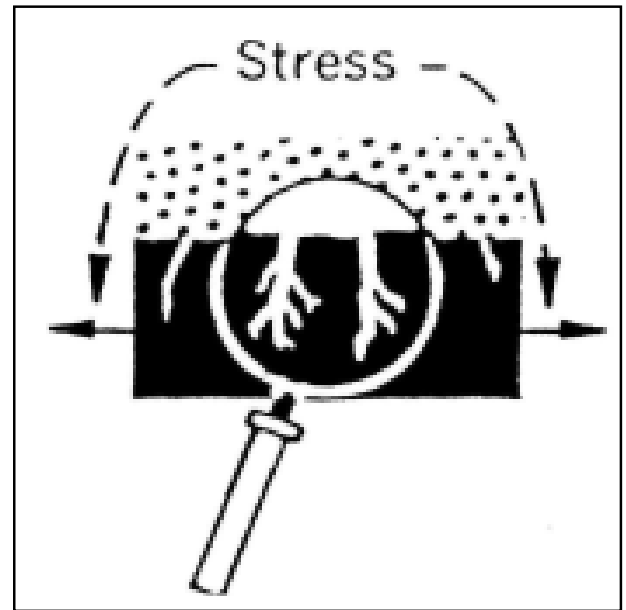

Figure A2b: Microscopic Photograph of Floor Tube Crack

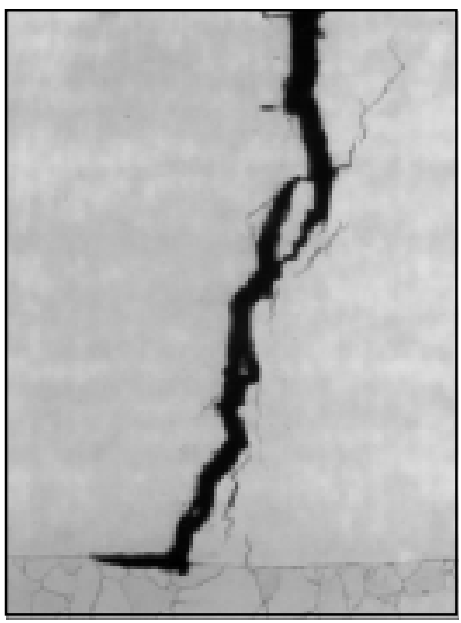

The results of these studies defined the general characteristics of composite tube cracking. ${ }^{68}$ These general characteristics suggested two potential cracking mechanisms. The first possibility is thermal fatigue. Thermal-fatigue cracking requires thermal variations that create stresses that exceed the yield strength of the composite tube. The second possibility is stress-corrosion cracking. This requires both a tensile stress and a liquid corrosive material to be present in the critical temperature range. Both of these mechanisms require tensile stresses to be present at the outer layer of the composite tube, which suggested the importance of residual stress measurements. ${ }^{69}$

\section{A.2 Residual Stress Measurements}

Residual stress measurements were performed on tubes, both exposed and unexposed, manufactured with an outer layer of stainless steel 304L, nickel-iron-chromium-based superalloy Incoloy 825 and nickel-based superalloy Inconel $625 .^{70} \mathrm{X}$-ray and neutron diffraction techniques were used to determine the type and magnitude of stresses present, respectively, on the outer surface and within the walls of the tubes. The goal of these tests was to determine if tensile stresses were present at the surface and within the tubes. Tensile stresses result from forces that pull the lattice structure of a material outwardly apart. This is a necessary component for both thermal-fatigue cracking and stress-corrosion cracking.

Compressive stresses are forces that push the lattice structure inward. These stresses are not directly responsible for stress-corrosion or thermal-fatigue cracking because the lattice structure is being pushed together rather than pulled apart. However, compressive stresses can cause the material to plastically deform if they exceed the yield strength. The effects of plastic deformation will be discussed in the next section. Compressive stresses were measured at the surface of the outer layer for all materials entering service. Therefore, when the tubes are first put into service, the necessary stress state does not exist at the outer surface of the tubes for stress-corrosion cracking to occur.

\footnotetext{
${ }^{68}$ Keiser, J.R. et al. “Overview of the DOE Studies of Recovery Boiler Floor Tube Cracking” (1998) op cit. 69 "FY 1995 - AIM Annual Progress Report," op cit.

${ }^{70}$ Note that Incoloy 825 began to be used as an alternative when the $304 \mathrm{~L}$ was showing signs of cracking. This was done because of the greater strength and sulfidation resistance of Incoloy 825 . Inconel 625 also was recognized as another candidate material because of its strength and sulfidation resistance.
} 
For all materials tested, the tubes entering service do not have the necessary stress state to be susceptible to stress-corrosion cracking.

When measurements were taken of composite tubes manufactured with 304L stainless steel after having been in service, tensile stresses were measured on the outer surface of the tubes. However, tubes manufactured with Incoloy 825 and Inconel 625 did not have the necessary stresses on the outer surface after service.

After having spent time in service, tubes made with $304 \mathrm{~L}$ stainless steel were in the necessary stress state for stress-corrosion cracking to occur.

Residual stress measurements of composite tubes with an outer layer of Incoloy 825 and Inconel 625, both of which have a thermal expansion coefficient closer to that of carbon steel and a higher yield strength than the 304L stainless steel, showed that the outer surface was not in a stress state susceptible to stress-corrosion cracking.

The results of the residual stress measurements support the claim that stress-corrosion cracking might be the mechanism responsible for the cracking of the boiler tubes. However, the results only confirm the presence of the necessary stress state in the 304L stainless steel. Stress-corrosion cracking requires more than the presence of a tensile stress on the outer surface. Finite element modeling and information on the service environment were needed to confirm the results of the residual stress measurements and discover if the other components that are necessary for thermal-fatigue or stress-corrosion cracking are present. $^{71}$

\section{A.3 Finite Element Modeling}

Finite element modeling was used to predict the stresses on the tubes when exposed to the operating conditions inside the recovery boiler. The results of the residual stress measurements indicated that all of the materials tested have compressive stresses present at the surface of the tubes when entering service. However, after exposure to the recovery boiler's service environment, only tubes manufactured with the 304L stainless steel had tensile stresses at the surface.

Finite element modeling suggests that the mismatched coefficient of thermal expansion of the 304L stainless steel with the carbon steel creates compressive stresses that exceed the low yield strength of the outer layer. This causes the outer (fireside) surface of the tube to undergo plastic deformation, which relieves a great deal of the stresses present at the surface of the tube. Since the 304L stainless steel (outer layer) has a much higher coefficient of thermal expansion than the carbon steel (inner layer), the outer layer of the tube will contract more rapidly than the inner layer when the boiler is cooled down from the operating temperature. This causes the carbon steel (inner layer) to effectively apply a tensile (outward) stress to the 304L stainless steel (outer layer). For a boiler tube that reaches a temperature of $315^{\circ} \mathrm{C}\left(600^{\circ} \mathrm{F}\right)$ during normal operation, stresses on the surface of tubes manufactured with $304 \mathrm{~L}$ stainless steel change from compressive to tensile at approximately $270^{\circ} \mathrm{C}\left(518^{\circ} \mathrm{F}\right) .^{72}$

The change in the stress state of the 304L stainless steel composite tube surface from compressive (before service) to tensile (after service) resulted from: (1) the mismatch between the coefficient of thermal expansion of the 304L stainless steel and the carbon steel, and (2) the relatively low yield strength of the $304 \mathrm{~L}$ stainless steel.

\footnotetext{
71 "FY 1996 - AIM Annual Progress Report," op cit.

${ }^{72}$ Keiser, J.R. et al. “Overview of the DOE Studies of Recovery Boiler Floor Tube Cracking” (1998) op cit.
} 


\section{A.4 Thermal Fluctuations (Thermal Spikes)}

Another factor that can affect the stresses present at the surface of the boiler tubes are thermal fluctuations. Localized areas of the boiler floor can experience thermal spikes of up to $150^{\circ} \mathrm{C}\left(300^{\circ} \mathrm{F}\right)$ that last for several minutes. The cause of thermal fluctuations is believed to be waste materials that accumulate at the top of the boiler and fall onto the protective smelt bed. If the impact is forceful enough, the solid smelt bed can fracture, allowing the top layer of liquid smelt to flow downward toward the floor tubes. ${ }^{73}$ This causes the temperature of the outer surface of the floor tubes to rise and fall very rapidly. Thermal fluctuations presented two potential implications that might promote cracking: (1) thermal-fatigue cracking and (2) creating the necessary tensile stress at the surface of the tube.

A.4.1 Thermal-Fatigue Cracking and Thermal Fluctuations

Before the AIM/IMF-funded boiler materials project, thermal fatigue was widely believed to cause composite tube cracking. Table A1 shows the frequency and magnitude of thermal fluctuations on selected locations of the floor tube surface; these data were taken during a five-month period from Weyerhaeuser's Prince Albert No. 1 recovery boiler.

Table A1: Frequency of Temperature Fluctuations ${ }^{74}$

\begin{tabular}{|c|c|c|c|c|}
\hline$\Delta \mathrm{T}$ & $\begin{array}{c}\text { Location 1 } \\
\text { Tube 33, in front of } \\
\text { spout No.2, about } \\
\mathrm{ft} \text {. from spout wall }\end{array}$ & $\begin{array}{c}\text { Location 2 } \\
\text { Tube 54, in front of } \\
\text { spout No.3, about 1 } \\
\mathrm{ft} \text {. from spout wall }\end{array}$ & $\begin{array}{c}\text { Location 4 } \\
\text { Tube 50, 3 ft. from } \\
\text { spout wall }\end{array}$ & $\begin{array}{c}\text { Location 6 } \\
\text { Tube 50, 6 ft. from } \\
\text { spout wall }\end{array}$ \\
\hline $10-50^{\circ} \mathrm{C}$ & 3 & 5 & 15 & 11 \\
\hline $51-100^{\circ} \mathrm{C}$ & 7 & 18 & 39 & 35 \\
\hline $101-150^{\circ} \mathrm{C}$ & 1 & 5 & 22 & 10 \\
\hline$>150^{\circ} \mathrm{C}$ & 0 & 2 & 1 & 0 \\
\hline
\end{tabular}

Comparison of thermal-fatigue behavior of 304L stainless steel against standard design curves for thermal fatigue suggested that, in order for thermal fatigue to cause cracking, a $150^{\circ} \mathrm{C}\left(300^{\circ} \mathrm{F}\right)$ fluctuation in temperature would require more than 100,000 cycles before cracking would occur. Thermal fluctuations of $240^{\circ} \mathrm{C}\left(460^{\circ} \mathrm{F}\right)$ would have to occur more than 10,000 times for cracking to occur. Since the data acquired from thermocouples do not suggest thermal fluctuations of such a high frequency, it is believed that thermal fatigue cannot be the cause of cracking. In addition, tubes that were exposed to conditions to induce thermal fatigue were compared with cracked and uncracked boiler tubes using a transmission electron microscope. The results showed that composite boiler tubes had been exposed to thermal fluctuations, but those fluctuations did not occur frequently enough to be the cause of thermal-fatigue cracking. ${ }^{75}$

While examination of tubes that had been in service revealed exposure to thermal fluctuations, an insufficient number of fluctuations were experienced to promote thermal-fatigue cracking. Thermalfatigue cracking was determined not to be the cause of recovery boiler floor tube cracking, although the thermal fluctuations could assist in crack propagation.

\footnotetext{
${ }^{73}$ Grace, T.M., "What's Causing Lower Furnace Problems?," PIMA Magazine, v. 77, (October 1995), pp.50-1.

${ }^{74}$ Keiser, J.R. et al. "Causes and Solutions for Cracking of Coextruded and Weld Overlay Floor Tubes in Black Liquor Recovery Boilers," (1998), op. cit.

${ }^{75}$ Keiser, J.R. et al. "Overview of the DOE Studies of Recovery Boiler Floor Tube Cracking," (1998), op cit.
} 
A.4.2 Outer-Layer Stress State and Thermal Fluctuations

Areas that experience these thermal excursions are subjected to additional compressive stresses that can lead to plastic deformation, depending on the yield strength of the materials in use and the magnitude of the thermal fluctuations. If plastic deformation occurs, then as the affected area cools down to the normal operating temperature, this area is subjected to a tensile stress. When the recovery boiler is shut down, these tensile stresses grow, which causes the material to plastically deform again. When the tubes are then reheated in subsequent operation, the stresses on the outer surface of the section that experienced the temperature excursion will become compressive.

Localized thermal fluctuations can cause tensile stresses in 304L stainless steel, Incoloy 825, and Inconel 625 depending on the magnitude of the thermal spike and the yield strength of the material. Materials with higher yield strengths are more resistant to the effects of thermal fluctuations. If plastic deformation occurs, the stress state of a localized area will become tensile. During shutdown, these tensile stresses will grow and cause further plastic deformation. When the tubes are reheated to operating temperature, the stresses will become compressive.

Thermal fluctuations can cause tensile stresses on the surface of the boiler tubes manufactured with $304 L$ stainless steel, Incoloy 825, or Inconel 625. This tensile stress state could aid in initiating stresscorrosion cracking.

The effect of these fluctuations on the stress state at the surface of the tube is dependent on the material used to manufacture the outer layer of the tube. Materials with higher yield strengths will be more resistant to plastic deformation, due to thermal fluctuations. It is estimated that tubes manufactured with $304 \mathrm{~L}$ stainless steel will plastically deform with a thermal fluctuation of approximately $50^{\circ} \mathrm{C}$ or greater, Incoloy 825 will plastically deform with a thermal fluctuation of approximately $100^{\circ} \mathrm{C}$ or greater, and Inconel 625 will plastically deform with a thermal fluctuation of $150^{\circ} \mathrm{C}$ or greater. Therefore, the distribution of thermal fluctuations shown in Table A1 suggests that the 304L stainless steel is highly susceptible to plastic deformation due to thermal excursions, Incoloy 825 is moderately susceptible to plastic deformation due to thermal excursions, and Inconel 625 is slightly susceptible to plastic deformation due to thermal excursions.

None of the materials tested are immune to tensile stresses caused by sufficient thermal excursions; however, larger temperature fluctuations are required to cause plastic deformation in materials with higher yield strengths.

Studies indicated a potential mechanism to create the necessary stress state for stress-corrosion cracking to occur in all materials tested. However, stress-corrosion cracking also necessitates the presence of a liquid corrosive. Information about the service environment needed to be collected to determine when liquid corrosives might be present in the recovery boiler.

\section{A.5 Characterization of Service Environment - Stress-Corrosion Cracking}

An accurate depiction of the service environment is needed to determine whether stress-corrosion cracking is the cause of the cracks in composite boiler tubes. For stress-corrosion cracking to occur, a tensile stress at the surface of the tube and a liquid corrosive material must be present simultaneously. Information about the service environment had to be collected to determine if these criteria were met.

\section{A.5.1 Service Environment During Normal Operation}

During normal operating conditions, a solid bed of salts (primarily $\mathrm{Na}_{2} \mathrm{~S}$ and $\mathrm{Na}_{2} \mathrm{CO}_{3}$ ), known as smelt, forms on the floor of the recovery boiler. These salts have a melting point of at least $500^{\circ} \mathrm{C}\left(930^{\circ} \mathrm{F}\right)$ depending on composition; therefore, barring a large temperature fluctuation, salts will remain in the 
form of a solid. Hence, stress-corrosion cracking cannot occur during normal operating conditions, because there is no liquid corrosive material present.

\section{A.5.2 Service Environment During Start-up, Dry-out, Shutdown, and Water-wash}

Shutdown is the period when boiler operation is stopped and the boiler is cooled to room temperature. Water-wash is an operation used during a shutdown to clean deposits from the boiler tubes. The purpose of water-wash is to remove deposits of primarily inorganic material from the tubes to facilitate maintenance and inspection. Boiler start-up is the period when the boiler is heating to operating temperatures. Often, a dry-out period is used by operators to remove excess moisture remaining from the water-wash. During the dry-out, tube temperatures can exceed $150^{\circ} \mathrm{C}\left(300^{\circ} \mathrm{F}\right)$.

The service environment consists of mainly $\mathrm{Na}_{2} \mathrm{~S}, \mathrm{Na}_{2} \mathrm{SO}_{4}$, and $\mathrm{Na}_{2} \mathrm{CO}_{3}$ during shutdown, waterwashing, start-up and dry-out. $\mathrm{Na}_{2} \mathrm{~S}$ is known to absorb and retain water at temperatures up to $180^{\circ} \mathrm{C}$ $\left(360^{\circ} \mathrm{F}\right)$ and the presence of $\mathrm{NaOH}$, that can form when water is introduced to the boiler, tends to increase its ability to retain a liquid phase at even higher temperatures, such as those during water-wash and dry-out. Therefore, stress-corrosion cracking is very likely to occur during water-wash and dry-out. In this environment, the composite tubes are in a tensile stress state with a liquid-corrosive material present.

Maintenance operations can create ideal conditions for stress-corrosion cracking to occur. These studies show that stress-corrosion cracking occurs when moist smelt is in contact with boiler tubes at temperatures between $160-250^{\circ} \mathrm{C}\left(320-480^{\circ} \mathrm{F}\right){ }^{76}$

\section{A.6 Summary and Solutions to Composite Floor-Tube Cracking}

A.6.1 Summary of Conclusions

Figure A3 shows a schematic representation-based on the data available in the literature - of the surface temperature of a point on the outer layer composite tube, during the different stages of operation: boiler start-up, dry-out, normal operation, boiler shutdown, and water-wash. The dry-out stage should ideally occur below temperatures of $150^{\circ} \mathrm{C}\left(300^{\circ} \mathrm{F}\right)$ to avoid conditions conducive to stresscorrosion cracking. Likewise, the water-wash stage begins during boiler shutdown, ideally when the tube temperatures are below $150^{\circ} \mathrm{C}\left(300^{\circ} \mathrm{F}\right)$ because hydrated salts are not liquid below this temperature; therefore, stress-corrosion cracking is unlikely. Hence, this schematic takes into account lessons learned from this project, by assuming that the process has been modified. If dry-out or water wash occurs when tube temperatures are above $150^{\circ} \mathrm{C}\left(300^{\circ} \mathrm{F}\right)$, then the service conditions are ideal for stress-corrosion cracking to occur, because the surface of the tube could be in a tensile stress state in the presence of hydrated-corrosive salts. Shaded portions of the graph denote areas where stress-corrosion cracking could potentially occur if moisture is allowed to come in contact with the boiler tubes. Note that the timescale on this graph is measured in arbitrary units for simplicity. A typical recovery boiler can operate continuously for about a year, assuming no problems occur that would necessitate an unplanned shutdown. Therefore, in reality, the normal operation portions of the graph could cover approximately one year. Table A2 can be used in conjunction with Figure A3 to determine the stress states at the surfaces of 304L stainless steel, Incoloy 825, and Inconel 625 composite tubes - and the presence of corrosive materials during the stages of operation.

The mechanism that causes stress-corrosion cracking is not present during normal operation. Instead, while the recovery boiler is being cooled, water-washed, and dried, a window of vulnerability to stresscorrosion cracking exists. It is crucial to note this, because it suggests two paths for a potential solution.

\footnotetext{
${ }^{76}$ Keiser, J.R. et al. "Overview of the DOE Studies of Recovery Boiler Floor Tube Cracking,” (1998), op cit.
} 
Figure A3: Temperature of Composite Tube Surface during Normal Operation

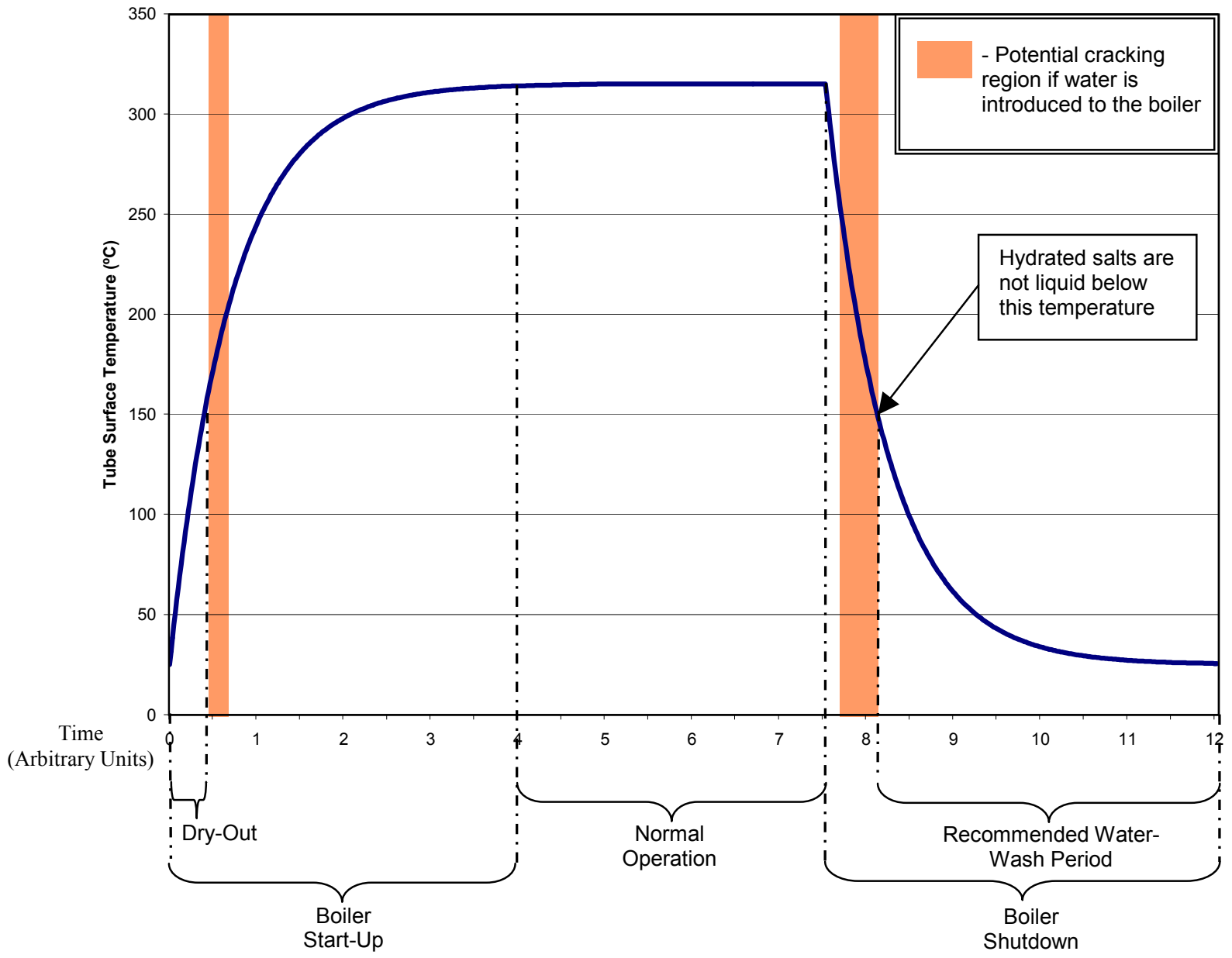

Table A2: Stress State and Corrosive Materials Present during Normal Operation

\begin{tabular}{|c|c|c|c|c|c|}
\hline \multirow{2}{*}{ Material } & \multirow{2}{*}{ Dry-Out } & \multirow{2}{*}{ Boiler Start-Up } & \multirow{2}{*}{$\begin{array}{c}\text { Normal } \\
\text { Operation }\end{array}$} & \multicolumn{2}{|c|}{ Boiler Shutdown } \\
\hline & & & & Pre-Water-Wash & Water-Wash \\
\hline $304 \mathrm{~L}$ & Compressive & Compressive & $\begin{array}{c}\text { Compressive } \rightarrow \\
\text { Slightly } \\
\text { Compressive } \\
\text { (relieved due to } \\
\text { plastic deformation) } \\
\end{array}$ & $\begin{array}{c}\text { Slightly Compressive } \\
\rightarrow \text { Tensile } \\
\text { at } \sim 270^{\circ} \mathrm{C}\end{array}$ & Tensile \\
\hline 825 & Compressive & Compressive & Compressive & Compressive & Compressive \\
\hline 625 & Compressive & Compressive & Compressive & Compressive & Compressive \\
\hline $\begin{array}{l}\text { Liquid corrosive } \\
\text { materials present if } \\
\text { water is added }\end{array}$ & $\begin{array}{c}\text { Aqueous solution } \\
\text { containing } \mathrm{Na}_{2} \mathrm{~S} \text {, } \\
\mathrm{NaOH}, \mathrm{Na}_{2} \mathrm{SO}_{4} \text {, and } \\
\mathrm{Na}_{2} \mathrm{CO}_{3}\end{array}$ & $\begin{array}{l}\mathrm{Na}_{2} \mathrm{~S}, \mathrm{NaOH} \text {, and } \\
\mathrm{Na}_{2} \mathrm{CO}_{3}\end{array}$ & - & $\begin{array}{c}\mathrm{Na}_{2} \mathrm{~S}, \mathrm{Na}_{2} \mathrm{SO}_{4} \text {, and } \\
\mathrm{Na}_{2} \mathrm{CO}_{3}\end{array}$ & $\begin{array}{c}\text { Aqueous solution } \\
\text { containing } \mathrm{Na}_{2} \mathrm{~S} \text {, } \\
\mathrm{NaOH}, \mathrm{Na}_{2} \mathrm{SO}_{4} \text {, and } \\
\mathrm{Na}_{2} \mathrm{CO}_{3}\end{array}$ \\
\hline
\end{tabular}


The occurrence of thermal fluctuations makes determining the stress state present at the surface of the tubes more difficult. Figure A4 and Table A3 show a representative case when a thermal fluctuation occurs. A $150^{\circ} \mathrm{C}\left(300^{\circ} \mathrm{F}\right)$ thermal spike was chosen because it is potentially large enough to affect the stress state on the surface of the 304L stainless steel, Incoloy 825, and Inconel 625. Table A3 lists the approximate threshold for which a thermal excursion might induce a tensile stress at the surface of the tubes. Above these threshold temperatures, as discussed above, plastic deformation of the material can occur, causing a tensile stress when the affected area cools back down to operating temperatures. Note that thermal fluctuations occur only for localized portions of the tube surface. Thus, the stress states indicated in Table A3 represent stresses present at a small area of the tube, not the entire tube surface.

Stress-corrosion cracking does not occur during the thermal excursion, but rather the excursion creates the necessary tensile stress at the surface of the tube where stress-corrosion cracking can occur during subsequent procedures. During shutdown, these tensile stresses will grow and cause further plastic deformation. When the tubes are reheated to operating temperature, the stresses will become compressive.

Figure A4: Temperature of Composite Tube Surface during Operation with a Thermal Fluctuation

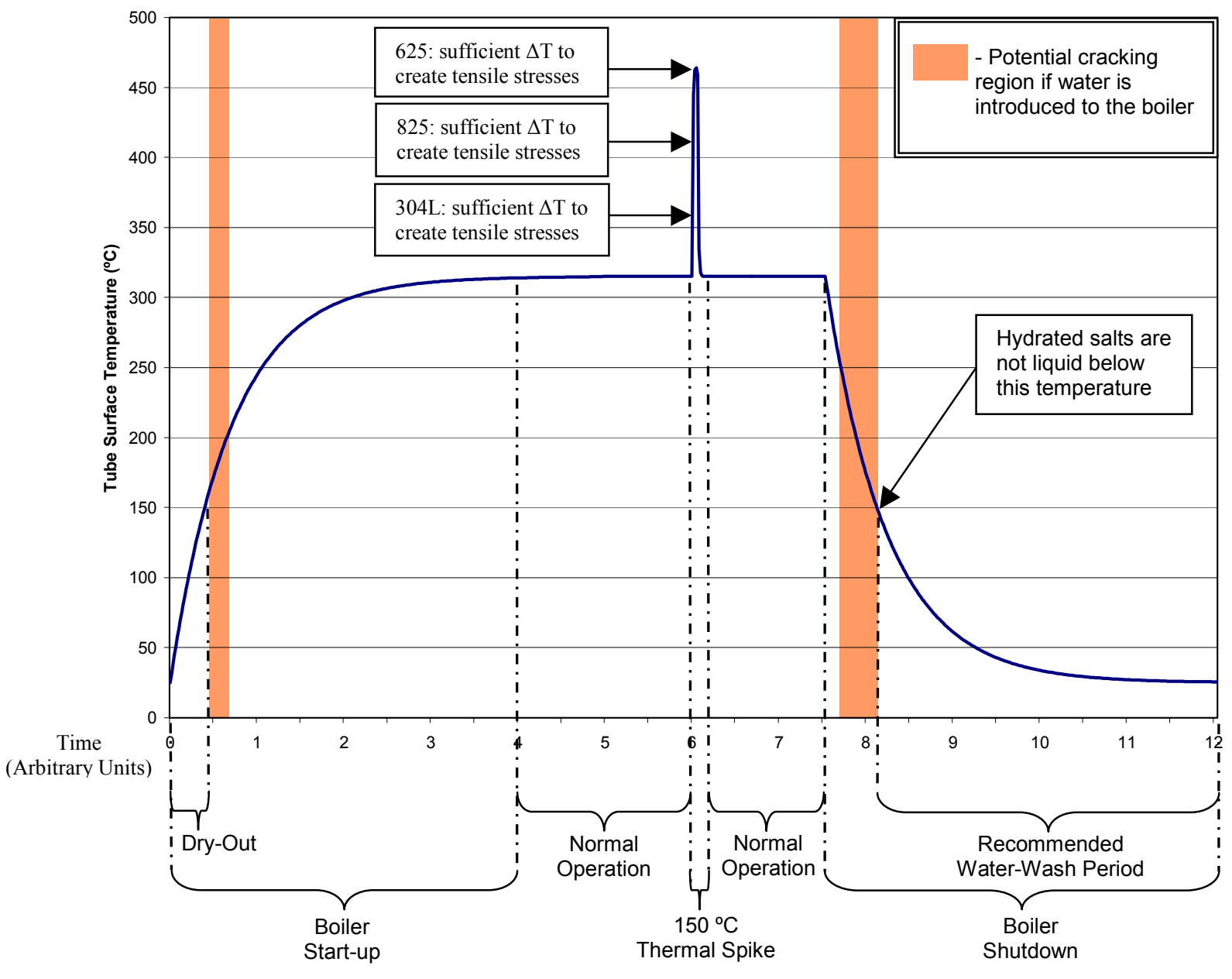


Table A3: Stress State and Corrosive Materials Present during Operation with a Thermal Fluctuation

\begin{tabular}{|c|c|c|c|c|c|c|c|}
\hline \multirow[b]{2}{*}{ Material } & \multirow[b]{2}{*}{ Dry-Out } & \multirow[b]{2}{*}{$\begin{array}{c}\text { Boiler Start } \\
\text {-Up }\end{array}$} & \multirow[b]{2}{*}{$\begin{array}{c}\text { Normal } \\
\text { Operation }\end{array}$} & \multirow[b]{2}{*}{$\begin{array}{c}\text { Thermal } \\
\text { Spike }\end{array}$} & \multirow{2}{*}{$\begin{array}{c}\text { Normal } \\
\text { Operation } \\
\text { (after } \\
\text { thermal } \\
\text { spike) } \\
\end{array}$} & \multicolumn{2}{|c|}{ Boiler Shutdown } \\
\hline & & & & & & $\begin{array}{c}\text { Pre- } \\
\text { Water- } \\
\text { Wash }\end{array}$ & $\begin{array}{l}\text { Water- } \\
\text { Wash }\end{array}$ \\
\hline $304 \mathrm{~L}$ & Compressive & Compressive & $\begin{array}{c}\text { Compressive } \rightarrow \\
\text { Slightly } \\
\text { Compressive } \\
\text { (relieved due to } \\
\text { plastic } \\
\text { deformation) }\end{array}$ & $\begin{array}{c}\text { Slightly } \\
\text { Compressive } \rightarrow \\
\text { Tensile } \\
\text { if } \Delta \mathrm{T} \geq \sim 50^{\circ} \mathrm{C}\end{array}$ & Tensile & Tensile & Tensile \\
\hline 825 & Compressive & Compressive & Compressive & $\begin{array}{c}\text { Compressive } \rightarrow \\
\text { Tensile } \\
\text { if } \Delta \mathrm{T} \geq \sim 100^{\circ} \mathrm{C}\end{array}$ & Tensile & Tensile & Tensile \\
\hline 625 & Compressive & Compressive & Compressive & $\begin{array}{c}\text { Compressive } \rightarrow \\
\text { Tensile } \\
\text { if } \Delta \mathrm{T} \geq \sim 150^{\circ} \mathrm{C}\end{array}$ & Tensile & Tensile & Tensile \\
\hline $\begin{array}{l}\text { Liquid } \\
\text { corrosive } \\
\text { materials } \\
\text { present if } \\
\text { water is } \\
\text { added }\end{array}$ & $\begin{array}{c}\text { Aqueous } \\
\text { solution } \\
\text { containing } \mathrm{Na}_{2} \mathrm{~S} \text {, } \\
\mathrm{NaOH}, \mathrm{Na}_{2} \mathrm{SO}_{4}, \\
\text { and } \mathrm{Na}_{2} \mathrm{CO}_{3}\end{array}$ & $\begin{array}{c}\mathrm{Na}_{2} \mathrm{~S}, \mathrm{NaOH}, \\
\text { and } \mathrm{Na}_{2} \mathrm{CO}_{3}\end{array}$ & - & - & - & $\begin{array}{c}\mathrm{Na}_{2} \mathrm{~S} \\
\mathrm{Na}_{2} \mathrm{SO}_{4}, \\
\text { and } \\
\mathrm{Na}_{2} \mathrm{CO}_{3}\end{array}$ & $\begin{array}{c}\text { Aqueous } \\
\text { solution } \\
\text { containing } \\
\mathrm{Na}_{2} \mathrm{~S}, \mathrm{NaOH}, \\
\mathrm{Na}_{2} \mathrm{SO}_{4} \text {, and } \\
\mathrm{Na}_{2} \mathrm{CO}_{3}\end{array}$ \\
\hline
\end{tabular}

Stress-corrosion cracking can occur only during maintenance procedures (dry-out and water-wash) when moist smelt could come into contact with the tubes at temperatures above $150^{\circ} \mathrm{C}\left(300^{\circ} \mathrm{F}\right)$. It appears unlikely that stress-corrosion cracking can occur during normal operation of the recovery boiler. This suggests two potential paths to address the problem.

\section{A.6.2 Path I: Improving Recovery Boiler Operating Procedures}

The first potential solution is to change the process so that the environment for stress-corrosion cracking does not exist. This can be done because the environment that allows cracking to occur is not a necessary component of the production process. In particular, the dry-out period can last for several hours and create an environment that is ideal for stress-corrosion cracking. The AIM/IMF-funded research discovered that pulp and paper mills were inadvertently creating a condition ideal for stresscorrosion cracking.

By avoiding the conditions under which stress-corrosion cracking is most likely to occur, it can be averted. These methods include burning out smelt completely before water washing, delaying water washing until the recovery boiler tube temperature has dropped below $150^{\circ} \mathrm{C}\left(300^{\circ} \mathrm{F}\right)$, and avoiding temperatures above $150^{\circ} \mathrm{C}\left(300^{\circ} \mathrm{F}\right)$ during dry out. ${ }^{77}$

\section{A.6.3 Path II: Improving Recovery Boiler Floor-Tube Materials}

The second potential solution to floor-tube cracking is to use different materials that are more resistant to stress-corrosion cracking. Deploying new materials into the industrial process yields several potential solutions to composite tube cracking. Two candidate materials are recommended as improvements from the 304L stainless steel. Both the nickel-iron-chromium-based superalloy Incoloy 825 and the nickelbased superalloy Inconel 625 represent better materials with higher yield strength and closer matches to the thermal expansion coefficient of carbon steel. In addition, in potassium- and sulfur-enriched environments, such as those found in the recovery boiler, both of these materials are more resistant to corrosion. The nickel-based material, Inconel 625, provides a better suite of properties, but is a more

\footnotetext{
${ }^{77}$ Keiser, J.R. et al. "Why do Kraft Recovery Boiler Composite Floor Tubes Crack?” op cit.
} 
expensive option. See Table A4 for a comparison of materials properties and Table A5 for a comparison of materials composition. Figure A5 shows the yield stress plotted versus the thermal-expansion coefficient for selected materials. Notice that the Inconel 625 and the Incoloy 825 fall in the preferred region, whereas the 304L stainless steel falls in the undesirable region.

An economical alternative to replacement with Inconel 625 composite tubing is applying an Inconel 625 weld overlay to carbon steel tubes. Some studies claim this method is just as effective as using Inconel 625 composite tubes and offers some additional benefits such as increased ductility. ${ }^{78}$

The materials used in the kraft recovery boiler floor tubes did not have the ideal suite of materials properties given the service environment. The AIM/IMF-funded research defined new materials that could lead to improved energy performance, environmental impact, and production efficiency.

Table A4: Comparison of Materials Properties ${ }^{79,80}$

\begin{tabular}{|c|c|c|c|c|}
\hline Material & $\begin{array}{l}\text { Thermal-Expansion } \\
\text { Coefficient Mean to } \\
370^{\circ} \mathrm{C}\left(700^{\circ} \mathrm{F}\right) \times 10^{-5}{ }^{\circ} \mathrm{C}^{-1} \\
\left(\times 10^{-6} \mathrm{~F}^{-1}\right)\end{array}$ & $\begin{array}{l}\text { Ultimate } \\
\text { Tensile } \\
\text { Strength, Ksi } \\
\text { @ } 540^{\circ} \mathrm{C} \\
\left(1000^{\circ} \mathrm{F}\right)\end{array}$ & $\begin{array}{c}\text { Corrosion Rate in } \\
\text { Typical Smelt at } \\
800^{\circ} \mathrm{C}\left(1500^{\circ} \mathrm{F}\right) \\
\mathrm{mm} / \mathrm{yr}(\text { in./yr) }\end{array}$ & $\begin{array}{c}\text { Corrosion Rate in Smelt } \\
\text { Enriched with Potassium } \\
\text { and Sulfur at } 580^{\circ} \mathrm{C} \\
\left(1100^{\circ} \mathrm{F}\right) \\
\mathrm{mm} / \mathrm{yr}(\text { in./yr })\end{array}$ \\
\hline $\begin{array}{c}\text { Carbon } \\
\text { Steel }\end{array}$ & $1.37(7.59)$ & - & $82.36(3.243)$ & $103.38(40.70)$ \\
\hline $304 \mathrm{~L}$ & $1.74(9.69)$ & 56 & $17.37(0.684)$ & $77.04(3.033)$ \\
\hline $\begin{array}{c}\text { Incoloy } \\
825 \\
\end{array}$ & $1.5(8.3)$ & 86 & $14.53(0.572)$ & $64.62(2.544)$ \\
\hline $\begin{array}{c}\text { Inconel } \\
625\end{array}$ & $1.4(7.5)$ & 132 & $54.79(2.157)$ & $59.99(2.362)$ \\
\hline
\end{tabular}

Table A5: Material Composition Comparison Chart ${ }^{81}$

\begin{tabular}{|c|c|c|c|c|}
\hline Element & $\begin{array}{c}\text { Type 304L } \\
\text { UNS 30403 }\end{array}$ & $\begin{array}{c}\text { Incoloy 825 } \\
\text { UNS 08825 }\end{array}$ & $\begin{array}{c}\text { Inconel 625 } \\
\text { UNS N06625 }\end{array}$ & $\begin{array}{c}\text { Inconel 625 } \\
\text { Weld Overlay }\end{array}$ \\
\hline $\mathrm{C}$ & $0.030 \max$ & $0.050 \max$ & $0.100 \mathrm{max}$ & 0.1 \\
\hline $\mathrm{Cr}$ & $18.00-20.00$ & $19.50-23.50$ & $20.00-23.00$ & 20.9 \\
\hline $\mathrm{Mn}$ & $2.00 \max$ & $1.00 \mathrm{max}$ & $0.50 \mathrm{max}$ & 0.1 \\
\hline $\mathrm{Ni}$ & $8.00-12.00$ & $38.00-46.00$ & Balance & 61.1 \\
\hline $\mathrm{P}$ & $0.045 \max$ & $0.030 \max$ & $0.015 \max$ & - \\
\hline $\mathrm{S}$ & $0.030 \max$ & $0.030 \max$ & $0.015 \max$ & - \\
\hline $\mathrm{Si}$ & $1.00 \max$ & $0.500 \max$ & $0.500 \max$ & 0.5 \\
\hline $\mathrm{Al}$ & - & $0.200 \max$ & $0.400 \max$ & 0.2 \\
\hline $\mathrm{Cu}$ & - & $1.50-3.00$ & - & - \\
\hline $\mathrm{Fe}$ & Balance & Balance & $5.00 \max$ & 5.2 \\
\hline $\mathrm{Mo}$ & - & $2.50-3.50$ & $8.00-10.00$ & 8.6 \\
\hline $\mathrm{Ti}$ & - & $0.600-1.200$ & $0.400 \mathrm{max}$ & 0.3 \\
\hline $\mathrm{Cb}$ & - & - & $3.15-4.15$ & 3.5 \\
\hline
\end{tabular}

\footnotetext{
${ }^{78}$ Barna, J.L., op cit.

${ }^{79}$ Ibid.

${ }^{80}$ Keiser, J.R. et al. "Overview of the DOE Studies of Recovery Boiler Floor Tube Cracking," (1998), op cit.

${ }^{81}$ Barna, J.L., op. cit.
} 
Figure A5: Yield Stress versus Thermal Expansion Coefficient for Selected Materials ${ }^{82}$

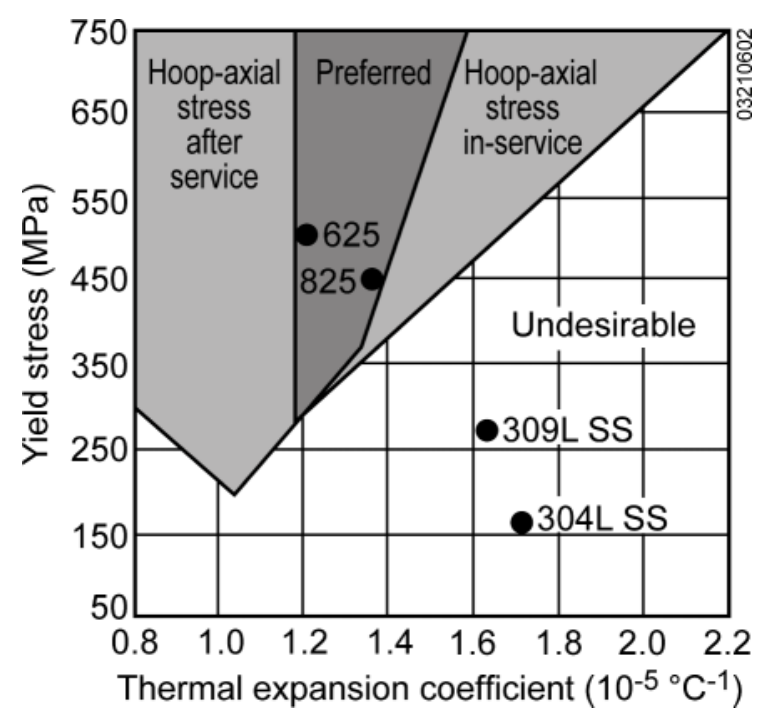

Stresses generated in coextruded tube materials at various thermal expansion coefficients and yield stresses for the outer clad layer. Alloys 625 and 825 have properties that result in less severe stresses being developed than with 304L or 309L.

${ }^{82}$ Figure taken from Keiser, J.R. et al. “Why do Kraft Recovery Boiler Composite Floor Tubes Crack?” op cit. 


\section{REPORT DOCUMENTATION PAGE}

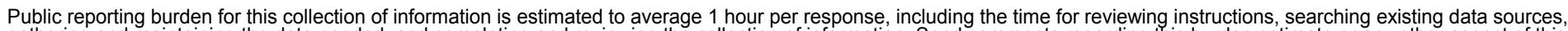

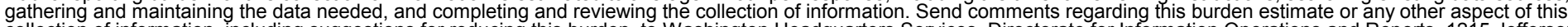

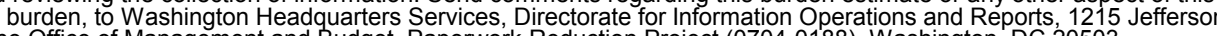
Davis Highway, Suite 1204, Arlington, VA 22202-4302, and to the Office of Management and Budget, Paperwork Reduction Project (0704-0188), Washington, DC 20503.
1. AGENCY USE ONLY (Leave blank)
2. REPORT DATE
November 2002

\section{REPORT TYPE AND DATES COVERED}
Technical Report - Analysis

\section{TITLE AND SUBTITLE} Industrial Materials for the Future R\&D Strategies: A Case Study of Boiler Materials for the Pulp and Paper Industry
5. FUNDING NUMBERS

TA: AS02.2025

6. $\operatorname{AUTHOR}(\mathrm{S})$

D. R. Howell, R. Silberglitt (RAND); D. Norland (NREL)

7. PERFORMING ORGANIZATION NAME(S) AND ADDRESS(ES)

National Renewable Energy Laboratory

1617 Cole Blvd.

Golden, CO 80401-3393
8. PERFORMING ORGANIZATION REPORT NUMBER
9. SPONSORING/MONITORING AGENCY NAME(S) AND ADDRESS(ES) National Renewable Energy Laboratory 1617 Cole Blvd.

Golden, CO 80401-3393
10. SPONSORING/MONITORING AGENCY REPORT NUMBER

NREL/TP-620-32106

11. SUPPLEMENTARY NOTES

12a. DISTRIBUTION/AVAILABILITY STATEMENT National Technical Information Service

U.S. Department of Commerce

5285 Port Royal Road

Springfield, VA 22161

13. ABSTRACT (Maximum 200 words)

This report describes a case study performed by RAND and NREL of government-industry research and development (R\&D) aimed at solving materials problems encountered by the forest products industry. The principal problem addressed by the R\&D was the failure of tubes that carry water and steam inside boilers used to recover chemicals during papermaking. These recovery boilers are an essential component of the papermaking process because, in addition to providing recycled chemicals to the wood digester, they also provide a significant portion of the process steam and electricity required for plant operation. The industry estimates that, on average, for each day a recovery boiler is shut down, a company loses $\$ 300,000$. The government-industry team performed systematic analysis, resulting in the recommendation of two possible solutions to the problem. This case study illuminated a number of critical factors in successfully solving industrial process problems through R\&D that should guide future efforts.

14. SUBJECT TERMS

industrial materials; boiler materials; pulp and paper industry; forest products; Douglas Norland; RAND; David R. Howell; Richard Silberglitt; recovery boiler; floor tubes; kraft chemical pulping process; R\&D; Industrial Materials for the Future; Babcock and Wilcox; American Forest and Paper Association; Energy Information Administration

17. SECURITY CLASSIFICATION OF REPORT Unclassified
18. SECURITY CLASSIFICATION OF THIS PAGE Unclassified
19. SECURITY CLASSIFICATION OF ABSTRACT

Unclassified
15. NUMBER OF PAGES

16. PRICE CODE

20. LIMITATION OF ABSTRACT

UL 